\title{
Testing self-testers: diagnostic self-testing for cholesterol and diabetes
}

Citation for published version (APA):

Ickenroth, M. H. (2013). Testing self-testers: diagnostic self-testing for cholesterol and diabetes. [Doctoral Thesis, Maastricht University]. Datawyse / Universitaire Pers Maastricht. https://doi.org/10.26481/dis.20131219mi

Document status and date:

Published: 01/01/2013

DOI:

10.26481/dis.20131219mi

Document Version:

Publisher's PDF, also known as Version of record

\section{Please check the document version of this publication:}

- A submitted manuscript is the version of the article upon submission and before peer-review. There can be important differences between the submitted version and the official published version of record.

People interested in the research are advised to contact the author for the final version of the publication, or visit the DOI to the publisher's website.

- The final author version and the galley proof are versions of the publication after peer review.

- The final published version features the final layout of the paper including the volume, issue and page numbers.

Link to publication

\footnotetext{
General rights rights.

- You may freely distribute the URL identifying the publication in the public portal. please follow below link for the End User Agreement:

www.umlib.nl/taverne-license

Take down policy

If you believe that this document breaches copyright please contact us at:

repository@maastrichtuniversity.nl

providing details and we will investigate your claim.
}

Copyright and moral rights for the publications made accessible in the public portal are retained by the authors and/or other copyright owners and it is a condition of accessing publications that users recognise and abide by the legal requirements associated with these

- Users may download and print one copy of any publication from the public portal for the purpose of private study or research.

- You may not further distribute the material or use it for any profit-making activity or commercial gain

If the publication is distributed under the terms of Article $25 \mathrm{fa}$ of the Dutch Copyright Act, indicated by the "Taverne" license above, 


\section{Testing self-testers}

Diagnostic self-testing for cholesterol and diabetes 
The research presented in this thesis was conducted at the School for Public Health and Primary Care: CAPHRI, Department of General Practice, of Maastricht University. CAPHRI participates in the Netherlands School of Primary Care Research CaRe. CAPHRI was classified as 'excellent' by the external evaluation committee of leading international experts that reviewed CAPHRI in December 2010.

The work presented in this dissertation was supported by the Netherlands Organization for Health Research and Development (ZonMw), grant number 50-50101-96-406. Supplementary financial support has been provided by the Centraal Ziekenfonds (CZ) health insurance company.

The printing of this thesis was financially supported by the SBOH, employer of GP trainees

\section{SBOHt}

voor artsen in opleiding

(C) Martine Helena Petronella Ickenroth, Maastricht 2013

No part of this book may be reproduced or transmitted in any form or by any means, without prior permission in writing by the author, or when appropriate, by the publishers of the publications.

Layout: Tiny Wouters

Cover: Bilbo Schickenberg www.bilbos.nl

Printed by: Datawyse Universitaire Pers Maastricht

ISBN 9789461592743 


\title{
Testing self-testers
}

\section{Diagnostic self-testing for cholesterol and diabetes}

\author{
PROEFSCHRIFT
}

ter verkrijging van de graad van doctor aan de Universiteit Maastricht, op gezag van de Rector Magnificus, Prof. dr. L.L.G. Soete, volgens het besluit van het College van Decanen, in het openbaar te verdedigen op donderdag 19 december 2013 om 14.00 uur

door

Martine Helena Petronella Ickenroth 


\section{Promotores}

Prof. dr. G.J. Dinant

Prof. dr. N. K. de Vries

Prof. dr. T. van der Weijden

\section{Beoordelingscommissie}

Prof. dr. H. de Vries (voorzitter)

Prof. dr. F.J.V.M. Buntinx

Prof. dr. G.C.M. Kusters (Universiteit Twente)

Dr. H.J.S. Maiburg

Prof. dr. D.R.M. Timmermans (EMGO Institute, VUMC Amsterdam) 


\section{Contents}

Chapter 1 General introduction $\quad 7$

$\begin{array}{lll}\text { Chapter } 2 & \text { Improving behaviour in self-testing (IBIS): } & 17\end{array}$

Study on frequency of use, consequences, information needs

and use, and quality of currently available consumer

information (protocol)

BMC Public Health 2010, 10:453

Chapter 3 How do people respond to self-test results?

31

A cross-sectional survey

BMC Family Practice 2010, 11:77

Chapter 4 Motivation and experiences of self-testers regarding tests

for cardiovascular risk factors

Health Expectations 2011 Oct 28

Chapter 5 Quality and use of consumer information provided with

65

home test kits: room for improvement

Health Expectations $2012 \mathrm{Jul} 19$

Chapter 6 Educating consumers in self-testing: lessons learned

85

from the development of an online decision aid on glucose and

cholesterol self-testing

Submitted

Chapter 7 A single-blind randomised controlled trial of the effects of a webbased decision aid on self-testing for cholesterol and diabetes.

Study protocol

BMC Public Health 2012, 12:6

Chapter 8 Effects of a web-based decision aid on knowledge and informed choice regarding diagnostic self-testing for cholesterol and diabetes.

A single-blind randomised controlled trial

Submitted

Chapter 9 General discussion

Chapter 10 Summary

Samenvatting

List of publications

Dankwoord

Curriculum Vitae 



\section{CHAPTER 1}

General introduction 


\section{Introduction}

In recent years, diagnostic self-tests have become directly available to consumers. Consumers are provided with the opportunity to gain more insight in their health status and screen themselves for certain conditions, without the need of consulting a doctor first. This development is in line with the current 'Medicine 2.0' movement: medical information has become easily accessible through the Internet, and can help prepare a doctors visit, or add extra information after a diagnosis has been established. ${ }^{1}$ Patients might be better informed, stimulating shared decision making between provider and patient. Self-management can be promoted, patients and consumers can be made more responsible for their own health, and patients can contact other patients and share their experiences, worries and advice. However there are also some important doubts concerning 'Medicine 2.0'. How trustworthy is ' $d r$ Google'? What if consumers start diagnosing themselves, not only by reading medical information, but also by ordering and performing self-tests? Or should this be limited to the doctor's responsibility? ${ }^{2}$

In this thesis, we will focus on the use of diagnostic self-tests on body materials, with the purpose to diagnose a certain disease or risk factor, without consulting a health professional first. The aim of our studies was to gain more insight in self-test behaviour, to assess the quality of the current consumer information, and to improve knowledge and informed choice in diagnostic self-testing for cholesterol and diabetes. Pregnancy tests are excluded from our studies, for these tests do not detect disease. Monitoring tests, such as glucose meters used by patients with diabetes or INR devices used by patients using anticoagulants, are also excluded, because these monitoring tests are often initiated and supervised by health professionals.

Four different modes of diagnostic self-testing can be differentiated ${ }^{3}$ :

1. Home tests, which are offered in for example chemists or through the Internet. Consumers can order a package, which contains everything needed to perform the test: an instruction leaflet, a test cassette or colour chart to determine the test result, and a pin needle in case a blood sample is needed. The test can completely be performed at home, giving a result in minutes.

2. Streetcorner tests, which are often offered by organisations in public places such as supermarkets, chemists or sports facilities. The test is carried out by trained personnel, and an immediate result is available.

3. Home-collect tests, in which a sample has to be sent to a laboratory, and consumers receive the result of the test at home by mail, email or telephone. 
4. Direct-access tests, in which a consumer goes to a laboratory, has a (blood) sample taken, and later receives the result of the test at home by mail, email or telephone.

\section{What is already known about self-testing?}

Research in the Netherlands in 2006 started to investigate the use of diagnostic selftests, and found self-tests available for 28 conditions, for example for diabetes, allergies, and prostate cancer. ${ }^{4}$ Prices for these tests ranged from 5.54 euro (urinary tract infection) to 335 euro (lactose intolerance and gluten intolerance). A survey among a Dutch Internet panel showed that $15.9 \%$ of the respondents had ever performed a diagnostic self-test. ${ }^{3}$ Self-testers were more likely to be female, reported a lower health status and had a higher BMI compared to non-testers. On the other hand, self-testers were more likely to engage in health related behaviour, they reported eating more fruit, less fat, and were more likely to use dietary supplements. Most performed self-tests in the Netherlands were those to detect diabetes, high cholesterol, allergies, urinary tract infections, HIV and ovulation.

There is little international literature on the use of self-tests worldwide. Studies in the UK also showed the availability of self-tests for 24 conditions. ${ }^{5}$ Several cancer self-tests were distinguished, and in a survey $1.2 \%$ of the respondents indicated to have performed a cancer related self-test. ${ }^{6}$ Another survey among pharmacists in Qatar showed that $44 \%$ had ever used a blood glucose test, and $8 \%$ another self-test. ${ }^{7}$

More scientific literature is available on the use of specific self-tests, especially genetic self-tests and self-testing on sexually transmitted disease (STD). The use of STD selftest has provided more insights in the pros and cons of self-testing. ${ }^{8-11}$ Campbell and Klein describe the worst and best case scenarios for HIV home testing, in which the pros but also possible pitfalls are described. ${ }^{12}$ In the worst case scenario, an expensive test, with an accuracy that in the hands of the consumers would perform less than intended, would be marketed beyond high risk groups. This would lead to high rates of false positive results in a low-risk population, and false reassurance and poor understanding of the test, such as the incubation period of HIV, would lead to a false sense of security and increase transmission. On the other hand, in the best case scenario, a rapid HIV test is distributed among high-risk persons, with sufficient accuracy in untrained hands. People who would otherwise not have been tested, would now perform a test, leading to earlier diagnosis, earlier care and less transmission. $^{12}$ 
Nevertheless, numerous questions concerning self-testing remain, especially regarding the most popular self-tests in the Netherlands: the diabetes en cholesterol tests. Little is known about why consumers perform these tests, and how they interpret the result. There is little insight in follow-up behaviour after self-testing. Although the consequences of self-testing are often described, it is unclear what effect these tests have on health outcomes. ${ }^{13}$ Tymstra et al. found that screening for cardiovascular risk factors led to an intention to change unhealthy behaviour in case of abnormal results, but also seemed to provide a 'certificate of health' to those with normal results, it gave them an excuse not to change unhealthy habits ${ }^{14,15}$, although this effect of false reassurance was not found among participants in a diabetes screening trial. ${ }^{16}$

While the outcomes of self-testing on health care remain unclear, the Royal Dutch Medical Association (KNMG) discourages self-testing, stressing the fact that only a doctor is entitled and equipped to diagnose a disease. (http://knmg.artsennet.nl/ Nieuws/Nieuwsarchief/Nieuwsbericht-1/Ga-niet-af-op-zelftest.htm) On the other hand, tests were distributed by organisations such as the Dutch Heart Foundation and the Dutch Kidney Foundation, and were promoted with the aim of early discovery of risk factors and the importance of a healthy lifestyle. Commercial tests are offered and promoted on the Internet, stressing the convenience and reliability of self-tests. Since self-testing has advantages as well as disadvantages, it is hard to say whether selftesting is 'good' or 'bad'. And with self-tests being easily accessible to the general public, consumers will have to decide for themselves whether they want to self-test or not.

If we gain more insight in self-test behaviour, and if we combine this information with the recommendations made on the use of the same diagnostic tests in clinical practice, would it be possible to guide consumers in the decision whether to self-test or not, and help them making an informed choice and use the test in a safe way? In this thesis, the development of a decision aid (DA) for self-testing is described, after which the effect of this DA on knowledge and informed choice is assessed.

\section{Decision aids}

Patient decision aids have been developed to support patients in making a choice in health decisions, in case of preference-sensitive decisions. ${ }^{17}$ Decisions are preferencesensitive when options have very different benefit and harms profiles and implications, and the specific trade-offs between these benefits, harms and implications can lead to large inter-individual variability; when options are about equally attractive or when their outcomes are about equally desirable; when there is insufficient evidence about 
the risks and benefits of one or more options; when the potential risks of the option are high regardless of its benefits (there is an impressive number needed to harm, even though the number needed to treat is low); or when the effect of the option depends on the patient's adherence or if the option intervenes with the patient's lifestyle.

These DAs are used as an adjunct to professional counselling. They differ from usual health education materials because they make explicit the decision being considered and the detailed, specific and personalised focus on options and outcomes for the purpose of preparing people for decision making. ${ }^{18}$ DAs have shown to improve knowledge, values-based choice, and reduce decisional conflict. ${ }^{18,19}$ In recent years, an instrument to assess the quality of decision aids has been developed, the IPDASi. ${ }^{20}$

Although decision aids are usually used as an adjunct to doctor-patient communication, in self-testing the decision whether to self-test or not is taken by consumers, typically without consulting a health professional. In this thesis, we discuss the development of a decision aid aimed at consumers, to support the decision making process, but also guiding them into a safe way of using these diagnostic self-tests. The decision aid www.zelftestwijzer.nl gives information about self-testing in general, and more specific on diabetes and cholesterol self-testing. The website was built and developed in an iterative process, combining the input of end-users as well as several experts.

\section{Informed choice}

Since both self-testing as not self-testing can be suitable options to an individual, how should we measure this 'best choice'? The uptake of self-tests alone would not reflect whether the choice to do a self-test was a choice based on a weighing of the pros and cons, leading to a choice that is in line with one's values. A measure of informed choice was proposed by Marteau et al. ${ }^{21}$ They describe two core characteristics that an informed choice consists of: that it is based on relevant, good quality information, and second that the choice reflects the decision maker's values. As an example one could imagine the decision an individual has to make whether to take part in a certain screening program. This screening program has a slight positive effect on mortality, but on the other hand also a certain chance on false positive test results, leading to anxiety and unnecessary further investigations. An informed choice can occur when an individual has a positive attitude towards screening, has the relevant knowledge about the test, including the positive and negative effects of the test, and probabilities on these outcomes, and undergoes the test. But also declining the test could reflect an informed choice, if this person has a negative attitude concerning the screening 
program, and also has relevant knowledge about the test. ${ }^{21}$ Uninformed choices occur when individuals do not have sufficient knowledge, or when their choice is not in line with their attitude. To measure this informed choice, we used the method suggested by Marteau et al. ${ }^{21,22}$

\section{Aim of the research project}

The aim of the project 'Improving behaviour in self-testing' is to gain more insight into diagnostic self-testing behaviour, to assess consumer's follow-up behaviour after performing a self-test, and to improve consumers knowledge about diagnostic selftesting and to stimulate an informed choice in diagnostic self-testing. We will discuss the following research questions in this thesis:

1. Which self-tests are currently used in the Netherlands, and is there a change in the frequency of self-testing in the period 2006- 2011?

2. What are consumers' reasons for using or not using a self-test?

3. What information do self-testers use, and what is the consumers' interpretation of the quality of this information?

4. What is the consumers' response to self-test results in terms of confidence in the result, reassurance by the test result, and follow-up behaviour?

5. What is the quality of the currently available information about a selected set of self-tests?

6. What is the effect of an online decision aid on self-testing on knowledge and informed choice?

\section{Outline of this thesis}

Chapter 2 describes the protocol of the quantitative and qualitative studies to gain more insight into self-test behaviour. In chapter 3, a cross-sectional survey is described, in which the frequency of self-testing among Dutch Internet users and follow-up behaviour of self-testers is assessed. Reasons why people self-test, their considerations concerning the validity of self-tests and how they react to the test result are further elaborated in chapter $\mathbf{4}$, in which the results of a qualitative interview study are reported. Chapter $\mathbf{5}$ focuses on the consumers' need for information about self-testing and the assessment of the quality of information that is provided with a selected set of self-tests. In chapter 6, we explain how we built the online decision aid www.zelftestwijzer.nl. Important consideration in educating consumers in self-testing are presented. The effect of the online decision aid is evaluated in chapters 7 and 8 , starting with the protocol for the randomised controlled 
trial on the effect of the decision aid for cholesterol and diabetes self-testing in chapter 7. Chapter 8 describes the results of the RCT, in which 1137 participants were randomised to viewing the online decision aid, or receiving general, short, noninteractive information about self-testing. Effects on knowledge and informed choice were assessed. In the general discussion in chapter 9 the main results and conclusions of the studies are described, and implications for daily practice and future research are discussed. 


\section{References}

1. RVZ-rapport. Gezondheid 2.0 [Medicine 2.0]. The Hague: RVZ (Council for Public Health and Care) 2010.

2. Greaney AM, O'Mathuna DP, Scott PA. Patient autonomy and choice in healthcare: self-testing devices as a case in point. Med Health Care Philos 2012;15:383-95.

3. Ronda G, Portegijs P, Dinant GJ, Buntinx F, Norg R, Van der Weijden T. Use of diagnostic self-tests on body materials among Internet users in the Netherlands: prevalence and correlates of use. BMC Public Health 2009;9:100.

4. CVZ-rapport. Diagnostische zelftests op lichaamsmateriaal. Aanbod, validiteit en gebruik door de consument [Diagnostic self-tests on bodymaterial. Supply, validity, and use by the consumer]. 2007.

5. Ryan A, Wilson S, Greenfield S, Clifford S, McManus RJ, Pattison HM. Range of self-tests available to buy in the United Kingdom: an Internet survey. J Public Health (Oxf) 2006;28:370-4.

6. Wilson S, Ryan AV, Greenfield SM, Clifford SC, Holder RL, Pattison HM, Fitzmaurice DA, McManus RJ. Self-testing for cancer: a community survey. BMC Cancer 2008;8:102.

7. El Hajj MS, El-Ajez RH, Al-Ismail MS, Sawaftah DM. Home diagnostic tests in the state of Qatar: a snapshot of public views, level of awareness and use. Int J Clin Pharm 2012;34:885-92.

8. Spielberg F, Levine RO, Weaver M. Self-testing for HIV: a new option for HIV prevention? Lancet Infect Dis 2004;4:640-6.

9. Walensky RP, Paltiel AD. Rapid HIV testing at home: does it solve a problem or create one? Ann Intern Med 2006;145:459-62.

10. Frith L. HIV self-testing: a time to revise current policy. Lancet 2007;369:243-5.

11. Lee VJ, Tan SC, Earnest A, Seong PS, Tan HH, Leo YS. User acceptability and feasibility of self-testing with HIV rapid tests. Acquir Immune Defic Syndr 2007;45:449-53.

12. Campbell S, Klein R. Home testing to detect human immunodeficiency virus: boon or bane? J Clin Microbiol 2006;44:3473-6.

13. Deutekom M, Bossuyt PM. [The increased availability of self-tests for medical analyses]. Ned Tijdschr Geneeskd 2007;151:901-4.

14. Tymstra T, Bieleman B. The psychosocial impact of mass screening for cardiovascular risk factors. Fam Pract 1987;4:287-90.

15. Tijmstra T, Spijkers W, Broer J, Janssen WM, de Jong PE. [Psychosocial consequences of screening for microalbuminuria and for some other risk factors]. Ned Tijdschr Geneeskd 2000;144:2460-4.

16. Paddison CA, Eborall HC, Sutton S, French DP, Vasconcelos J, Prevost AT, Kinmonth AL, Griffin SJ.. Are people with negative diabetes screening tests falsely reassured? Parallel group cohort study embedded in the ADDITION (Cambridge) randomised controlled trial. BMJ 2009;339:b4535.

17. van der Weijden $T$, Pieterse AH, Koelewijn-van Loon MS, Knaapen L, Légaré $F$, Boivin A, Burgers JS, Stiggelbout AM, Faber M, Elwyn G. How can clinical practice guidelines be adapted to facilitate shared decision making? A qualitative key-informant study. BMJ Qual Saf. 2013 Jun 7. Epub ahead of print

18. Stacey D, Bennett CL, Barry MJ, Col NF, Eden KB, Holmes-Rovner M, et al. Decision aids for people facing health treatment or screening decisions. Cochrane database of systematic reviews (Online). 2012(10):CD001431.

19. O'Connor AM, Rostom A, Fiset V, Tetroe J, Entwistle V, Llewellyn-Thomas H, Holmes-Rovner M, Barry $M$, Jones J. Decision aids for patients facing health treatment or screening decisions: systematic review. BMJ 1999;319:731-4.

20. Elwyn G, O'Connor AM, Bennett C, Newcombe RG, Politi M, Durand MA, Drake E, Joseph-Williams N, Khangura S, Saarimaki A, Sivell S, Stiel M, Bernstein SJ, Col N, Coulter A, Eden K, Härter M, Rovner MH, Moumjid N, Stacey D, Thomson R, Whelan T, van der Weijden T, Edwards A. Assessing the quality of decision support technologies using the International Patient Decision Aid Standards instrument (IPDASi). PloS One 2009;4:e4705.

21. Marteau TM, Dormandy E, Michie S. A measure of informed choice. Health Expect. 2001;4:99-108.

22. Michie S, Dormandy E, Marteau TM. The multi-dimensional measure of informed choice: a validation study. Patient Educ Couns 2002;48:87-91. 


\section{CHAPTER 2}

Improving behaviour in self-testing (IBIS): Study on frequency of use, consequences, information needs and use, and quality of currently available consumer information (protocol)

Janaica Grispen ", Martine Ickenroth ${ }^{*}$, Nanne de Vries, Geert-Jan Dinant, Gaby Ronda, Trudy van der Weijden

*Authors contributed equally to this work BMC Public Health 2010, 10:453 


\section{Abstract}

\section{Background}

Self-tests are available to consumers for more than 25 conditions, ranging from infectious diseases to cardiovascular risk factors. Self-tests are defined as in-vitro tests on body materials such as blood, urine, faeces, or saliva that are initiated by consumers to diagnose a particular disorder or risk factor without involving a medical professional. In 2006, $16 \%$ of a sample of Dutch Internet users had ever used at least one self-test and $17 \%$ intended to use a self-test in the future. The objectives of this study are to determine (1) the frequency of self-test use, (2) the consumers' reasons for using or not using a self-test, (3) the information that is used by selftesters in the different self-test stages and the consumers' interpretation of the quality of this information, (4) the consumers' response to self-test results in terms of their confidence in the result, reassurance by the test result, and follow-up behaviour, (5) the information consumers report to need in the decision making process of using or not using a self-test, and in further management on the basis of the self-test result, and (6) the quality of the currently available consumer information on a selected set of self-tests.

\section{Methods}

Mixed methods study with (1) a cross-sectional study consisting of a two-phase Internetquestionnaire, (2) semi-structured interviews with self-testers and consumers who intend to use a self-test, and (3) the assessment of the quality of consumer information of self-tests. The Health Belief Model and the Theory of Planned Behaviour will serve as the theoretical basis for the questionnaires and the interview topic guides.

\section{Conclusions}

The self-testing area is still in a state of flux and therefore it is expected that self-test use will increase in the future. To the best of our knowledge, this is the first study which combines quantitative and qualitative research to identify consumers' information needs and use concerning self-testing, and the consumers' actual follow-up behaviour based on the self-test result, and simultaneously investigates the quality of the currently available consumer information. The results of this study will be used as an input in developing consumer information on self-testing. 


\section{Background}

A range of self-tests has become available to consumers in the Netherlands and elsewhere. ${ }^{1}$ Self-test are currently available for more than 25 conditions, ranging from infectious diseases to cardiovascular risk factors. Self-tests are not rarely used; $16 \%$ of a sample of Dutch Internet users indicated they had ever used at least one self-test in 2006, whereas $17 \%$ of those who had never used a self-test indicated they would probably or definitely use one in the future. The five most frequently used self-tests were tests for diabetes, cholesterol, allergies, urinary tract infection, and HIV. ${ }^{1}$

We defined self-tests as in-vitro tests on body materials such as blood, urine, faeces, or saliva that are initiated by consumers to diagnose a particular disorder or risk factor. In other words, by using a self-test, consumers completely avoid the traditional health care systems. Pregnancy tests, home blood-pressure meters, and monitoring tests, e.g. serum glucose for patients with diabetes mellitus to follow-up on their disease and therapy, are excluded by this definition. Self-tests can be subdivided into four distinct types that are directly accessible to consumers without the need for a preceding consultation with a doctor. ${ }^{1}$ The first type of self-test concerns self-tests for home use or over-the-counter tests, in which the consumer is responsible for the execution and interpretation of the test as well as their follow-up behaviour. The second type of selftest comprises self-tests that are offered by an organization which carries out the test in public areas such as local supermarkets and the results are presented immediately. These tests are the so-called street-corner tests like the national cholesterol test offered by the Dutch Heart Association. ${ }^{2}$ The third and fourth self-test categories include tests in which a consumer attends a laboratory facility to have body material taken (direct-access laboratory test) or sends body material to a laboratory where the test is executed (home-collect test), after which the result is sent to them by mail or via the Internet.

Four separate phases can be distinguished within the self-test procedure, namely (1) the decision process preceding the performance of a self-test, (2) the actual execution of the self-test (only applicable to over-the-counter tests), (3) the interpretation of the test-result, and (4) the consumers' follow-up behaviour based on the test-result.

In line with the current views on patient autonomy and self-management, selfdiagnosis and self-testing can be used as a tool to take responsibility for one's own health. ${ }^{3,4}$ However, the value of self-tests is heavily debated in the scientific literature. Proponents argue that self-testing increases testing rates, resulting in more timely diagnosis and treatment, self-testing is convenient and provides anonymity, and it promotes patient empowerment. ${ }^{5-8}$ Opponents hold that at-risk populations do not use self-tests, self-tests entail relatively high costs, and testing without consulting a physician may result in adverse medical or psychological outcomes. ${ }^{5-7}$ In view of this 
debate, effective consumer education seems essential in this new area, as self-tests are likely to become even more easily available and more widely used. ${ }^{1,3}$ To the best of our knowledge, however, this is the first study to combine quantitative and qualitative research to identify consumers' information needs and use related to self-testing, and the consumers' actual follow-up behaviour based on the self-test result, and at the same time investigates the quality of the currently available consumer information. This study aims to identify potential problems and benefits with self-test use and to explore the impact of self-testing for health-care use. Furthermore, the results will be used as an input for a follow-up study which is aimed at the development of consumer information, including a decision aid, for self-testing. By developing new consumer information for self-testing, we aim to provide consumers with a basis for a deliberate and informed choice.

\section{Theoretical framework}

The Health Belief Model (HBM) $)^{9}$ as well as the Theory of Planned Behaviour (TPB) ${ }^{10}$ will be used as the theoretical framework in constructing the questionnaires (Study 1 ) and the interview topic guides (Study 2). The HBM was originally designed to explain health behaviours, such as screening, which may be comparable to self-testing. Nowadays the model has been used to explain and predict a wide variety of health-related behaviours (e.g. diabetes self-care, alcohol consumption, and smoking). ${ }^{9,11,12}$ The HBM is based on psychological expectancy-value models which state that human behaviour is the result of the valence that an individual relates to a specific goal and on the individual's assessment that a certain action will accomplish that goal. The HBM hypothesizes that health-related behaviour is the result of the individual's appraisal of the susceptibility to and the severity of a certain condition or illness and the individual's belief that a specific health action would result in a decrease of the susceptibility to or the severity of that condition. However, the health-related behaviour will only be performed if perceived barriers to that behaviour are compensated by the perceived benefits of performing it. Additionally, action is more likely to be initiated if cues (e.g. bodily or environmental events) are available and if the person has a high level of self-efficacy; e.g. if the person is confident that he or she is able to perform that action. ${ }^{9,11,13}$

Although the HBM and the TPB partially overlap, the TPB adds some important concepts to the HBM. According to the $\mathrm{TPB},{ }^{10}$ intention is the most proximal determinant of behaviour. Intention, in turn, is determined by three constructs which are conceptually independent: attitude, subjective norms, and perceived behavioural control. Attitude is based on an evaluation of the individual's positive and negative beliefs about consequences of that behaviour. ${ }^{10}$ Subjective norms represent the idea that important others approve or disapprove of the person performing that behaviour. 
Perceived behavioural control is approximately similar to the self-efficacy concept of the HBM which comprises the individual's belief that (s)he is able to successfully perform the behaviour. ${ }^{9,12}$ According to the TPB, perceived behavioural control influences behaviour both directly and indirectly, through intention. ${ }^{14}$ The HBM as well as the TPB have shown to successfully explain several health-related behaviours. $^{9,11,12,15-17}$

\section{Study aim and research questions}

The present study aims to validate the 2006 findings on frequency in self-test use, to describe information needs and information use of self-testers and non-testers, as well as the self-testers' further management on the basis of the test result. Furthermore, the quality of the existing consumer information for the most frequently used selftests will be described.

This study will investigate the following research questions:

1. What is the frequency of self-test use?

2. What are the consumers' reasons for using or not using a self-test?

3. What information do self-testers use in the different self-test stages and what is the consumers' interpretation of the quality of this information?

4. What is the consumers' response to self-test results in terms of their confidence in the result, reassurance by the test result, and follow-up behaviour?

5. What information do consumers need in the decision making process of using a self-test or not using a self-test, and in further management on the basis of the self-test result?

6. What is the quality of the currently available consumer information on a selected set of self-tests?

\section{Methods}

\section{Study design}

Mixed methods study with (1) a cross-sectional study consisting of a two-phase Internet-questionnaire, (2) semi-structured interviews with self-testers and consumers who intend to perform a self-test, and (3) the assessment of the quality of consumer information accompanying self-tests.

\section{Ethical approval}

The Medical Ethical Committee of Maastricht University indicated that no ethical approval was needed for this study. 


\section{Study 1: Cross-sectional study}

\section{Aim}

The aim of this cross-sectional study is to answer research questions (1) what is the frequency of self-test use?, (2) what are the consumers' reasons for using or not using a self-test?, (3) what information do self-testers use in the different self-test stages and what is the consumers' interpretation of the quality of this information?, and (4) what is the consumers' response to self-test results in terms of their confidence in the result, reassurance by the test result, and follow-up behaviour?

\section{Selection criteria}

Individuals aged 12 years or older who have an e-mail address will be randomly selected from the Flycatcher Internet panel.

\section{Methods of data collection}

The survey will be conducted by Flycatcher, a Dutch ISO-certified institute for online research (ISO 26361 and ISO 20252), which will handle the recruitment of participants and the distribution of the questionnaires. Individuals aged 12 years or older who have an e-mail address can apply for the Flycatcher Internet panel by registering at the Flycatcher website http://www.flycatcher.eu. New panellists are recruited through various channels: e.g. 'send-to-a-friend' actions by existing panel members, newsletters, directories of third parties (after permission), other private panels (after permission), and word-of-mouth advertising. Panellists are invited by e-mail to participate in a survey. This e-mail contains a short description of the study and an expiration date for filling out the survey. Panellists receive a gift voucher when they have completed a certain number of questionnaires.

In this survey, two consecutive questionnaires will be used. The first questionnaire will be based on the questionnaire that was used in the 2006 study to identify the use of self-tests. ${ }^{1}$ This questionnaire will be sent to approximately 6,500 panellists and will determine the prevalence of and intention to use self-tests, types of self-tests used, and a number of demographic and lifestyle characteristics of participants (e.g. gender, age, level of education, perceived health status). The second questionnaire will be based on results of the 2006 study, $^{1,18}$ and on consensus among the research team. This questionnaire will be sent to a selection of self-testers and will determine the information needs and information use, the consumers' interpretation of the quality of this information, the consumers' confidence in and their reassurance by the testresult, and their follow-up behaviour. Both questionnaires will be piloted in a small sample of the target population before being distributed on the Internet. The 
questionnaire will start with a short introduction of the purpose of the study and will provide a definition of self-testing with examples of what is considered a self-test and what is not. Finally, consent for recontacting respondents for further participation in the study will be asked. After one week, one reminder will be sent to non-responders.

\section{Justification of sample size}

Results of the 2006 study indicated that $16 \%$ of respondents had used a self-test. Based on Flycatcher's previous experiences we expect a response rate of $60 \%$. The survey will be sent to 6,500 respondents, which will result in a response of 3,900 respondents and will include approximately 700 self-testers and 3,200 non-testers.

\section{Methods of data analysis}

Analysis will be performed by using SPSS 16.0. Basic descriptive statistics will be used to describe the respondents' socio-demographic and lifestyle characteristics, the frequency of self-test use, their information use and information needs during the different self-test phases, the degree of consumer confidence in and reassurance by the test-result, and their follow-up behaviour.

\section{Study 2: Semi-structured interviews}

\section{Aim}

The purpose of the semi-structured interviews will be to gain more in-depth understanding of consumers' considerations about self-testing. More specifically, we aim to answer research questions (2) what are the consumers' reasons for using a selftest?, (3) what information do self-testers use in the different self-test stages and what is the consumers' interpretation of the quality of this information?, (4) what is the consumers' response to self-test results in terms of their confidence in the result, reassurance by the test result, and follow-up behaviour?, and (5) what information do consumers need in the decision making process of using a self-test or not using a selftest, and in further management on the basis of the self-test result.

\section{Selection criteria}

Individuals who indicate in the Internet survey that they are willing to be recontacted for participating in a face-to-face interview, will be approached. From this selection, individuals will be contacted if they performed a top-five most frequently used selftest within the last two years or intend to perform such a test, and live within a twohour drive radius. We will purposively sample consumers with regard to gender, age, and level of education. 


\section{Methods of data collection}

Semi-structured interviews will be held in order to explore the considerations of selftesters and consumers who intend to perform a self-test about using or potentially using a self-test. Respondents will be approached by e-mail that provides a short introduction of the research team and the research project, a description of the purpose of the interview, the duration of the interview and the incentive that participants will receive ( $€ 25$ for a 1-hour interview). Furthermore, individuals will be asked to provide their name and phone number by e-mail if they are willing to participate in an interview. The researchers will contact them by phone to schedule an appointment for the interview. A semi-structured topic guide will be used for the interviews in which the reasons to use a self-test, the user-friendliness of the test, the interpretation and perceived reliability of the test result, the information needs and use, and follow-up actions based on the test result will be addressed. Interviews will be held at the homes of the participants. At least 8 participants per test will be interviewed and in case data-saturation is not met, additional participants will be invited for an interview. All interviews concerning a particular test will be held by one researcher (JG, MI, or a medical student) and will be audiotaped.

\section{Justification of sample size}

Assuming that $50 \%$ of respondents who have used a self-test and $25 \%$ of respondents who intend to use a self-test respond to the invitation to take part in an interview, we will need to approach 100 self-testers in total ( 20 persons per test divided over 5 tests) and 60 respondents who intend to use a self-test to take part in the interviews ( 30 persons per test divided over 2 tests).

\section{Methods of data analysis}

The audiotaped interviews will be transcribed verbatim and imported as text documents into the qualitative analysis program, NVivo 2.0, that will be used to code and analyze the data. Analysis will be performed by using qualitative content analysis with a directed approach. Directed content analysis is aimed at validating or conceptually extending a theoretical framework. Existing theory serves as a basis for an initial coding scheme. Each code is accompanied by a specific definition which is derived from the theory. ${ }^{19,20}$ Our coding scheme will reflect the concepts of the $\mathrm{HBM}^{9,12}$ and the TPB ${ }^{10}$. The initial coding scheme will be developed by two researchers (JG and $\mathrm{MI}$ ) and will cover the topics of the interview route (e.g. self-testing in general, reasons for testing, performing the self-test, information, and follow-up behavior) and prompts (e.g. barriers, benefits, self-efficacy). Furthermore, free codes will be formulated to label additional topics that emerge during data-analysis. 
Two researchers (JG and $\mathrm{MI}$ ) will independently code all interviews. Meetings will be held in order to check the coding on exhaustiveness and appropriateness. Furthermore, it will be verified whether all theoretical concepts are identified and correctly categorized. Disagreements will be solved by comparing the text fragments and the conceptual definitions of the codes until consensus is reached. If consensus is not reached, a third independent rater will be appointed in order to achieve consensus (GR). Finally, all free codes will be integrated in the original coding scheme that is conceptually similar to the $\mathrm{HBM}^{9,12}$ and $\mathrm{TPB} .{ }^{10}$ If these free codes appear to be a separate concept, the theoretical framework will be extended.

After coding is completed, the coding of the different self-tests will be compared and assessed on their similarities. If certain self-tests are conceptually similar to one another, clusters will be made based on diseases and risk factors, (e.g. a cluster for CVD and related risk factors consisting of diabetes and cholesterol tests or a cluster for STDs consisting of Chlamydia and HIV). Analyses will result in a description of self-test behaviour, information needs and use of consumers, and their follow-up behaviour based on the test-result.

\section{Study 3: Assessment of the quality of consumer information of self-tests}

\section{Aim}

The purpose of this study is to assess the quality of the instruction leaflets that are included in diagnostic self-test kits for home-use that are available on the Internet (research question 6).

\section{Selection criteria}

We will only include diagnostic self-tests for home use on body materials with the aim to diagnose a certain disease or risk factor. The home-tests under consideration will be the top-5 most frequently used self-tests in the Netherlands. ${ }^{1}$

\section{Methods of data collection}

Dutch and English consumer information concerning the selected set of self-tests will be collected. First, we will perform an Internet search using Google which will only be aimed at websites which are available in Dutch or in English. If more than one producer has marketed one specific test, all available types will be included. The following key words will be used: selftesting, selftest, self test, home test, laboratory test, point-of-care test, direct-access test, lab test, home collect test. Additionally, we will search the Internet for specific tests and/or producers. The first 7 pages that come 
up at each key word will be consulted. If relevant links are identified in one of these pages, these sites will also be consulted. An overview will be made of the different test kits. The available consumer information will be downloaded from the Internet. Second, if the consumer information is not available on the Internet, producers or suppliers of self-tests will be contacted in order to collect this information.

\section{Methods of data analysis}

A checklist will be developed based on the validated English version of the International Patient Decision Aids Standard (IPDAS), ${ }^{21,22}$ the DISCERN criteria, ${ }^{23,24}$ and the Dutch regulations for content of IVD patient information ${ }^{25,26}$. Additionally, items derived from the Internet survey and qualitative research will be included (e.g. which information is important according to consumers). The research team will be asked to assess the resulting initial and provisional checklist and to provide suggestions for improvement. Based on these comments, the checklist will be adapted and will be reviewed by the research team once again. If written comments are unclear, the specific member of the research team will be consulted for additional oral comments.

The checklist will be tested for its usability by applying the list on consumer information that was collected in the Internet search. Two researchers will each code three different leaflets of the users' instructions. Each criterion will be coded on a 5-point Likert-scale which ranges from 1 = definite no - the quality criterion has not been fulfilled at all, to 5 = definite yes - the quality criterion has been completely fulfilled. The researchers have the opportunity to indicate if they perceived any problems when applying the checklist. Potential problems or suggestion for better use will be incorporated in the final version of the checklist.

Finally, the consumer information will be coded by means of the checklist. Furthermore, cut-off points will be determined to establish the overall quality level of the information. Two coders will independently code each leaflet of consumer information that was identified. Consensus meetings will be held in order to reach valid judgment of the quality of the consumer information.

\section{Discussion}

Self-testing is a relatively new area and is still in a state of flux. Since the start of our 2006 study, we have observed a shift in the self-testing area. In 2006, most self-tests were at the consumer's own expense. In the last few years we observed that associations like the Dutch Kidney Association and the Municipal Health Services actively offer free self-tests to the Dutch public to detect kidney disease or Chlamydia infection. Media campaigns alert the Dutch public on the option to order a self-test for 
kidney disease or the target group receives an invitation by mail to order a self-test for Chlamydia. The tests are sent at no charge to the home of all individuals who request for it on a website. ${ }^{27-28}$ We consider this a grey area in between pure self-diagnosis on the consumer's own initiative and testing initiated by a professional. Furthermore, some of the larger Dutch Health Insurance Companies partly compensate for the costs of a self-test. As a result of these developments in combination with the increase in Internet use and the current development of patient autonomy in health care, it is expected that self-tests are likely to become even more easily available and more widely used.

The studies described in this protocol are characterized by some innovative aspects. First, information about self-testing is scarce. Most studies on self-testing have focused on socio-demographic characteristics ${ }^{1,2,5,8,29-32}$ of self-testers and technical aspects of self-tests. ${ }^{33-39}$ To the best of our knowledge, studies concerning the considerations of individuals who intend to perform a self-test are lacking. In our opinion, this group is still undecided about performing or not performing a self-test and therefore has the highest information needs concerning self-testing. It is important to guide these individuals in making an informed choice about performing or not performing a selftest. Second, by combining quantitative and qualitative studies into a mixed-methods design, we aim to gain both general and more in-depth insight into considerations of self-testers and individuals who intend to perform a self-test.

By using an Internet research institute we are able to reach a large group of individuals which is necessary to gain insight into the general public's considerations about selftesting. On the one hand, it can be argued that using an Internet panel may result in a selection bias because these are individuals who are highly motivated to participate in surveys and who might be more concerned with their health. On the other hand, studies on Internet surveys versus paper-and-pencil surveys indicate that Internet surveys may yield similar results as traditional paper-and pencil surveys. ${ }^{40-42}$ The Internet panel is not completely representative of the general Dutch population as panellists are slightly younger, more often female and more highly educated. ${ }^{1}$ However, the Internet research institute claims that their panel is representative for the Dutch Internet population and since most self-tests are bought via the Internet, we consider the use of this Internet panel as an acceptable option.

From a methodological perspective, a large scale Delphi study would have been optimal to develop the checklist assessing the quality of the consumer information about self-testing. However, due to financial and logistic restrictions, we use a small scale Delphi study consisting of experts of our research team. We believe that the checklist will have satisfying face-validity, is evidence-based, and is well-founded in 
theory since the checklist will be based on the results of our 2006 study, the results of studies one and two described in this protocol, and on the IPDAS criteria for decision aids, ${ }^{21,22}$ the Discern criteria for judging the quality of written consumer information on treatment choices, ${ }^{23,24}$ and the Dutch regulations for content of IVD patient information. $^{25,26}$

The study will allow us to get more insight into the considerations of self-testers and individuals who intend to perform a self-test and on the quality of the currently available consumer information. As far as we are aware, this will be the first study which focuses on these different aspects of self-testing simultaneously. The findings from the studies described above will provide the basis for new to develop consumer information on self-testing which will be tested on its effectiveness using an RCT. The development process and the outline of the RCT will be described in a second study protocol. 


\section{References}

1. Ronda G, Portegijs P, Dinant GJ, Buntinx F, Norg R, Van der Weijden T. Use of diagnostic self-tests on body materials among Internet users in the Netherlands: prevalence and correlates of use. BMC Public Health 2009;9:100.

2. Deutekom M, Aziz Y, van Dis I, Stronks K, Bossuyt PM. De Nationale Cholesteroltest: vooral gezonde deelnemers [The Dutch National Cholesterol Test: participants mainly healthy]. Ned Tijdschr Geneeskd 2008;152:2425-9.

3. Ryan A, Greenfield S, Wilson S. Prevalence and determinants of the use of self-tests by members of the public: a mixed methods study. BMC Public Health 2006;6:193.

4. Ryan A, Wilson S, Greenfield S, Clifford S, McManus RJ, Pattison HM. Range of self-tests available to buy in the United Kingdom: an Internet survey. Journal of Public Health 2006;28:370.

5. Colfax GN, Lehman JS, Bindman AB, Vittinghoff E, Vranizan K, Fleming PL, et al. What happened to home HIV test collection kits? Intent to use kits, actual use, and barriers to use among persons at risk for HIV infection. Aids Care 2002;14:675-82.

6. Campbell S, Klein R. Home Testing To Detect Human Immunodeficiency Virus: Boon or Bane? J Clin Microbiol 2006;44:3473-6.

7. Frith L. HIV self-testing: a time to revise current policy. Lancet 2007;369:243-5.

8. Phillips KA, Chen JL. Willingness to use instant home HIV tests Data from the California Behavioral Risk Factor Surveillance Survey. Amer J Prev Med 2003;24:340-8.

9. Janz NK, Champion VL, Strecher VJ. The Health Belief Model. In: Glanz K, Rimer BK, Lewis FM, eds. Health behavior and health education: Theory, research, and practice. 3 ed. San Francisco: Jossey-Bass 2002:45-66.

10. Ajzen I. The theory of planned behavior. Organizational Behavior and Human Decision Processes 1991;50:179-211.

11. Bartolomew LK, Parcel GS, Kok G, Gottlieb NH. Behavior-oriented theories use in health promotion In: Bartolomew LK, Parcel GS, Kok G, Gottlieb NH, eds. Planning health promotion programs: An Intervention Mapping approach. 1 ed. San Francisco, CA: Jossey-Bass 2006.

12. Janz NK, Becker MH. The Health Belief Model: A Decade Later. Health Educ Q 1984;11:1.

13. Rosenstock IM, Strecher VJ, Becker MH. The health belief model and HIV risk behavior change. In: DiClemente RJ, Peterson JL, eds. Preventing Aids: Theories and methods of behavioral interventions. New York, NY: Springer 1994:5-24.

14. Kok G, de Vries H, Mudde AN, Strecher VJ. Planned health education and the role of self-efficacy: Dutch research. Health Education Research 1991;6:231-8.

15. Armitage CJ, Conner M. Efficacy of the Theory of Planned Behaviour: A meta-analytic review. Br J Soc Psychol 2001;40:471-99.

16. Conner M, Armitage CJ. Extending the theory of planned behavior: A review and avenues for further research. Journal of Applied Social Psychology 1998;28:1429-64.

17. Cooke R, French DP. How well do the theory of reasoned action and theory of planned behaviour predict intentions and attendance at screening programmes? A meta-analysis. Psychology and Health 2008;23:745-65.

18. CVZ-rapport. Diagnostische selftests op lichaamsmateriaal. Aanbod, validiteit en gebruik door de consument [Diagnostic self-tests on bodymaterial. Supply, validity, and use by the consumer]; 2007.

19. Harting J, Rutten GMJ, Rutten STJ, Kremers SPJ. A qualitative application of the Diffusion of Innovations Theory to examine determinants of guideline adherence among physical therapists. Physical Therapy 2009;89:221-32.

20. Hsieh H, Shannon SE. Three approaches to qualitative content analysis. Qualitative Health Research. 2005;15:1277-88.

21. Elwyn G, O'Connor A, Stacey D, Volk R, Edwards A, Coulter A, et al. Developing a quality criteria framework for patient decision aids: online international Delphi consensus process. BMJ (Clinical research ed 2006;333:417.

22. Elwyn G, O'Connor AM, Bennett C, Newcombe RG, Politi M, Durand MA, et al. Assessing the quality of decision support technologies using the International Patient Decision Aid Standards instrument (IPDASi). PloS One 2009;4:e4705. 
23. Charnock D, Shepperd S, Needham G, Gann R. DISCERN: an instrument for judging the quality of written consumer health information on treatment choices. J Epidemiol Community Health. 1999;53:105-11.

24. Discern Genetics Quality Criteria. [cited; Available from: http://www.discern-genetics.org/

25. Annual report on screening for disease 2007 - The self-testing of body samples. The Hague: Health Counsil of the Netherlands. 2007.

26. Wielders JPM, Loeber JG, Bartels PCM. Praktische consequenties van IVD-Richtlijn voor laboratoria, kansen en beperkingen. Nederlands Tijdschrift voor Klinische Chemie en Labgeneeskunde 2004;29:209-13.

27. Nielen M, Schellevis F, Verheij R. The usefulness of a free self-test for screening albuminuria in the general population: a cross-sectional survey. BMC Public Health 2009;9:381.

28. Op de Coul E, Weenen T, Van der Sande M, Van den Broek I. Process evaluation of the Chlamydia Screening Implementation in the Netherlands: phase 1. Challenges and opportunities during preparation and first operational phase: The National Institute for Public Health and the Environment; 2009. Report No.: 210261006/2009.

29. Ryan A, Wilson S, Taylor A, Greenfield S. Factors associated with self-care activities among adults in the United Kingdom: a systematic review. BMC Public Health. 2009;9:96.

30. Shiloh S, Vinter M, Barak M. Correlates of health screening utilization: The roles of health beliefs and self-regulation motivation. Psychology and Health 1997;12:301-17.

31. Ford CA, Jaccard J, Millstein SG, Viadro Cl, Eaton JL, Miller WC. Young adults' attitudes, beliefs, and feelings about testing for curable STDs outside of clinic settings. J Adolesc Health 2004;34:266-9.

32. Skolnik HS, Phillips KA, Binson D, Dilley JW. Deciding where and how to be tested for HIV: what matters most? J AIDS 2001;27:292.

33. Bais AG, van Kemenade FJ, Berkhof J, Verheijen RH, Snijders PJ, Voorhorst F, et al. Human papillomavirus testing on self-sampled cervicovaginal brushes: an effective alternative to protect nonresponders in cervical screening programs. Int J Cancer. 2007;120:1505-10.

34. Belinson JL, Pretorius RG, Enerson C, Garcia F, Cruz EP, Belinson SE, et al. The Mexican Cervical Cancer Screening Trial: self-sampling for human papillomavirus with unaided visual inspection as a secondary screen. Int J Gyneocol Cancer. 2009;19:27-32.

35. Hsieh YH, Howell MR, Gaydos JC, McKee KT, Jr., Quinn TC, Gaydos CA. Preference among female Army recruits for use of self-administrated vaginal swabs or urine to screen for Chlamydia trachomatis genital infections. Sex Transm Dis 2003;30:769-73.

36. Kahn JA, Slap GB, Huang B, Rosenthal SL, Wanchick AM, Kollar LM, et al. Comparison of adolescent and young adult self-collected and clinician-collected samples for human papillomavirus. Obstet Gynecol 2004;103:952-9.

37. Nielen MM, Schellevis FG, Verheij RA. The usefulness of a free self-test for screening albuminuria in the general population: a cross-sectional survey. BMC Public Health 2009;9:381.

38. Szarewski A, Cadman L, Mallett S, Austin J, Londesborough P, Waller J, et al. Human papillomavirus testing by self-sampling: assessment of accuracy in an unsupervised clinical setting. J Med Screen 2007; 14:34-42.

39. Mahilum-Tapay L, Laitila V, Wawrzyniak JJ, Lee HH, Alexander S, Ison C, et al. New point of care Chlamydia Rapid Test bridging the gap between diagnosis and treatment: performance evaluation study. BMJ 2007;335:1190.

40. Donovan MA, Drasgow F, Probst TM. Does computerizing paper-and-pencil job attitude scales make a difference? New IRT analyses offer insight. J Appl Psychol 2000;85:305-13.

41. Knapp H, Kirk SA. Using pencil and paper, Internet and touch-tone phones for self-administered surveys: does methodology matter? Computers in Human Behavior 2003;19:117-34.

42. Mead AD, Drasgow F. Equivalence of computerized and paper-and-pencil cognitive ability tests: $A$ meta-analysis. Psychological Bulletin 1993;114:449-. 


\section{CHAPTER 3}

How do people respond to self-test results?

A cross-sectional survey

Martine Ickenroth, Gaby Ronda, Janaica Grispen, Geert-Jan Dinant, Nanne de Vries, Trudy van der Weijden BMC Family Practice 2010, 11:77 


\section{Abstract}

\section{Background}

Self-tests, tests on medical conditions that can be performed by consumers without consulting a doctor first, are frequently used. Nevertheless, there are concerns about the safety of selftesting, as it may delay diagnosis and appropriate treatment in the case of inappropriate use of the test, or false-negative results. It is unclear whether self-tests stimulate appropriate follow-up behaviour. Our aim was to examine the frequency of self-test use, consumers' response to selftest results in terms of their confidence in the result, reassurance by the test result, and followup behaviour.

\section{Methods}

A two step cross-sectional survey was designed. A random sample of 6700 Internet users in an existing Internet panel received an online questionnaire on the use of self-tests. Self-tests were defined as tests on body materials, initiated by consumers with the aim to diagnose a disease or risk factor. A second questionnaire on consumers' response to self-test results was sent to the respondents who were identified as a self-tester in the first questionnaire $(n=703)$.

\section{Results}

$18.1 \%(799 / 4416)$ of the respondents had ever performed a self-test, the most frequently used tests being those for diabetes $(5.3 \%)$, kidney disease $(4.9 \%)$, cholesterol $(4.5 \%)$, urinary tract infection (1.9\%) and HIV/ AIDS and Chlamydia (both 1.6\%). A total of $78.1 \%$ of the testers with a normal test result and $81.4 \%$ of those with an abnormal result reported confidence in this result. Almost all (95.6\%) of the testers with a normal result felt reassured. After a normal result, $78.1 \%$ did not take any further action and $5.8 \%$ consulted a doctor. The corresponding figures after an abnormal test result were $9.3 \%$ and $72.2 \%$, respectively.

\section{Conclusions}

Respondents who had performed a self-test seemed to base their follow-up behaviour on the result of the test. They had confidence in the test result, and were often reassured by a normal result. After an abnormal result, most self-testers sought medical care. Because consumers seem to trust the self-test results, further research should focus on the development of consumer information addressing indications for performing a self-test, the validity of self-tests and appropriate interpretation of and management after a test. 


\section{Background}

Self-testing, which implies that consumers can decide to test themselves for medical conditions without consulting a doctor first, seems to fit in perfectly with our current views of people taking responsibility for their own health. In recent years, self-testing has become a phenomenon that cannot be ignored. A survey among Dutch Internet users in 2006 showed that 16 percent of all respondents had ever used a self-test. ${ }^{1}$ Invitro self-tests are available for about 25 conditions, for example to detect high cholesterol, HIV or prostate cancer. ${ }^{2}$ Self-tests can be bought through the Internet or at a chemist's (home-tests), or are offered and performed by organisations in public places like supermarkets (street-corner tests). Other forms of self-tests are directaccess tests or home collect tests, in which consumers can go to a laboratory (or send body materials to a laboratory) and later receive the results by post or the Internet. Self-tests have regularly attracted media attention in recent years.

We defined a self-test as an in-vitro test on body materials, initiated by a consumer (without consulting a doctor or other health professional), and with the aim of diagnosing a particular disease or identifying a risk factor. We excluded monitoring tests, as they are generally initiated on the advice of a doctor, and pregnancy tests, because these do not detect disease.

Self-testing can offer people a convenient alternative to tests initiated by a doctor. Consumers may perceive fewer barriers to testing, such as embarrassment in the case of HIV or Chlamydia testing. ${ }^{3-5}$ It also gives consumers an opportunity to take responsibility for their own health, and could make them conscious of the importance of a healthy lifestyle. Nevertheless, there are concerns about the safety of self-testing, as it may delay diagnosis and appropriate treatment in the case of inappropriate use of the test, or false-negative results. ${ }^{6,7}$ For example, a false negative result on a HIV selftest may delay treatment or result in infection of other individuals. It is unclear whether self-tests stimulate appropriate follow-up behaviour. Self-testing might result in a higher burden on the health care system, for example when false-positive results lead to further and more expensive investigations. Hardly any specific research findings on self-testing are currently available. The consequences of self-testing are still unknown, and are the subject of debate..$^{8-12}$

Investigating the consequences of self-testing requires research into the extent of the use of self-tests and the perceptions of self-testers with regard to the interpretation of the test result, confidence in the result, reassurance and follow-up behaviour. Our aim was to validate earlier findings about the frequency of self-testing and to investigate consumers' follow-up behaviour after performing a self-test by assessing the actions 
taken by self-testers. Secondary goals were to describe the confidence self-testers have in self-tests and reassurance experienced after a normal test result.

\section{Methods}

\section{General design}

We designed a cross-sectional two-step questionnaire survey among an existing Internet panel.

\section{Study population and procedure}

Questionnaires on self-testing were sent to an open-access panel managed by Flycatcher, an ISO-certified institute for online research associated with Maastricht University. All persons aged 12 years and older and who have an e-mail address can join the panel. Members are recruited online, by written invitation, face-to-face contacts or by intermediaries. The panellists are invited by e-mail to participate in surveys and they receive a gift voucher when they have completed a certain number of questionnaires. Currently, the Flycatcher Panel consists of people between 12 and 96 years of age, with a mean age of 37 (http://www.flycatcher.eu). Compared with the Dutch population, the panellists in the Flycatcher Panel are younger, have a higher level of education and are more often female. The total panel is representative of the Dutch Internet population.

In September 2008, a questionnaire on the use of self-tests was sent to a random sample of 6700 people in the panel. This number was based on the results of an earlier questionnaire on self-testing in $2006 .{ }^{1}$ A second questionnaire about follow-up behaviour was sent in November 2008, and was only addressed to those respondents who were identified by the first questionnaire as being self-testers. On further consideration, we excluded self-testers who had performed an ovulation test, because this test is often used by healthy persons, rather than by those who want to detect infertility disorders. We asked self-testers questions about one specific self-test they had mentioned in the first questionnaire. If respondents had mentioned multiple tests, a hierarchical selection procedure was applied to select one of the tests they had used, in order to collect information on different types of self-tests. Both questionnaires were online for 2 weeks; non-responders were sent a reminder after one week.

\section{Ethical approval}

The Medical Ethical Committee of Maastricht University indicated that no ethical approval was needed for this study. 


\section{Variables}

The first questionnaire that was sent to the Flycatcher panel contained questions on whether people had ever heard of self-tests, and whether they had ever performed a self-test or were likely to perform a self-test in the future. We also asked for sociodemographic characteristics. The questionnaire had been developed by Ronda et al. and has already been used to describe the use of self-tests in $2006 .{ }^{1}$

The second questionnaire was newly developed for consumers who had ever used a self-test, and contained questions on confidence in the test result, reassurance and follow-up behaviour. This questionnaire was based on the results of earlier research, ${ }^{13}$ and on consensus among the research team. We asked self-testers questions on the following topics:

- Respondent characteristics. Did the respondents have certain complaints at the time they performed the self-test (yes, no)?

- Test result. Was the result of the test normal (negative test result), abnormal (positive test result) or inconclusive?

- Confidence in test result and reassurance. Were they reassured by a normal test result (options: yes, completely reassured; yes, partly reassured or no, not reassured) and did they have confidence in the test result? (I have confidence in the result of the self-test, answered on a 5-point scale: totally agree, agree, neutral, disagree and totally disagree).

- Follow-up behaviour after the self-test. The next topic was about management related to the test result. Respondents could select multiple options: no further action, consulted a doctor, consulted another health care professional (e.g. dietician, physician assistant, doctor's assistant), changed lifestyle, used complementary medicine (e.g. acupuncture), bought self-medication, searched for more information, discussed result with family or friends, performed a self-test for other diseases or risk factors, or other. In the case of a positive test result, we added an extra question for those respondents who had not taken any action after the test result, and asked them why (options: already been diagnosed with the disease, did not trust test result or not knowing what to change or what to do).

If a respondent had consulted a doctor, we asked what kind of doctor (options: general practitioner, specialist at hospital, doctor at a municipal health service or other). We also asked them to indicate their most important reason for consulting a doctor, from the following options: to discuss complaints, to discuss concerns about having a disease, to ask for more information about the test or the disease, to discuss the test result, to ask for a new test, to ask for other tests or for referral to a hospital. In the case of a positive test result, another option was to receive treatment. 
Final questions were whether they had told their doctor that they had performed the test, and whether they had received treatment or had been referred to a hospital.

\section{Statistical analysis}

Basic descriptives statistics were used to describe the respondents' characteristics, the use of self-tests, and consumers' response to self-test results in terms of their confidence in the result, reassurance by the test result, and follow-up behaviour. Answers to the question whether respondents were reassured by the test result were recoded into yes (totally reassured and partly reassured) or no (not reassured). Confidence in the test result was recoded into having confidence (I agree or totally agree with having confidence in the test result), neutral, or not having confidence in the test result (disagree or totally disagree). Chi-square and Fisher exact tests were used to assess differences in follow-up behaviour between self-testers with a normal test result and self-testers with an abnormal test result. Differences were considered to be statistically significant if $p<0.05$ (two-sided). Analysis were performed with SPSS (Version 16.0).

\section{Results}

The response to the first survey in September 2008 was 66\% ( $n=4416)$ (Figure 3.1). Of the respondents in 2008, 2613 had completed a similar questionnaire in 2006 as well; the other 1803 respondents had received the questionnaire for the first time in 2008. The November 2008 questionnaire with questions on follow-up behaviour was sent to 703 self-testers, 555 of whom responded (response rate $79 \%$ ). Self-testers who had performed an ovulation test or for whom it was unclear which specific test they had performed, were not addressed in the second questionnaire $(n=96)$.

\section{Respondents' characteristics and frequency of self-test use}

The mean age of the respondents in September $2008(n=4416)$ was 40.2 years (SD 14.1). Sixty-four percent of the respondents were female. Twenty-one percent had a low level of education (primary school, lower general secondary education or lower vocational education), $42 \%$ an intermediate level (higher general secondary education or intermediate vocational education), and $36 \%$ a high level of education (higher vocational education or university).

The group of self-testers ( $n=555$ ) had a mean age of 42.2 years (SD 14.0), and $70.5 \%$ of the self-testers were female. Seventeen percent of the self-testers had a low level of education, $43.4 \%$ an intermediate level, and $39.8 \%$ a high level of education. 
The percentage of respondents who had ever performed at least one self-test was $18.1 \%(n=799)$, and $73 \%$ of the self-testers had performed their most recent self-test in the past two years. The most commonly used self-tests were those to detect diabetes ( $n=232,5.3 \%$ of all respondents), kidney disease $(n=216,4.9 \%)$, cholesterol $(n=198$, $4.5 \%)$, urinary tract infection $(n=85,1.9 \%)$, Chlamydia $(n=71,1.6 \%)$ and HIV/AIDS $(n=71,1.6 \%$ ) (Table 3.1). Forty-four percent of all self-tests had been performed as true home tests. The self-tests to detect kidney disease, ovulation tests and tests for female fertility were most often used as true home tests (Table 3.1).

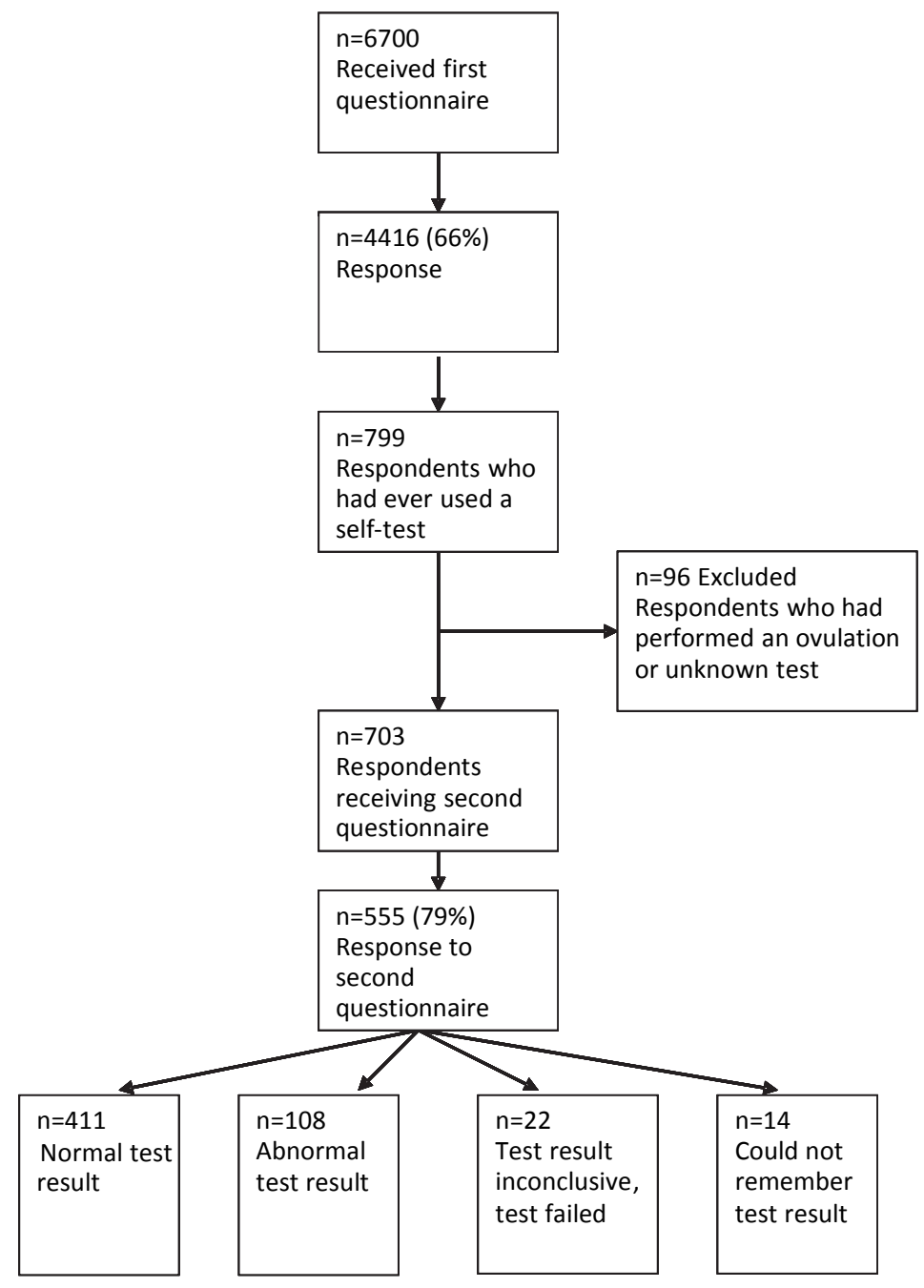

Figure 3.1 Respondents to the questionnaires sent in September 2008 (first questionnaire) and November 2008 (second questionnaire). 
Table 3.1 Number and percentage of respondents who had ever performed a self-test (multiple entries possible) and frequency of true home testing.

\begin{tabular}{|c|c|c|c|}
\hline & $n$ & $\begin{array}{c}\% \text { of all respondents } \\
(n=4416)\end{array}$ & $\%$ true home tests* \\
\hline Total & 799 & 18.1 & 44 \\
\hline Diabetes & 232 & 5.3 & 56 \\
\hline Kidney disease & 216 & 4.9 & 92 \\
\hline Cholesterol & 198 & 4.5 & 23 \\
\hline Urinary tract infection & 85 & 1.9 & 46 \\
\hline AIDS/HIV & 71 & 1.6 & 9 \\
\hline Chlamydia & 71 & 1.6 & 3 \\
\hline Ovulation** & 53 & 1.2 & 98 \\
\hline Allergies & 49 & 1.1 & 14 \\
\hline Anaemia & 48 & 1.1 & 13 \\
\hline Syphilis & 38 & 0.9 & 8 \\
\hline Hepatitis B/C & 37 & 0.8 & 3 \\
\hline Female fertility & 35 & 0.8 & 80 \\
\hline Glandular fever & 34 & 0.8 & 29 \\
\hline Vaginal infection/ candida & 34 & 0.8 & 12 \\
\hline HPV & 18 & 0.4 & 17 \\
\hline Influenza & 17 & 0.4 & 65 \\
\hline Pharyngitis & 16 & 0.4 & 50 \\
\hline Male fertility & 14 & 0.3 & 29 \\
\hline Thyroid disease & 12 & 0.3 & 8 \\
\hline Blood coagulation & 9 & 0.2 & 33 \\
\hline Osteoporosis & 8 & 0.2 & 13 \\
\hline Hereditary disease & 6 & 0.1 & 0 \\
\hline Prostate cancer & 5 & 0.1 & 40 \\
\hline Intestinal cancer & 3 & 0.1 & 67 \\
\hline Gluten intolerance & 2 & 0.04 & 50 \\
\hline Helicobacter pylori & 2 & 0.04 & 50 \\
\hline Liver disease & 2 & 0.04 & 0 \\
\hline Other** & 93 & 2.1 & 60 \\
\hline
\end{tabular}

* Percentage of the tests that were performed as true home tests; ** Tests excluded in second questionnaire

\section{Test result, reassurance and confidence in test result}

Overall, 411 respondents had received a negative test result (normal test result), 108 had tested positive (abnormal test result) and 22 reported that the test had failed or that the test result had been inconclusive (Figure 3.1).

Of the self-testers with a normal test result, $78.1 \%(n=321)$ reported they had confidence in this result, while $3.4 \%(n=14)$ had no confidence in the result. Almost $96 \%(n=393)$ of the testers were reassured by the normal result.

In the case of an abnormal test result, $81.4 \%(n=88)$ of the respondents had confidence in this result. Almost $4 \%(n=4)$ of the self-testers who tested positive did not have confidence in the result. 


\section{Follow-up behaviour based on the test result}

\section{Normal test result}

Self-testers who had a normal test result $(n=411)$ generally had not taken any further action ( $n=321,78.1 \%)$ (Table 3.2). Six percent of the respondents $(n=24)$ with a normal test result had consulted a doctor, and $1.0 \%(n=4)$ had consulted another health professional. The other respondents had engaged in self-management, for example by changing their lifestyle ( $n=20,4.9 \%)$, or searched for more information $(n=16,3.9 \%)$. Eight percent of the respondents who had a normal test result $(n=33)$ had discussed the result with friends or family. None of the respondents had decided to perform selftests for other diseases after the first test.

\section{Abnormal test result}

After an abnormal test result ( $n=108)$, most respondents had sought medical care (72.2\% ( $n=78)$ consulting a doctor and $8.3 \%(n=9)$ another health professional). Nine percent of the self-testers with an abnormal test result $(n=10)$ had not taken any further action despite the abnormal result. Reasons for not taking further action included already having been diagnosed with the disease $(n=5)$ or not knowing what to do or what to change $(n=2)$. Others had engaged in self-management. Almost $19 \%$ of the self-testers had changed their lifestyle $(n=20)$, and $18 \%$ had told others about the self-test they had performed ( $n=19)$. Other forms of self-management used after performing a self-test were self-medication and complementary medicine. The differences in follow-up behaviour between a normal and an abnormal test result were all statistically significant (Table 3.2).

Self-test follow-up behaviour seemed to be similar for most tests. After the self-test to detect allergies $(n=19)$ respondents were more likely to engage in self-management than after the other tests. They had used self-medication or complementary medicine, or had changed their lifestyle. Only one person had consulted a doctor. The urinary tract infection self-test had been performed by 61 respondents, of which 22 had a normal and 35 an abnormal test result. Almost all of these testers had been having complaints (52/57). All respondents who tested negative had been reassured by this result, and only $13.6 \%$ of them had consulted a doctor. A positive test result led to a consultation in $85.7 \%$ of all cases. 


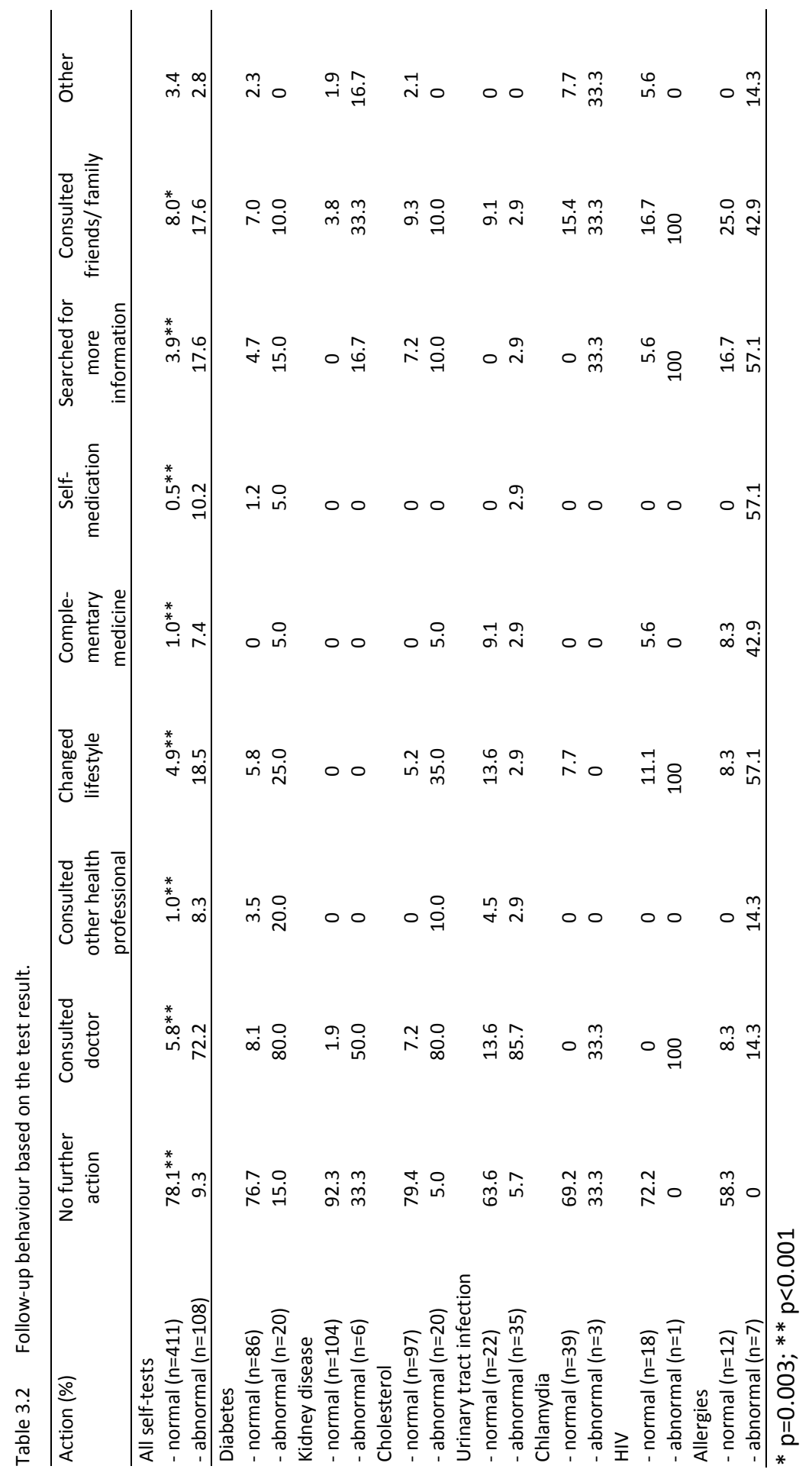




\section{Reasons for consulting a doctor}

Of the self-testers with a normal test result $(n=411), 24(5.8 \%)$ had decided to consult a doctor, despite the normal test result. Their reasons for consulting a doctor are shown in Table 3.3. Almost all self-testers with a normal test result had told the doctor about the self-test they had performed $(n=22)$. Of the 24 respondents who had consulted a doctor, 12 had received treatment and 5 had also been referred to a hospital.

Of the self-testers with an abnormal test result $(n=108), 78$ (72.2\%) had consulted a doctor (Table 3.3). Almost all of these respondents had told their doctor they had performed a self-test $(n=73)$. Of the 78 respondents with an abnormal test result who had consulted a doctor, 59 had received treatment, of which 16 were also referred to a hospital and 5 were only referred to a hospital.

Table 3.3 Reasons for consulting a doctor after normal and abnormal self-test result (multiple entries possible).

\begin{tabular}{lcc}
\hline & $\begin{array}{c}\text { Abnormal test result } \\
\mathrm{n}=108\end{array}$ & $\begin{array}{c}\text { Normal test result } \\
\mathrm{n}=411\end{array}$ \\
\hline Consulted doctor & $\mathrm{n}=78(72.2 \%)$ & $\mathrm{n}=24(5.8 \%)$ \\
\hline To discuss complaints & 41 & 9 \\
For treatment & 31 & 0 \\
To discuss the self-test result & 27 & 8 \\
To ask for a new test & 16 & 6 \\
To discuss concerns about having a disease & 6 & 6 \\
To receive more information about a disease & 4 & 0 \\
To receive more information about the self-test & 2 & 4 \\
To ask for other tests & 2 & 2 \\
To ask for referral to a hospital & 2 & 0 \\
\hline
\end{tabular}

\section{Discussion}

\section{Main findings}

In $2008,18.1 \%$ of the respondents in our Internet survey had ever performed a selftest. The most frequently used self-tests were those to detect diabetes, kidney disease, high cholesterol, urinary tract infections, HIV/AIDS and Chlamydia. Respondents who had performed a self-test seemed to base their follow-up behaviour on the test result. Most of the self-testers had confidence in the test result. In the case of a normal test result, they had generally been reassured by this result, and had not taken any further action. After an abnormal test result, many had sought medical care, engaged in selfmedication, searched for more information or changed their lifestyle. Follow-up behaviour seemed to be similar for most self-tests, except for a self-test on allergies, after which the respondents seemed to be more likely to engage in self-management 
than after other tests. This might be explained by the test specific properties of a selftest to detect allergies; after a positive result, consumers can adjust their lifestyle, a consultation with a doctor is often not necessary.

\section{Strengths and limitations}

Using the Flycatcher Internet panel, we were able to send our questionnaires to a large sample of Dutch Internet users. Because this sample is not completely representative of the Dutch population, it might overestimate the frequency of self-testing. Internet users may be more interested in self-testing, since they will probably more often search the Internet for health related questions, and therefore can be more informed of the existence of self-tests and more willing to use one. Another reason for a possible overestimation of the frequency of self-testing is because women are overrepresented in the panel. Women are more likely to engage in self-testing. ${ }^{14}$ Additionally, some selftests are gender specific tests (e.g. ovulation tests) or are more often used by women (e.g. urinary tract infection self-test). We think the overestimation due to respondents using monitoring tests (e.g. glucose testing in diabetes) instead of diagnostic self-tests is small. Secondary analysis showed that only 22 respondents who had performed a diabetes self-test were actually diabetics.

Our results do not allow us to conclude what the exact consequences of self-testing are at individual level or for health care providers. For example, we do not know whether self-testing leads to overconsultation of doctors because of increased anxiety among consumers with a positive result (which may be false-positive), or whether selftests effectively help consumers diagnose a disease or identify a risk factor at an earlier stage, and can prevent disease or complications. To determine these consequences, the whole process of self-testing should be investigated, starting with the way each consumer decided to do a test, and ending with verifying the diagnosis with a gold standard clinical investigation and the actual follow-up behaviour of the self-tester. The steps in the self-testing process involve challenging decisions for consumers to make, for example deciding whether there is a medical indication for the test, dealing with possible false-positive or false-negative results, and seeing the results in the light of multiple risk factors, for example in cardiovascular disease. Although we cannot say whether all self-testers made the right decisions during this process, we can conclude that consumers seem to rely on self-test results, and that they should be informed about the pitfalls and possible consequences of self-testing.

\section{Comparison with other studies}

We compared our data on the prevalence of self-testing with the results of the survey done in 2006. The use of self-tests seems to be stable, as the only slight increase was 
seen in the use of the Chlamydia self-test and a test to detect kidney disease. Both of these tests have been offered for free to the Dutch population in the past two years, accompanied by a mass media campaign. For example, a self-test to detect renal disease which was provided for free by the Dutch kidney association, was ordered by $7.8 \%$ of the Dutch population during the first thirty days. ${ }^{15}$

Respondents in our study seemed to have confidence in the test result. Even when they had symptoms (e.g. in the urinary tract infection self-test) they often relied on the test result. Since we found no published articles on consumers' confidence in selftests, we cannot compare our findings with those of other studies. Qualitative research in general practice showed that patients have high expectations of medical lab tests ${ }^{16}$, and consumers may think likewise about self-tests.

\section{Conclusions}

Our research assessed the actual actions taken by consumers who had performed a self-test. Further details on consumers' belief in self-test results, the way they interpret self-test results and whether and how they engage in certain follow-up behaviours should be investigated in qualitative research. This could also shed more light on the psychological and medical consequences of self-testing.

It is almost impossible to answer the question whether self-tests should be either encouraged or prohibited, the pros and cons of self-testing should always have to be weighed for each test and each individual. Consumers should be able to weigh the pros and cons themselves and make an informed decision. As consumers have a high level of confidence in self-tests, and are reassured by a negative test result, it is very important that consumers have adequate information on the reliability and the validity of self-tests in general, that tests can give false positive and false negative results, and how consumers should interpret test results. Health professionals should be able to provide this information, but this should also be available on the Internet, since selftesting often does not involve a health professional.

Further research should focus on information that explains to consumers for whom it is important to do a test, as well as information that consumers need to correctly perform a self-test, so they can make informed choices when they intend to do a selftest, and have sufficient knowledge to respond suitably to the test result. 


\section{References}

1. Ronda G, Portegijs P, Dinant GJ, Buntinx F, Norg R, Van der Weijden T. Use of diagnostic self-tests on body materials among Internet users in the Netherlands: prevalence and correlates of use. BMC Public Health 2009;9:100.

2. Ryan A, Wilson S, Greenfield S, Clifford S, McManus RJ, Pattison HM. Range of self-tests available to buy in the United Kingdom: an Internet survey. J Public Health (Oxf) 2006;28:370-4.

3. Pavlin NL, Gunn JM, Parker R, Fairley CK, Hocking J. Implementing chlamydia screening: what do women think? A systematic review of the literature. BMC Public Health 2006;6:221.

4. Tebb KP, Paukku MH, Pai-Dhungat MR, Gyamfi AA, Shafer MA. Home STI testing: the adolescent female's opinion. J Adolesc Health 2004;35:462-7.

5. Skolnik HS, Phillips KA, Binson D, Dilley JW. Deciding where and how to be tested for HIV: what matters most? Journal of acquired immune deficiency syndromes (1999) 2001;27:292-300.

6. Deutekom M, Bossuyt PM. [The increased availability of self-tests for medical analyses]. Ned Tijdschr Geneeskd 2007;151:901-4.

7. Walensky RP, Paltiel AD. Rapid HIV testing at home: does it solve a problem or create one? Annals of internal medicine 2006;145:459-62.

8. Ryan A, Greenfield S, McManus R, Wilson S. Self-care--has DIY gone too far? Br J Gen Pract 2006. 56:907-8.

9. Frith L. HIV self-testing: a time to revise current policy. Lancet 2007;369:243-5.

10. Spielberg F, Levine RO, Weaver M. Self-testing for HIV: a new option for HIV prevention? Lancet Inf Dis 2004;4:640-6.

11. Campbell S, Klein R. Home testing to detect human immunodeficiency virus: boon or bane? J Clin Microbiol 2006;44:3473-6.

12. Borriello SP. Science, medicine, and the future. Near patient microbiological tests. BMJ (Clinical Research ed 1999;319:298-301.

13. Weijden T, Ronda G, Norg R, Portegijs P, Buntinx F, Dinant GJ. Diagnostische zelftests op lichaamsmateriaal: aanbod, validiteit en gebruik door de consument [Diagnostic self-tests on body materials: availability, validity and frequency of use]. In. Maastricht: Maastricht University, School for Public Health and Primary Care (Caphri); 2007.

14. CVZ-rapport. Diagnostische zelftests op lichaamsmateriaal. Aanbod, validiteit en gebruik door de consument [Diagnostic self-tests on body materials. Supply, validity and use by the consumer]. 2007

15. Nielen MM, Schellevis FG, Verheij RA. The usefulness of a free self-test for screening albuminuria in the general population: a cross-sectional survey. BMC Public Health 2009, 9:381.

16. van Bokhoven MA, Pleunis-van Empel MC, Koch H, Grol RP, Dinant GJ, van der Weijden T. Why do patients want to have their blood tested? A qualitative study of patient expectations in general practice. BMC Fam Pract 2006;7:75. 


\section{CHAPTER 4}

\section{Motivation and experiences of self-testers regarding}

tests for cardiovascular risk factors

Martine Ickenroth, Janaica Grispen, Gaby Ronda, Marloes Tacken, Geert-Jan Dinant, Nanne de Vries, Trudy van der Weijden Health Expectations 2011, Oct 28 


\section{Abstract}

\section{Background}

In recent years, self-tests have become increasingly available to the general public, though their value is still being debated. Since these tests are available, consumers should have access to clear information about self-testing. Examining experiences of self-testers could contribute to the development of consumer information.

\section{Objective}

Detailed exploration of consumers' experiences with self-testing for cardiovascular risk factors.

\section{Methods}

Semi-structured interviews with 20 consumers who had performed a self-test for glucose, cholesterol or albuminuria. The main topics of the interviews were reasons for self-testing, performing the self-test, follow-up behaviour and perceived need for information on self-testing. Data were analysed using thematic content analysis.

\section{Results}

Regarding the reason for self-testing, three types of users were distinguished: those who engaged in self-testing when a test was offered, either with or without previous knowledge about the disease or risk factor, and those who had actively decided to test and had searched for a self-test themselves. Self-testers had generally experienced no problems performing the test or interpreting the result, and had considerable confidence in the result. They were easily reassured by a normal result, while an abnormal result did not automatically mean they consulted a doctor. Most participants did not feel the need for more information.

\section{Conclusions}

Self-testers often perform tests for reassurance, without considering the disadvantages, such as the absence of professional counselling and the risk of false-positive or false-negative results. Consumer information should promote more informed and deliberate choices for self-testing. 


\section{Introduction}

Self-tests, tests on medical conditions which can be performed without the involvement of a health care professional, have become increasingly available to the general public. ${ }^{1,2}$ In this study, we define a self-test as an in-vitro test on body materials, initiated by a consumer, with the aim of diagnosing a particular disease or identifying a risk factor. These tests, which include tests on cardiovascular risk factors, infectious diseases or cancer, are available as home tests, streetcorner tests, directaccess or home collect tests (Table 4.1). ${ }^{3}$ They give consumers the opportunity to assume responsibility for their own health, and can offer people a convenient alternative to tests initiated by a doctor. ${ }^{4,5}$ Nevertheless, there are concerns about the safety of self-testing. ${ }^{6,7}$ Some of the self-tests have shown to be unreliable ${ }^{8}$, and there are concerns whether people consider the negative sides of self-testing, such as the risk of false positive results, which could lead to anxiety and unnecessary medical investigations, or false reassurance in case of false negative results. ${ }^{9}$

A survey among Dutch Internet users in 2006 showed that $16 \%$ of the respondents had ever used a self-test, the most frequently used self-tests being those for cardiovascular risk factors: $6.2 \%$ of the respondents had performed a glucose self-test, and $5.4 \%$ had performed a cholesterol test without consulting a doctor first. ${ }^{3}$ In September 2006, free home tests to detect albuminuria were offered to the Dutch public by the Dutch Kidney Foundation, accompanied by a mass media campaign on asymptomatic kidney disease. This self-test was ordered by $7.8 \%$ of the Dutch population in the first thirty days of the campaign. ${ }^{10}$

A survey among consumers who had had a cholesterol streetcorner test done showed that it was particularly the healthy and slightly worried consumers who took these tests (the 'worried well'). ${ }^{11}$ A problem of screening in low-risk populations is the considerable rate of false-positive results. Another concern is whether consumers can adequately interpret the results of self-tests. Risks of developing cardiovascular diseases in particular have to be interpreted in the light of multiple risk factors. As a result, consumers are faced with difficult decisions to make, concerning indications for doing a test, understanding of the validity of the self-test, and deciding about appropriate follow-up behaviour.

Because these tests are available to the general public, it is important that consumers have access to clear and easy to understand information about the pros and cons of self-testing, the interpretation of test results and appropriate follow-up behaviour. Developing such specific self-test information requires knowledge about the experiences of people who have used self-tests. The main objective of our qualitative study was to gain an in-depth understanding of the experiences of self-testers who had performed self-tests for cardiovascular risk factors. 


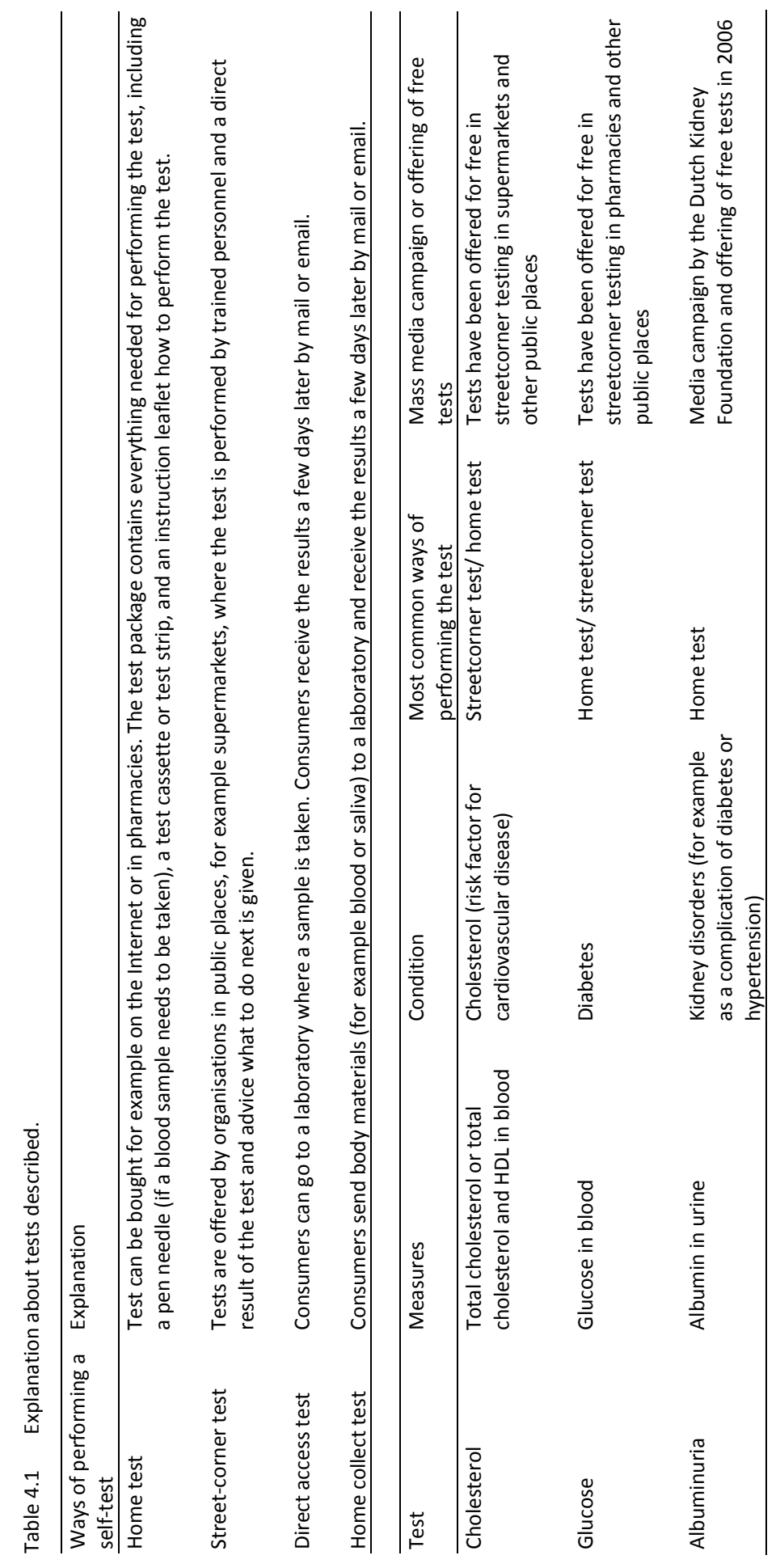


The interview topic guide was based on earlier research, the Health Belief Model $(\mathrm{HBM})^{12}$ and topics considered important by the research team. According to the HBM, an individual's decision to engage in health-related behaviour is defined by the perceived severity of and the perceived susceptibility to a particular condition or illness and the evaluation of the effectiveness of a certain action that would reduce their susceptibility to or the severity of this condition. However, individuals are only inclined to perform a certain action if they perceive more benefits than barriers associated with that action and if certain cues (e.g. bodily or environmental events) are present that trigger action. Furthermore, the individual's confidence in his or her capability to successfully perform a certain action (self-efficacy) is an important concept within the HBM. $^{12-14}$ In the present qualitative study, in addition to these HBM-concepts about determining to do the test, we also asked consumers what information they thought was important to enable them to correctly perform and interpret self-tests.

\section{Methods}

\section{Participants}

Participants were recruited from an online access panel managed by Flycatcher, an ISO certified institute for online research associated with Maastricht University (http://www.flycatcher.eu). People can apply for the panel if they have an e-mail address and are aged 12 years or over. In September 2008, a random sample of 6700 panel members received a questionnaire on self-testing. They were asked whether they had ever used a self-test, which self-test they had performed, what the result of the test was and if researchers could contact them for further research. Of the 4416 respondents, 799 (18\%) had used a self-test at least once. The question if the respondent did not mind being contacted for an invitation to take part in a face-to-face interview received a positive response from 72 of the 198 respondents who had performed a cholesterol self-test, 49 of the 232 glucose self-testers, and 78 of the 218 respondents who had performed an albuminuria test.

We selected all respondents who had performed a self-test during the past two years and who were living within a two-hour driving distance from Maastricht University (for logistical reasons). We deliberately sampled people with a range of characteristics in terms of gender, age, type of self-test used and result of the self-test. The selected self-testers received an e-mail explaining the goal of our research and the nature of the interview. We asked the respondents to reply to our mail if they were willing to participate, and contacted them by telephone to make an appointment. If they did not respond within a week, we sent a reminder. Participants received a gift voucher as an incentive to participate. 


\section{Ethical approval}

The Medical Ethical Committee of Maastricht University indicated that no ethical approval was needed for this study.

\section{Interview route}

Themes and questions on self-test behaviour were derived from earlier research ${ }^{3}$, from the Health Belief Model ${ }^{12,15}$ and from topics considered important by the research team. The research team then reached consensus on the themes and questions that should be addressed during the interview. This resulted in four themes becoming the main topics of our interviews: the reason for performing a self-test, performing the self-test, the follow-up behaviour and the perceived need for information about the self-test. We asked open-ended questions about the four main themes, encouraging respondents to talk about their experiences and stimulating them to express their opinion. In the interview plan, each main theme was addressed by questions on subthemes that had to come up during the interviews and that were used to further encourage participants to talk about their experiences. A general impression of users' ideas on self-testing was obtained by starting each interview with the open question how the respondent had experienced performing the self-test. The complete topic guide for the interviews can be found in an online supplemental file published with the protocol article (http://www.biomedcentral.com/1471-2458/10/453/additional). ${ }^{16}$

\section{Interviews and analysis}

The semi-structured interviews took place at the participants' homes and were conducted by one of the researchers or a final-year medical student, between May and September 2009. Respondents were informed about the goal of the study, and were asked if they agreed to the conversation being audiotaped. Field notes were made after the interviews about the atmosphere of the interview, personal characteristics of the participant, and any comments that were not on the audiotape (for example statements made after the recorder had been switched off). To standardise the interviews, the researchers and the medical student used the same interview scheme. The scheme was piloted by interviewing medical students, and the interviewers practiced their interview skills by listening to each other's interviews and giving feedback.

The recorded interviews were transcribed verbatim and analysed with NVivo 2.0, using thematic content analysis. ${ }^{17}$ An initial set of codes was derived from the answers that were given to the questions in the interviews. To begin with, five interviews were analysed. They were independently coded by one researcher [MI] and a medical student [MT], and codes were discussed until consensus had been achieved. After 
these interviews had been coded, all codes were discussed and assigned to one of the main themes. Some codes with similar meaning were merged. This new coding scheme was then used to code the remaining interviews. Each interview was coded by two researchers $[\mathrm{MI}$ and $\mathrm{JG}]$ and discussed until consensus was reached. If a new topic was found, a new code was added. Respondents' experiences with self-testing were described by grouping together and analysing the codes that belonged to the same theme. The quotes included in this article were translated from Dutch into English by a professional translator.

\section{Results}

Eighty questionnaire respondents were invited by e-mail for an interview. A total of 28 of them responded and were interviewed subsequently. During the interviews, we found eight of them not to have performed a self-test according to our definition (for example, they were diabetics using diabetes monitoring tests, or the test had been initiated by a doctor) and were excluded for further analysis. Hence, 20 interviews were analysed (Figure 4.1). Participants' characteristics are listed in Table 4.2. Although some of the participants had performed multiple tests, the main topic during the interview was the test for which they had been invited, although they were given an opportunity to share their experiences with other tests they might have used.

There was a considerable amount of overlap between the three tests in terms of the themes emerging from the interviews, and data saturation occurred after fifteen interviews.

Five main themes emerged from the data, corresponding to a large extent to the main themes of our interview plan. The themes were as follows: the reason to perform a self-test, performing and interpretation of the test, follow-up behaviour, information needs and confidence in the test result. The results of the interviews are discussed below for each of the main themes (Table 4.3).

\section{Reasons for self-testing}

Three types of testers were distinguished. The first was the passive self-tester who became aware of the risk factor or disease when a self-test was offered; the second was the passive self-tester who was already aware of the risk factor or disease and the third was the active self-tester, who had actively sought an opportunity to self-test, or had bought one. 

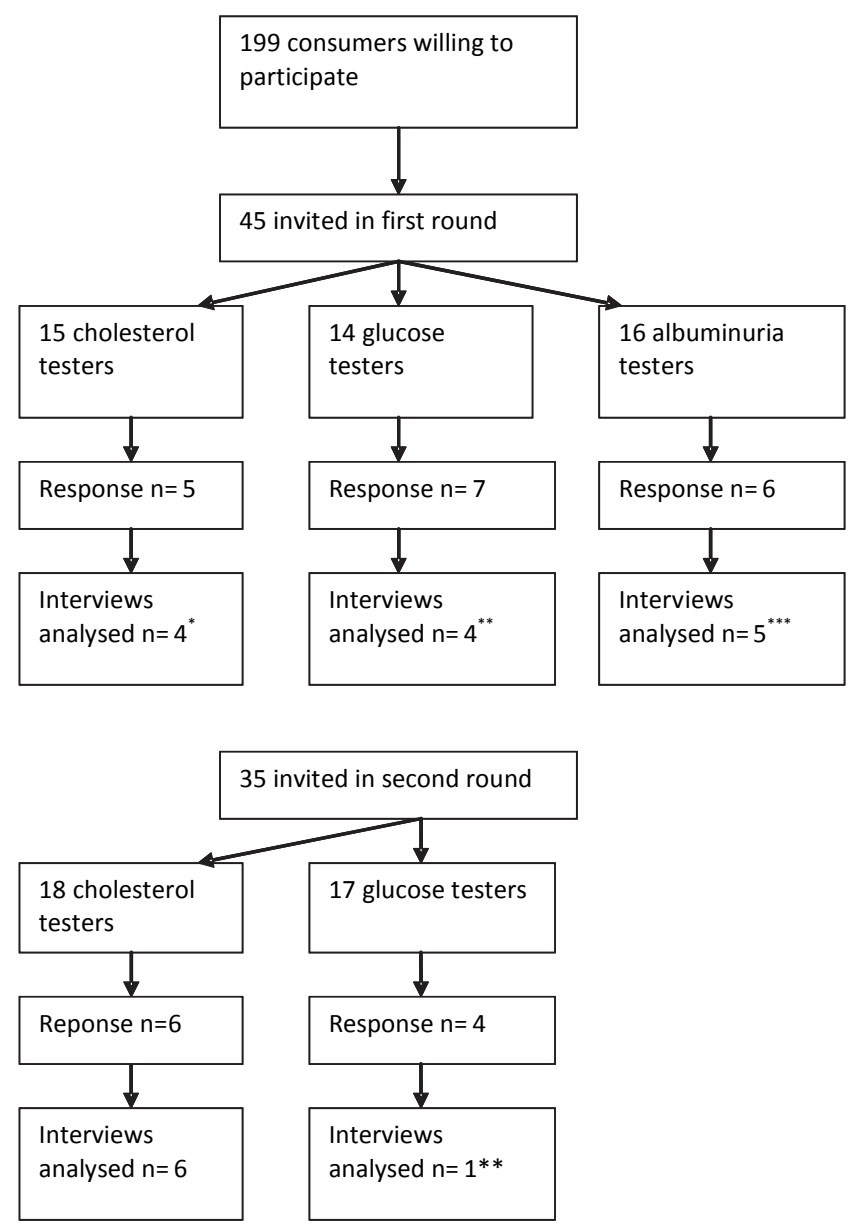

Figure 4.1 Selection of participants.

* One respondent excluded; had not performed self-test according to our definition; ** Three respondents excluded; were using glucose monitoring tests; *** One respondent excluded; had not performed the test

The first type of self-tester had never had the intention to do a test for a particular disease or risk factor until they were confronted with the opportunity to test. Media, commercials and streetcorner tests had made respondents aware of the fact they could have a risk factor without knowing it, and gave them the opportunity to do a self-test. The respondents then became curious about these tests, and thought it would be good to know if they had the disease or risk factor. This was the most common reason in the group of respondents who had taken an albuminuria self-test. 
Table 4.2 Participants' characteristics.

\begin{tabular}{lcclll}
\hline Respondent & Gender & Age & Test (test result*) & Type of test & Other tests (test result*) \\
\hline 1 & $\mathrm{~F}$ & 56 & Cholesterol (positive) & Streetcorner & - \\
2 & $\mathrm{~F}$ & 53 & Cholesterol (negative) & Streetcorner & - \\
3 & $\mathrm{~F}$ & 72 & Cholesterol (negative) & Streetcorner & - \\
4 & $\mathrm{~F}$ & 45 & Cholesterol (negative) & Home test & - \\
5 & $\mathrm{~F}$ & 24 & Cholesterol (negative) & Home test & - \\
6 & $\mathrm{~F}$ & 41 & Cholesterol (negative) & Streetcorner & Albuminuria (positive) \\
7 & $\mathrm{~F}$ & 58 & Cholesterol (negative) & Home test & Albuminuria (negative) \\
8 & $\mathrm{~F}$ & 45 & Cholesterol (negative) & Streetcorner & - \\
9 & $\mathrm{M}$ & 40 & Cholesterol (positive) & Lab test & - \\
10 & $\mathrm{~F}$ & 42 & Cholesterol (negative) & Streetcorner & Albuminuria (negative) \\
11 & $\mathrm{~F}$ & 58 & Albuminuria (negative) & Home test & Cholesterol (positive) \\
12 & $\mathrm{M}$ & 55 & Albuminuria (positive) & Home test & - \\
13 & $\mathrm{~F}$ & 52 & Albuminuria (negative) & Home test & Cholesterol (positive) \\
14 & $\mathrm{~F}$ & 33 & Albuminuria (positive) & Home test & - \\
15 & $\mathrm{~F}$ & 44 & Albuminuria (negative) & Home test & - \\
16 & $\mathrm{M}$ & 63 & Glucose (negative) & Home test & Cholesterol (negative) \\
17 & $\mathrm{~F}$ & 55 & Glucose (negative) & Home test & Cholesterol (negative) \\
18 & $\mathrm{~F}$ & 74 & Glucose (negative) & Home test & Albuminuria (negative) \\
19 & $\mathrm{~F}$ & 35 & Glucose (positive) & Home test & - \\
20 & $\mathrm{~F}$ & 56 & Glucose (negative) & Home test & - \\
\hline
\end{tabular}

* Test result as perceived and remembered by the respondent

It was offered to me. I was given something somewhere and I could apply for a kidney test, for free, so I thought, well, why not. It's just to check yourself. Especially when you're getting on a bit, you start to take more notice of your body. So you think, well, such a check-up, that's like, is everything still OK with those kidneys. And well, you could always decide later, you know, if there's an unfavourable result, or a less favourable one, you can still go see your general practitioner.

(Female, age 44, albuminuria, normal test result)

The second type of self-testers, mostly those using cholesterol self-tests, already had some knowledge about the disease or risk factor, for example because of some kind of personal involvement with the condition (e.g. having family or friends with cardiovascular disease, or because they had had a cholesterol test done before), or were already conscious of the importance of a healthy life style. These respondents wanted to do the test to get more information about their health status, to confirm that they were in good health, or because they were seeking reassurance. On the other hand, they had not actively sought medical advice, because they did not have any complaints and were feeling healthy; they said they would only go to a doctor if they had good reason to think something might be wrong. 


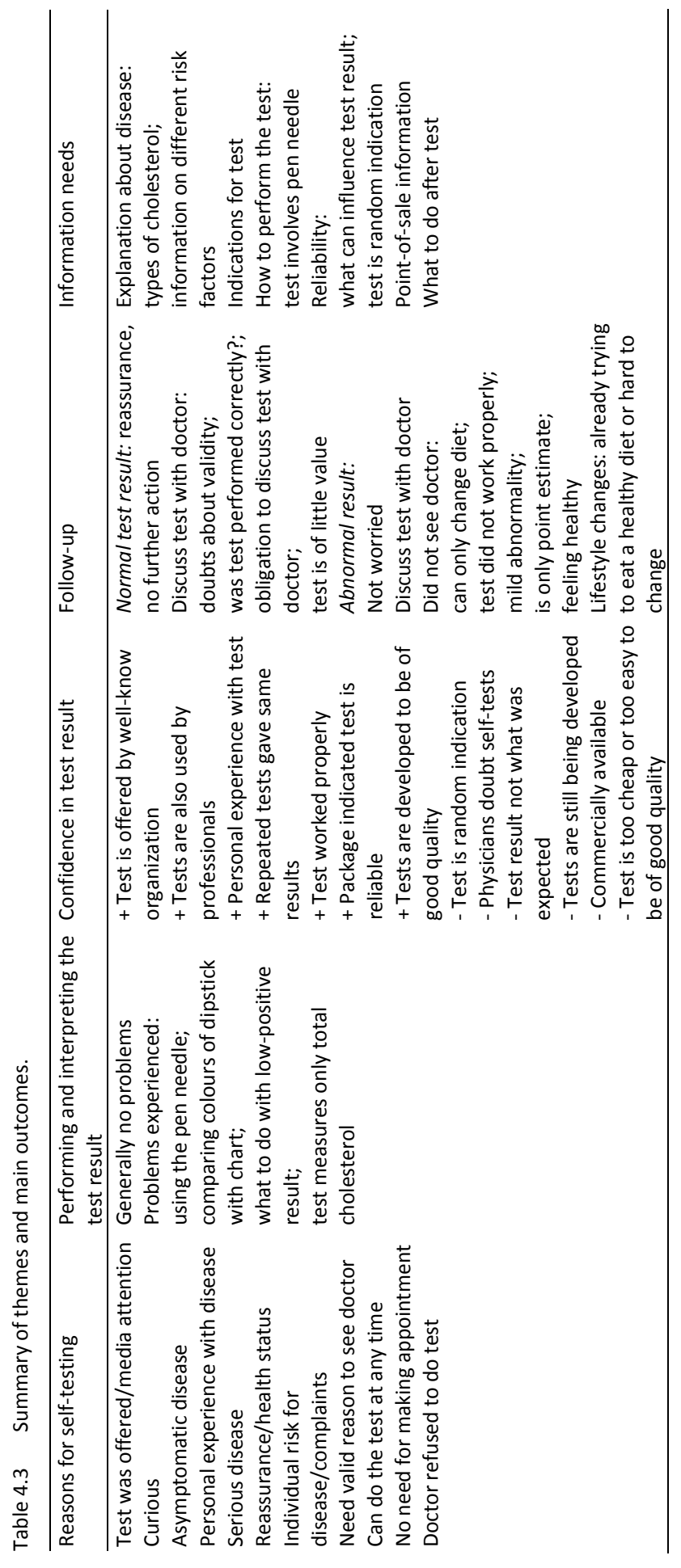


Others felt no need to see a doctor when they did not have any complaints, but might ask for a test in the future when they had to see their general practitioner (GP) for some other reason. Some respondents did not want to take up their doctor's time without (in their opinion) having a valid reason. When a self-test was offered, they saw this as an easy opportunity to be tested, because there was no need to make an appointment and they could do the test whenever they wanted to.

Well, you know, not necessarily having it tested at the doctor's, but just because I wanted to know. Because, well, not that I'm fat or whatever, but you might still have high cholesterol. [...] And your GP, well, you go see him when you don't feel well, right, then you think I'd better go see my doctor and have it checked. But actually I feel OK, and so I'd still want to know if it might be too high or if it's good; I also want to know if it's $O K$.

(Female, age 53, cholesterol, normal test result)

The third type, the active self-testers, had actively decided to do a self-test and had looked for opportunities to do one, often resulting in home tests. The reasons to do a test were mainly the same as those for the second type (looking for confirmation that they were in good health or having some personal involvement with the disease), or because they thought they were at risk for developing cardiovascular disease, considered the disease to be a serious condition, or had certain complaints. These respondents also said they needed a valid reason to go to a GP: some participants thought they would have to justify why they wanted to do the test, and the doctor might refuse to have it done. Other reasons to purchase a self-test included that their doctor had previously refused to do the test at their request, that self-tests give immediate results, that they could do the test whenever they wanted, that they did not have to make an appointment and that they did not have to go to the hospital to have fasting blood samples taken without having had breakfast.

Well, as I said, you know, it's a bit easier, not having to make another appointment. The GP might ask do you really want to have that checked again; you've had it checked and it was OK. So I sort of wanted to know if the result was still the same. And yes, I didn't want to bother my GP again, that sort of thing.

(Female, age 58, cholesterol, normal test result)

\section{Performing the self-test and interpreting the result}

Most self-testers had not experienced any problems in performing the self-test. Some cholesterol self-testers who had performed a home test indicated they had had problems using the pen needle, and reported that it was difficult to use it on oneself. 
They indicated that the packaging should explain that a pen needle had to be used, or that it was easier to ask someone else to help you.

Some of the self-testers who had performed the albuminuria test had experienced difficulties in comparing the colour of the dipstick with the colour chart to determine the level of albumin in their urine. This had to be done in daylight, because the results were difficult to read in artificial light. Since the test had to be performed with first void urine and the test was distributed in winter, when it is still dark in the morning, not all testers were able to decide the results correctly, due to lack of daylight. The albuminuria test also caused some problems regarding the interpretation of the test result. The result could be negative (no albumin in urine), low positive (trace of albumin) or high positive (albuminuria). Testers with a low positive result did not know exactly what to do; one consulted a doctor for further explanation of the result, while another respondent said a low positive result was nothing to worry about, especially since he was feeling healthy, and therefore did not take any further action.

Some cholesterol testers were disappointed that the test measured only total cholesterol, and said it left them without information about their 'bad' cholesterol. They thought the test had not been very useful.

\section{Confidence in the test result}

Many self-testers had considerable confidence in the test result. Reasons for this confidence in self-tests were that the test was offered by a well known organization (for example the Dutch Kidney Foundation), that they thought these tests were also used by professionals, or that they had had previous experience with the tests. Further reasons to trust the test result were that the test had worked properly, that the package indicated that the test was reliable, and some just assumed that such tests were developed to high standards. For example a female respondent indicated she had confidence in the self-test for the following reasons:

Well, I'm thinking it's from the Heart Foundation, you know. So I thought that's a reliable organisation, right? And I mean, well, I guess these self-tests have been carefully developed so they're really reliable. It feels safe to me.

(Female, age 42, cholesterol, normal test result)

Some respondents reported using strategies to ensure valid results, such as repeating the test or having it repeated by a GP; if the result remained same, they would consider the test to be reliable.

Some of the respondents, particularly those using cholesterol self-tests, realized that the test only gave an indication, and that it should be repeated because test results vary over time. Reasons to doubt the test result were that doctors have expressed 
doubts about self-tests, that self-tests are still under development or that the test result was not what they had expected (for example receiving an abnormal test result while not having complaints). Some respondents had doubts because the tests were commercially available, or thought that cheap tests that are very easy to perform might be of poor quality.

Of course I'm, well yes, I'm a bit sceptical about it, not 100\%, you know, as it's still, it's in its infancy, and you don't hear much about it, and you still think, well, I did the test, the result was normal, that's good. But is it really OK? But I don't dwell on that too long. I think, well, it's OK, or it would have found at least some minor abnormality. (Female, age 44 albuminuria, normal test result)

\section{Follow-up behaviour after performing a self-test}

Respondents were easily reassured by a normal test result. The test provided a sense of safety, and respondents felt they no longer had to worry about having a disease. Most of them did not discuss the test result with a doctor, although some did make an appointment with their family doctor, because they doubted whether they had performed the test correctly or were not sure about the validity of the test. Other reasons to see a doctor despite a normal test result were that they felt obliged to discuss medical concerns with their doctor and did not want to hide things from their doctor, or doubted the value of the test since it only measured one risk factor for cardiovascular disease. Most respondents did not change their lifestyle: they were already trying to live a healthy lifestyle, or found it difficult to change anything. Those respondents who did change their lifestyle improved their dietary habits. Some respondents indicated they would use the self-test again in the future, because they knew the outcome could change over time. One female respondent explained why she did not want to see a doctor after a normal test result:

When I'm reassured, and I see there's no need. Then it's OK. Then I'm not going to get it done again at the GP's. I really wouldn't do that, no, because then I might just as well go to my GP straightaway. No, I didn't do that, no. Of course if it had been too high or whatever, then I'd go to the doctor. But if I see that the value is what it's supposed to be, I really don't go see my GP. No, I'm reassured, and I think: Oh good. So I just go on. (Female, age 55, glucose, normal test result)

After an abnormal test result, respondents were not very alarmed. Some made an appointment with their general practitioner to discuss the test result and to have the test repeated, but were reassured by the knowledge that the condition was being diagnosed at an early stage and could be treated. Other reasons not to be alarmed 
were that respondents felt healthy, and thought their condition was probably not very serious. Several respondents who had an abnormal result decided nevertheless not to see a doctor. The reasons they gave were that all they could do was to start eating a healthier diet, that they doubted whether the test had worked properly, that the test result showed only mild abnormality, that test results were liable to change over time, that they felt healthy, or that they had not got the right information about how to interpret the result and what to do next and did not take any further action.

So well, it actually came out pretty bad, this test, and so I asked our GP, and he checked my urine and it, well, it was fine. I didn't really worry about it, because I thought well, I have no complaints, so it's probably not serious. But then, err, you never know. It's inside your body and you don't notice it. So yes, I guess it might be a good idea to consult the doctor.

(Female, age 41, albuminuria, abnormal test result)

Yes, it wasn't quite 100\% OK. But it was, sort of, what shall I say, a bit below average. But then I thought, well, those colours weren't 100\% clear, and so I didn't do anything about it. [...] Well if it had been really clear, a clear signal that, you know, something's wrong here, then I'd certainly have seen my general practitioner. Sure. But then it would have to be, err, have to be really clear. Not this sort of in-between case as it was in my case, as I saw it. [...] And well, I don't have any complaints in that department.

(Male, age 55, albuminuria, abnormal test result)

Some respondents said they would do further self-tests in the future, because they thought it is important to have regular check-ups or because the tests are offered for free. Others did not intend to do more self-tests if they were expensive; they preferred to see a doctor who could give them advice or they did not want to diagnose a serious condition themselves. Some had been discouraged from doing more tests by their family doctor.

Respondents would recommend self-tests to others, because they thought it was important to check for risk factors regularly, especially since these tests are easy to perform and easily accessible. Reasons not to engage in self-testing included fear of panic and worries, the fact that mistakes can easily be made, or that self-tests are considered not to be very reliable. One male participant would not recommend doing a self-test to all people: 
Well, I think it's easy to make a mistake. And if someone's like, at the very first sign, thinking Oh my God, I've got a terrible disease, well, I wouldn't recommend such a test to someone like that, no. In that case l'd say, sort of, never mind, ignorance is bliss.

(Male, age 55, albuminuria, abnormal test result)

\section{Need for information}

Most respondents were satisfied with the information provided with the test. They indicated that if the test result was normal, they felt no need for more information. Some of the cholesterol testers would have liked more information on the different types of cholesterol, about other cardiovascular risk factors, about the fact that test results can change over time and about using the pen needle.

Two respondents had bought their home test at a drug store. They were surprised that there was no point-of-sale information (for example the shop assistant did not give any additional information when the test was bought), which one of them would have preferred.

Respondents generally thought that information should be given on indications for doing a test and on how to perform it, as well as explanations about the disease, that the disease can be asymptomatic, and about what to do after performing the test. They would also like to get information on lifestyle factors. The aspect of test reliability was mentioned by three respondents, who thought it was important to have information on factors that could influence the reliability of the test. Others did not think this was very important, since they assumed the quality of the test to be good.

If respondents needed more information, they preferred to receive it via Internet sites operated by well-known and independent organisations. One female respondent indicated she did not feel she needed more information after doing a streetcorner test.

No, because I would have just thrown it away anyway, as I just know that I'm living a healthy lifestyle. So no, no. And I don't usually take away leaflets anyway, as you just end up throwing them all in the wastepaper basket. [...] No, I wouldn't have, well, except if it wasn't good. Then I'd have wanted it very much. I think that's when it's really important. If it's bad news. But it was actually good, so that's the end for me then, finished.

(Female, age 42, cholesterol test, normal test result) 


\section{Discussion}

\section{Main findings}

In-depth interviews with consumers who had performed a self-test on cardiovascular risk factors revealed three types of testers: those who engaged in self-testing when a test was offered, either with or without previous knowledge about the disease or risk factor, and those who had actively decided to test and had searched for a test themselves. Reasons for consumers to perform these self-tests included wanting to be reassured about their health, responding to commercials or media campaigns, having personal experience with a disease and having symptoms. Self-test behaviour often seemed to be rather straightforward: consumers came across self-tests and used them because they were looking for reassurance or were curious about the test. We found that respondents did not want to see a doctor without having a 'valid reason'; this was the main reason to do a self-test instead of seeing a doctor, because they did not have complaints and felt healthy.

Respondents had experienced no major problems in performing and interpreting the test. They generally had considerable confidence in the test result, and were generally reassured after a normal test result. Many respondents with a normal test result were already trying to live a healthy lifestyle, and would not change this, although some intended to improve dietary habits. The self-testers who had tested positive did not experience distress: they generally contacted their family doctor to discuss this result. Nevertheless, several did not contact a doctor despite an abnormal result.

Most respondents thought the information provided with the test was sufficient. If they needed more information, they would like to receive it preferably on the Internet, on sites operated by well-known and independent organizations.

\section{Strengths and limitations}

Participants were deliberately sampled to cover a broad range of characteristics such as age, gender and type of test performed. Hence, we were able to interview selftesters about different types of tests, test results and personal characteristics. The response to our invitation to participate in the interviews was $35 \%(28 / 80)$. The actual number of interviews analysed was 20 , since several participants appeared to be either diabetics using monitoring tests, or had performed tests that were not self-tests according to our definition (the test having been initiated by a doctor). Most participants said to feel healthy and to already pay attention to a healthy lifestyle, although these self-reports might be influenced for example by participants giving socially acceptable answers. Earlier research showed that self-testers in general are more likely to engage in health related behaviour, but report lower health status. ${ }^{3}$ 
During the interviews, most of our respondents indicated they worked or had had working experience in health care, which may have biased our data, because we therefore probably interviewed a more informed population than the average user of self-tests. Because of these participants' characteristics, we might have interviewed a population that is probably better informed and feeling healthier than the average self-test user.

\section{Comparison with other studies}

The reasons for self-testing seem to fit in with the Health Belief Model. Perceived susceptibility and perceived severity of the disease were mentioned as reasons for selftesting, especially among glucose self-testers. Cues to action included media campaigns, but also friends or relatives who had a cardiovascular disease. Respondents were often already conscious of the risk caused by factors like high cholesterol, which induced them to do a self-test.

Ryan et al. found similar reasons for self-testing: reassurance, out of curiosity or looking for a diagnostic outcome. ${ }^{18}$ They also reported that people frequently perform these tests simply because they are confronted with them. In their interview study, respondents indicated that they would not like to see a doctor without knowing something is wrong, and were afraid to waste the doctor's time.

In our study, respondents said they wanted to take responsibility for their own health, and be reassured about being in good health. This suggests that it is especially the worried well, that is, those consumers who already have a healthy lifestyle and actually have a lower risk of developing cardiovascular disease, who engage in self-testing. On the other hand, those truly at risk but unaware of their health status do not benefit from self-testing. It is known that unrealistic optimism among high-risk patients and unjustified pessimism in the low-risk population are frequently found in the assessment of cardiovascular risk. ${ }^{19}$

Little distress was experienced by participants who had tested positive. They realised that the test was intended to screen for a risk factor or disease, and that they were supposed to discuss a positive test result with their family doctor. They felt that the risk factor would be modifiable, and were not very alarmed. These findings are in line with earlier research on diabetes and microalbuminuria screening. ${ }^{20,21}$ A negative test result was generally perceived as reassuring, not necessitating further action. Negative test results can, however, lead to a false sense of reassurance, and the perception of a 'certificate of health', which may induce or prolong unhealthy behaviour. ${ }^{22}$ In our study, there were no respondents who indicated they felt no need to improve their lifestyle, as was also reported by Paddinson et $a .^{23}$ for diabetes screening. By contrast, Tijmstra found some evidence for this 'certificate of health' perception in screening for microalbuminuria. $^{21}$ 


\section{Conclusions and implications for further research}

In this study, we found that consumers have great confidence in self-tests. They generally do not doubt the test result, unless performing the test is difficult or the test result deviates from what they expect. When we discussed the validity of the test, our respondents generally did not mention the possibility that the test can give a falsepositive or false-negative result. Moreover, consumers do not seem to weigh the pros and cons before engaging in self-testing. This stresses the need for easy-to-understand consumer information on the pros and cons and validity of self-tests. We found that some self-testers did not visit a doctor even when receiving an abnormal test result: one of the reasons for this was not having appropriate information on what to do with the result. The results regarding the perceived need for information, combined with expert opinions on adequate consumer information, should be used to develop new, accessible information for consumers who are considering performing a self-test for cardiovascular risk factors. 


\section{References}

1. Ryan A, Wilson S, Greenfield S, Clifford S, McManus RJ, Pattison HM. Range of self-tests available to buy in the United Kingdom: an Internet survey. J Public Health (Oxf) 2006;28:370-4.

2. CVZ-rapport. Diagnostische zelftests op lichaamsmateriaal. Aanbod, validiteit en gebruik door de consument [Diagnostic self-tests on bodymaterial. Supply, validity, and use by the consumer]. 2007.

3. Ronda G, Portegijs P, Dinant GJ, Buntinx F, Norg R, Van der Weijden T. Use of diagnostic self-tests on body materials among Internet users in the Netherlands: prevalence and correlates of use. BMC Public Health 2009;9:100.

4. Pavlin NL, Gunn JM, Parker R, Fairley CK, Hocking J. Implementing chlamydia screening: what do women think? A systematic review of the literature. BMC Public Health 2006;6:221.

5. Skolnik HS, Phillips KA, Binson D, Dilley JW. Deciding where and how to be tested for HIV: what matters most? J Acquir Immune Defic Syndr 2001;27:292-300.

6. Campbell S, Klein R. Home testing to detect human immunodeficiency virus: boon or bane? J Clin Microbiol 2006;44:3473-6.

7. Borriello SP. Science, medicine, and the future. Near patient microbiological tests. BMJ 1999;319: 298-301.

8. van Dommelen L, van Tiel FH, Ouburg S, Brouwers EE, Terporten PH, Savelkoul PH, et al. Alarmingly poor performance in Chlamydia trachomatis point-of-care testing. Sex Transm Infect 2010;86:355-9.

9. Ryan A, Greenfield S, McManus R, Wilson S. Self-care--has DIY gone too far? Br J Gen Pract 2006;56: 907-8.

10. Nielen MM, Schellevis FG, Verheij RA. The usefulness of a free self-test for screening albuminuria in the general population: a cross-sectional survey. BMC Public Health 2009;9:381.

11. Deutekom M, Aziz Y, van Dis I, Stronks K, Bossuyt PM. [The Dutch National Cholesterol Test: participants mainly healthy]. Ned Tijdschr Geneeskd 2008;152:2425-9.

12. Janz NK CV, Strecher VJ. The Health Belief Model. In: Glanz K RB, Lewis FM, (ed.) Health behavior and health education: Theory, research, and practice 3 ed San Francisco: Jossey-Bass, 2002.

13. Bartolomew LK, Parcel GS, Kok G, Gottlieb NH. Behavior-oriented theories used in health promotion. In: Bartolomew LK PG, Kok G, Gottlieb NH, (ed.) Planning health promotion programs: An Intervention Mapping approach. 1 ed. San Francisco, CA: Jossey-Bass, 2006.

14. Rosenstock IM, Strecher VJ, Becker MH. The health belief model and HIV risk behavior change. In: DiClemente R, Peterson, JL, (ed.) Preventing AIDS: Theories and methods of behavioral interventions. New York, NY: Springer, 1994.

15. Janz NK, Becker MH. The Health Belief Model: a decade later. Health Educ Q 1984;11:1-47.

16. Grispen JE, Ickenroth MH, de Vries NK, Dinant GJ, Ronda G, van der Weijden T. Improving behaviour in self-testing (IBIS): Study on frequency of use, consequences, information needs and use, and quality of currently available consumer information (protocol). BMC Public Health 2010;10:453.

17. Green J, Thorogood N. Qualitative methods for health research. London: SAGE publications Ltd, 2004.

18. Ryan A, Ives J, Wilson S, Greenfield S. Why members of the public self-test: an interview study. Fam Pract 2010;27:570-81.

19. van der Weijden T, Bos LB, Koelewijn-van Loon MS. Primary care patients' recognition of their own risk for cardiovascular disease: implications for risk communication in practice. Curr Opin Cardiol 2008;23: 471-6.

20. Adriaanse MC, Snoek FJ. The psychological impact of screening for type 2 diabetes. Diabetes Metab Res Rev 2006;22:20-5.

21. Tijmstra T, Spijkers W, Broer J, Janssen WM, de Jong PE. [Psychosocial consequences of screening for microalbuminuria and for some other risk factors]. Ned Tijdschr Geneeskd 2000;144:2460-4.

22. Tymstra T, Bieleman B. The psychosocial impact of mass screening for cardiovascular risk factors. Fam Pract 1987;4:287-90.

23. Paddison CA, Eborall HC, Sutton S, French DP, Vasconcelos J, Prevost AT, et al. Are people with negative diabetes screening tests falsely reassured? Parallel group cohort study embedded in the ADDITION (Cambridge) randomised controlled trial. BMJ 2009;339:b4535.

24. Ickenroth MH, Ronda G, Grispen JE, Dinant GJ, de Vries NK, van der Weijden T. How do people respond to self-test results? A cross-sectional survey. BMC Family Practice 2010;11:77. 


\section{CHAPTER 5}

\section{Quality and use of consumer information provided with home test kits: room for improvement}

Janaica Grispen, Martine Ickenroth, Nanne de Vries, Trudy van der Weijden, Gaby Ronda

Health Expectations $2012 \mathrm{Jul} 19$ 


\section{Abstract}

\section{Background}

Diagnostic self-tests (tests on body materials that are initiated by consumers with the aim of diagnosing a disorder or risk factor) are becoming increasingly available. Although the pros and cons of self-testing are currently not clear, it is an existing phenomenon that is likely to gain further popularity.

\section{Objective}

To examine consumers' use of and needs for information about self-testing, and to assess the quality of consumer information provided with home test kits, as perceived by consumers and as assessed using a checklist of quality criteria.

\section{Methods}

A cross-sectional Internet survey among 305 self-testers assessed their use of and needs for information and their perception of the quality of consumer information provided with self-test kits. A meta-search engine was used to identify Dutch and English consumer information for home diagnostic tests available online at the time of the study. The quality of this consumer information was evaluated using a checklist of quality criteria.

\section{Results}

The consumers' information needs were in line with the most frequently used information and the information was perceived as being of moderate to good quality. The information was mostly in agreement with clinical practice guidelines, although information on reliability and follow-up behaviour was limited. Approximately half of the instruction leaflets did not include information on the target group of the test.

\section{Conclusions}

Although generally of moderate to good quality, some aspects of the information provided were in many cases insufficient. European legislation concerning self-tests and accompanying information needs to be adapted and adhered to more closely. 


\section{Introduction}

Diagnostic self-tests have become available for over 25 conditions, ranging from infectious diseases like HIV to cardiovascular risk factors such as detecting high cholesterol. ${ }^{1}$ Self-tests are defined as in vitro tests on body materials such as blood, urine, faeces, or saliva that are initiated by consumers to diagnose a particular disorder or risk factor. ${ }^{2}$

The use of self-tests is in line with current views on patient autonomy, as it implies that consumers can test themselves for health conditions without the need to consult a doctor first. ${ }^{1,3}$ When using a home self-test, consumers are the only ones responsible for performing the test and interpreting its result, and for their own follow-up behaviour. On the basis of these distinct responsibilities, we can distinguish four phases within the home self-testing process, namely (i) the decision process preceding the performance of a self-test, (ii) the actual performance of the self-test, (iii) the interpretation of the test result, and (iv) the consumer's follow-up behaviour based on the test result. ${ }^{4}$ In addition to true home tests, three additional types of self-tests are available, namely (i) street corner tests that are offered by organizations and are administered in public places such as supermarkets, (ii) direct-access laboratory tests for which consumers can visit a laboratory, and (iii) home collect tests for which body material is sent to a laboratory.

Although self-testing is a relatively new area and is still in a state of flux, it is a phenomenon that cannot be ignored. In 2008, 18.1\% of a sample of Dutch Internet users had ever used a self-test and $18.3 \%$ probably or definitely intended to use a selftest in the future, whereas the corresponding figures for 2006 were 16 and 17\%, respectively (Grispen JEJ, Ickenroth MHP, Ronda G, Hurenkamp L, De Vries NK, van der Weijden T, Submitted). ${ }^{2,5}$ However, the value of self-tests has been questioned; it is unclear whether self-tests are used in a way that is advantageous to the users and the consequences of self-testing are still unknown. ${ }^{6-9}$

An important prerequisite for proper self-test use is an instruction leaflet that provides good quality information on how to use the self-test. Research regarding patient information leaflets (PILs) indicates that good quality PILs improve a patient's retention of the information and increase the likelihood that the patient will use this information appropriately. ${ }^{10-12}$ Despite European legislations to improve the quality of PILs (e.g. http://europa.eu/rapid/pressReleasesAction.do?reference=IP/11/1171\&format=HTML \&aged=0\&language=EN\&guiLanguage=en), studies have shown that the overall quality of PILs is insufficient, for instance in that scientific medical terms are frequently used, clear instructions are lacking, and the use of long paragraphs make the texts hard to understand. ${ }^{10,12-14}$ Given these findings and the lack of knowledge about the quality of the information provided with home test kits, combined with the fact that self-tests 
are easily available and widely used, ${ }^{2-5}$ it is important to know if the instructions accompanying self-tests are of good quality and whether they fit in with the actual use of information by consumers and their needs concerning self-test information. The purpose of the present study was therefore to assess whether the instruction leaflets that are included in diagnostic self-test kits for home use satisfy the consumers' information needs regarding self-testing and whether this information complies with medical guidelines. This was assessed by means of two independent studies. In the first study we used an online Internet panel to identify (i) the way consumers use the information and their information needs concerning self-testing and (ii) the perceived quality of the consumer information provided with home test kits. In the second study we assessed the quality of consumer information accompanying home test kits by reviewing information leaflets using a checklist of quality criteria. As these were two independent studies, the information leaflets used in the first study could not be matched to those used in the second study.

\section{Study 1}

\section{Methods}

\section{Participants and procedure}

A cross-sectional survey was performed by Flycatcher, a Dutch ISO-certified institute for online research, which took care of the recruitment of participants and the distribution of the questionnaires. The Flycatcher panel currently consists of approximately 14,000 active members between 12 and 96 years old. Members of the panel are recruited online, by written invitation, face-to-face contacts or by intermediaries. Individuals aged 12 years or older who have an e-mail address can apply to join the Flycatcher Internet panel by registering at the Flycatcher website (www.flycatcher.eu). Compared with the Dutch population, the panellists are overall younger, have a higher level of education, and are more often female. The total panel is representative of the Dutch Internet population. Panel members receive invitations to participate in online questionnaires approximately eight times per year and receive an incentive when they have completed a certain number of questionnaires. Sociodemographic characteristics of the panellists for example, age, gender, and level of education, are provided by Flycatcher.

For the current study, a total of 6700 panellists were approached by e-mail to participate in this study. The e-mail provided a link to the questionnaire. After one week, a reminder was sent, including an expiration date after one additional week for participation. Panellists received a gift voucher after completion of the questionnaires. 
For the current study, we only selected panellists who indicated having used a home test as these are tests in which consumers are responsible themselves for performing the test and interpreting its result, and for their follow-up behaviour, and it is therefore very important that consumers understand and are able to use the tests by themselves.

\section{Ethical approval}

The Medical Ethical Committee of Maastricht University Medical Centre indicated that no ethical approval was needed for this study.

\section{Measurements}

This survey used two consecutive questionnaires. ${ }^{4}$ The first determined the prevalence of the use of self-tests and the intention to use self-tests, the types of self-tests used, and a number of lifestyle characteristics of the respondents (e.g. perceived health status).

After two months, a second questionnaire was sent to all respondents who had reported having used a self-test. Respondents received a questionnaire concerning the test they had used (e.g. cholesterol test), assessing their use of the information and their information needs as well as the perceived quality of the consumer information provided with the test kit package. Tables 5.2 and 5.3 provide an overview of the answering options for information use and information needs.

\section{Information use}

The way the information was used was assessed by nine items, for example, "Before you tested yourself (or had yourself tested), had you heard or read any information about this test?" If respondents indicated to not have heard or read information concerning the self-test, no additional questions concerning the information were asked.

\section{Information needs}

Information needs were assessed by two items, "In what way would you prefer to get information about self-tests?", and "What would be important for you to know before you do a test?"

\section{Perceived quality of the consumer information}

The respondents' perception of the quality of consumer information was established by assessing six different aspects associated with quality, asking "What was your general opinion about the information you heard or read?", with answering options $1=$ very poor - 5=very good; $1=$ very hard to understand - 5=very easy to understand; $1=$ very unclear - 5=very clear; 1=very unreliable - 5=very reliable; 1=very incomplete - 
$5=$ very complete; and 1=very difficult $-5=$ very easy. These quality aspects were assessed for all four self-test phases and were combined into four overall quality measures within each test phase; 'before testing' (Cronbach's $\alpha$ 0.92), 'information on the actual use of the test provided on the package' (Cronbach's $\alpha$ 0.96), 'information on the actual use of the test provided in the instruction leaflet' (Cronbach's $\alpha$ 0.97), 'information on the interpretation of the test result' (Cronbach's $\alpha$ 0.95). These overall quality scores for each test phase were combined into one overall quality score (Cronbach's $\alpha$ 0.93).

The complete questionnaires that were used in this study are available elsewhere. ${ }^{4}$

\section{Statistical analysis}

Analyses were performed using SPSS 17.0. Basic descriptive statistics were used to describe the respondents' socio-demographic and lifestyle characteristics, their information use and information needs, and the perceived quality of the consumer information.

\section{Results}

\section{Socio-demographic characteristics}

The first questionnaire was sent to a total of 6700 panellists, and had a response rate of $66 \%$. The second questionnaire was sent to all respondents who had indicated in the first questionnaire to have performed a self-test $(n=703$, response rate $79 \%)$. Participants who indicated having used an ovulation test or a test in the 'other' category were excluded since ovulation tests are often performed by healthy individuals and information on the tests used in the 'other' category was lacking. For the current study, we only selected individuals who had used a home test resulting in a total of 305 respondents who were selected for further analyses (Figure 5.1). Of the 305 respondents who had ever used a home-test, 112 indicated to have a chronic condition or a disability, varying from psychological problems (e.g. ADHD, bipolar disorders), chronic pain (e.g. migraine, chronic back pain), pulmonary disorders (e.g. COPD), and diabetes to high blood pressure. Respondents were between 18 and 77 years of age, with a mean age of 41.8 years $(S D=13.02)$. Table 5.1 describes the sociodemographic characteristics of the self-testers.

\section{Information use}

A large majority of the respondents indicated having read the consumer information accompanying the test before testing (i.e. before deciding to buy or use the self-test), as well as when performing the test, and while interpreting the test result. Most 
respondents indicated that this information had helped them to better use the selftest. The most frequently read information concerned the use of the test, the target population of the test, what disease or risk factor the test identifies, the meaning of the test result, and the reliability of the test result. See Table 5.2.

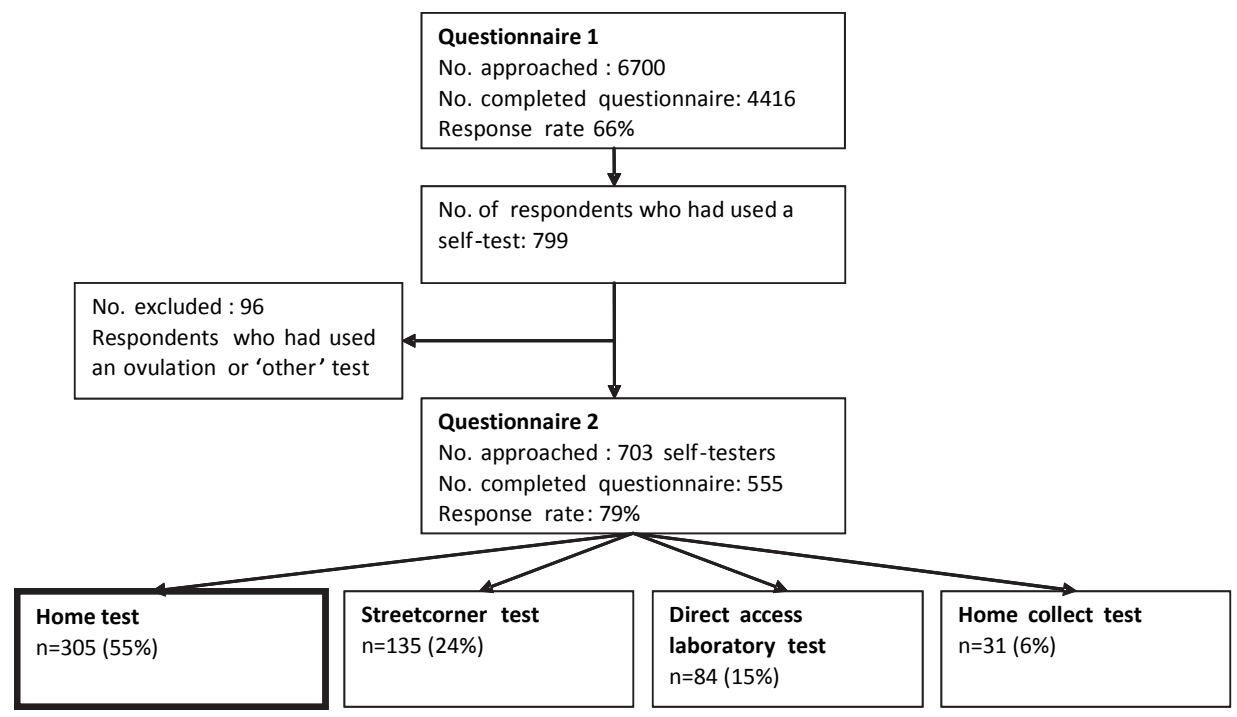

Figure 5.1 Flowchart for the questionnaires.

\section{Information needs}

Respondents indicated that they preferred the Internet, a pharmacy, their family doctor or specialist, or brochures at their family doctor's office as sources of information about self-testing.

The information topics considered to be the most important to know before doing the test were instructions for carrying out the test, the reliability of the test result, the disease or risk factor identified by the test, and the meaning of the test result. Table 5.3 provides an overview of all information needs. 
Table 5.1 Characteristics of self-testers.

\begin{tabular}{lcc}
\hline $\begin{array}{l}\text { Characteristics } \\
\mathrm{n}=305\end{array}$ & $\begin{array}{c}\text { Respondents } \\
\mathrm{n}(\%)\end{array}$ & $\begin{array}{c}\text { Dutch population } \\
\text { b }\end{array}$ \\
\hline Age (mean and SD in years) & $\mathrm{M}=41.80$ & $\mathrm{M}=40,3$ \\
& $(\mathrm{SD}=13.02)$ & \\
Gender & & $49,5 \%$ \\
- male & $87(28.5 \%)$ & $50,5 \%$ \\
- female & $218(71.5 \%)$ & $31 \%$ \\
Level of education $^{\mathrm{a}}$ & & $41 \%$ \\
- low & $58(19.0 \%)$ & $28 \%$ \\
- intermediate & $133(43.6 \%)$ & \\
- high & $114(37.4 \%)$ & \\
Test & & \\
Kidney disease & $121(39.7 \%)$ & \\
Diabetes & $70(23.0 \%)$ & \\
Urinary tract infection & $36(11.8 \%)$ & \\
Cholesterol & $26(8.5 \%)$ & \\
Female fertility & $13(4.3 \%)$ & \\
Allergies & $8(2.6 \%)$ & \\
Chlamydia & $7(2.3 \%)$ & \\
Glandular fever & $6(2.0 \%)$ & \\
Aids / HIV & $5(1.6 \%)$ & \\
Other & $13(4.4 \%)$ & \\
\hline
\end{tabular}

${ }^{\mathrm{a}}$ Low = primary and secondary school, intermediate = intermediate vocational education, high = higher vocational education and university; ${ }^{\mathrm{b}}$ Numbers provided by Statistics Netherlands (www.cbs.nl).

\section{Reported quality of consumer information}

The mean quality of the instruction leaflets on information before testing was 3.98 $(S D=0.63)$, on information on the actual use of the test provided at the package was $3.91(S D=0.69)$, on information on the actual use of the test provided in the instruction leaflet was $4.02(S D=0.68)$ and on information on the interpretation of the test result was $3.93(S D=0.72)$. The overall mean quality score of the information was 3.94 $(S D=0.61)$. 
Table 5.2 Information use.

\begin{tabular}{|c|c|}
\hline $\begin{array}{l}\text { Test phase } \\
\text { Item } \\
\text { Answering options / } \mathrm{n}=305\end{array}$ & $\mathrm{n}(\%)$ \\
\hline \multicolumn{2}{|l|}{ Before testing (before deciding to do the self-test) } \\
\hline \multicolumn{2}{|c|}{ Before you tested yourself (or had yourself tested), had you heard or read any information about this test? } \\
\hline Yes & $254(83.3 \%)$ \\
\hline No & $51(16.7 \%)$ \\
\hline \multicolumn{2}{|l|}{ What was the information about? (multiple answers allowed) } \\
\hline How the test should be carried out & $167(54.8 \%)$ \\
\hline For whom the test is intended & $133(43.6 \%)$ \\
\hline What disease or risk factor the test identifies & $129(42.3 \%)$ \\
\hline The meaning of the test result & $121(39.7 \%)$ \\
\hline The reliability of the test result & $97(31.8 \%)$ \\
\hline Where the test is done or sold & $50(16.4 \%)$ \\
\hline The costs of the test, and if they are reimbursed by my insurance & $34(11.1 \%)$ \\
\hline Whether I can have the test done at my family doctor's & $11(3.6 \%)$ \\
\hline Other, namely........ & $9(3.0 \%)$ \\
\hline \multicolumn{2}{|l|}{ Actual performance of the test } \\
\hline \multicolumn{2}{|l|}{ Did you read the information on the packaging before you bought the test? } \\
\hline Yes & $241(79.0 \%)$ \\
\hline No & $34(11.1 \%)$ \\
\hline Not applicable, there was no information on the packaging & $30(9.8 \%)$ \\
\hline \multicolumn{2}{|l|}{ Do you think the information on the packaging helped you to better perform the test? } \\
\hline Yes & $240(78.7 \%)$ \\
\hline No & $23(7.5 \%)$ \\
\hline Missing & $42(13.8 \%)$ \\
\hline \multicolumn{2}{|c|}{ Did you read the information in the instruction leaflet about the way to perform this self-test? } \\
\hline Yes & $272(89.2 \%)$ \\
\hline No & $14(4.6 \%)$ \\
\hline Not applicable, the instruction leaflet was not included & $19(6.2 \%)$ \\
\hline \multicolumn{2}{|c|}{ In your opinion, did the information in the instruction leaflet help you to better perform the test? } \\
\hline Yes & $248(81.3 \%)$ \\
\hline No & $24(7.9 \%)$ \\
\hline Missing & $33(10.8 \%)$ \\
\hline \multicolumn{2}{|l|}{ Interpretation of the test result } \\
\hline \multicolumn{2}{|c|}{ Did you read the information about the meaning of your test result in the instruction leaflet? } \\
\hline Yes & $269(88.2 \%)$ \\
\hline No & $17(5.6 \%)$ \\
\hline $\begin{array}{l}\text { Not applicable, this information was not included in the instruction leaflet or } \\
\text { the instruction leaflet was missing }\end{array}$ & $19(6.2 \%)$ \\
\hline \multicolumn{2}{|l|}{ Do you think this information helped you to better interpret your test result? } \\
\hline Yes & 241 (79.0\%) \\
\hline No & $28(9.2 \%)$ \\
\hline Missing & $36(11.8 \%)$ \\
\hline
\end{tabular}


Table $5.3 \quad$ Information needs.

\begin{tabular}{lc}
\hline Item & $\mathrm{n}(\%)$ \\
Answering options / $\mathrm{n}=305$ & \\
\hline In what way would you prefer to get information about self-tests? (multiple answers allowed) \\
From the Internet & $151(49.5 \%)$ \\
At the pharmacy & $137(44.9 \%)$ \\
From my family doctor, from a specialist & $122(40.0 \%)$ \\
At my family doctor's office (e.g. from a brochure) & $116(38.0 \%)$ \\
E-mail & $82(26.9 \%)$ \\
At the chemist's & $58(19.0 \%)$ \\
From TV or radio & $58(19.0 \%)$ \\
From newspapers, magazines or books & $58(19.0 \%)$ \\
From relatives, friends or colleagues & $40(13.1 \%)$ \\
At the supermarket & $13(4.3 \%)$ \\
Text message & $2(0.7 \%)$ \\
Other, namely...... & $3(1.0 \%)$ \\
What would be important for you to know before you do a test? (multiple answers allowed) \\
How the test should be carried out & $242(79.3 \%)$ \\
The reliability of the test result & $225(73.8 \%)$ \\
What disease or risk factor the test identifies & $205(67.2 \%)$ \\
The meaning of the test result & $201(65.9 \%)$ \\
For whom the test is intended & $169(55.4 \%)$ \\
The costs of the test, and if they are reimbursed by my insurance & $142(46.6 \%)$ \\
Where the test is done or sold & $88(28.9 \%)$ \\
Whether I can have the test done at my family doctor's & $49(16.1 \%)$ \\
Other, namely....... & $2(0.7 \%)$ \\
\hline
\end{tabular}

\section{Study 2}

\section{Methods}

\section{Identification of instruction leaflets}

An Internet search was used to identify instruction leaflets for home diagnostic tests that are available online, since most home self-tests available in the Netherlands can only be purchased online instead of being available at drugstores or pharmacies. To identify these leaflets, we used the meta-search engine Google since most consumers indicated in previous research to start an Internet search by using Google (Grispen JEJ, Ickenroth MH, Hurenkamp L, Ronda G, De Vries NK, Van der Weijden T, Submitted). In an iterative search process, we searched for (i) each of the following key words in English and in Dutch: self-testing [zelftesten], self-test [zelftest], self-test [zelf test], home test [thuis-test], point-of-care test; and (ii) each test by name, and (iii) by manufacturer. Instruction leaflets were excluded if they were not available in Dutch or English, if they concerned test methods other than in vitro home diagnostic tests or if they were not available online. The selected set of self-tests consisted of all instruction 
leaflets included in home test kits that were available online at the time of the study and included instruction leaflets for tests on Candida, Chlamydia, syphilis, urinary tract infections, cholesterol and diabetes. If different producers marketed the same test or if different tests were marketed for the same purpose, all available types were included. Of the websites found by Google, the first 70 hits for each key word were consulted. Our method was based on the methods used by others in which the first twenty hits were assessed. ${ }^{15}$ As we found new additional information after viewing the first twenty hits, we decided to assess additional hits until data saturation was met. After reviewing the first fifty hits, we saw that the following hits were not directly related to our search criteria, and after seventy hits data-saturation was met as no relevant sites were found additionally. If one of the initial web pages contained a relevant link to another web page, that page was also examined. The available consumer information was then downloaded from the Internet. The search was performed in July 2009 and updated in July 2010.

\section{Assessment of information quality}

Specific guidelines for assessing the quality of consumer information accompanying self-tests were not available at the start of our study. However, the European In-Vitro Diagnostic guidelines describe the essential requirements which in vitro diagnostics have to meet. ${ }^{16,17}$ Furthermore, the International Patient Decision Aids Standard (IPDAS), ${ }^{18,19}$ Discern, ${ }^{20,21}$ a checklist to assess manufacturers' documentation on medical diagnostic self-tests, ${ }^{22}$ and a checklist to assess the quality of websites marketing medical home diagnostic tests were available. ${ }^{15}$ These information sources were combined with information derived from previous research to generate a checklist for assessing instruction leaflets on self-testing.(Grispen JEJ, Ickenroth MHP, Ronda G, Hurenkamp L, De Vries NK, Van der Weijden T, Submitted). ${ }^{25,23,24}$ Consensus was achieved among the research team on the items that were included in the checklist. Our research team consisted of experts in the field of health promotion, medicine, cognitive psychology, epidemiology, and clinical practice guidelines. The complete checklist is presented in Table 5.4. 
Table 5.4 Checklist to assess the quality of consumer information leaflets accompanying diagnostic selftests.

\begin{tabular}{|c|c|c|c|c|}
\hline \multicolumn{2}{|c|}{ Quality criteria } & $\begin{array}{c}\text { Yes } \\
\mathrm{n}(\%)\end{array}$ & $\begin{array}{c}\text { No } \\
n(\%)\end{array}$ & $\begin{array}{l}\% \text { of initial } \\
\text { agreement }\end{array}$ \\
\hline \multicolumn{5}{|c|}{ Section A. Product description } \\
\hline 1 & Visuals & & & \\
\hline 1.1 & Pictures & $21(100 \%)$ & - & $100 \%$ \\
\hline 1.2 & Diagrams / tables & $8(38 \%)$ & $13(62 \%)$ & $100 \%$ \\
\hline 1.3 & Instruction video & $3(14 \%)$ & $18(86 \%)$ & $100 \%$ \\
\hline 2 & FAQ-section present & $12(57 \%)$ & $9(43 \%)$ & $100 \%$ \\
\hline 3 & When was the information last updated? & $17(81 \%)$ & $4(19 \%)$ & $100 \%$ \\
\hline 4 & Are research references presented? & $1(5 \%)$ & $20(95 \%)$ & $100 \%$ \\
\hline 5 & Does the producer guarantee the product's quality? & $7(33 \%)$ & $14(67 \%)$ & $100 \%$ \\
\hline \multicolumn{5}{|c|}{ Section B. Content } \\
\hline 1 & Lists the contents of the test package & $17(81 \%)$ & $4(19 \%)$ & $100 \%$ \\
\hline 2 & Specifies use-by date & $18(86 \%)$ & $3(14 \%)$ & $100 \%$ \\
\hline 3 & Indicates whether test was correctly performed & $14(67 \%)$ & $7(23 \%)$ & $100 \%$ \\
\hline 4 & Describes the relevant health problem & $19(90 \%)$ & $2(10 \%)$ & $81.0 \%$ \\
\hline 5 & Describes what the test determines & $20(95 \%)$ & $1(5 \%)$ & $90.5 \%$ \\
\hline 6 & Indentifies the target group of the test & $11(52 \%)$ & $10(48 \%)$ & $85.7 \%$ \\
\hline 7 & Indicates other test options / alternative tests & - & $21(100 \%)$ & $81 \%$ \\
\hline \multicolumn{5}{|c|}{ Describes how the test is to be carried out } \\
\hline 8.1 & $\begin{array}{l}\text { Provides instructions for using the test (including } \\
\text { interpretation of the test result) }\end{array}$ & $21(100 \%)$ & - & $100 \%$ \\
\hline 8.2 & Indicates when the test is to be used & $18(86 \%)$ & $3(14 \%)$ & $90.5 \%$ \\
\hline \multicolumn{5}{|c|}{ Describes the likelihood of: } \\
\hline 9.1 & Correct test results & $11(52 \%)$ & $10(48 \%)$ & $85.7 \%$ \\
\hline 9.2 & False-positive or false-negative test results & $18(86 \%)$ & $3(14 \%)$ & $85.7 \%$ \\
\hline \multicolumn{5}{|c|}{ Describes possible further actions in case of: } \\
\hline 10.1 & A positive test result & $20(95 \%)$ & $1(5 \%)$ & $95.2 \%$ \\
\hline 10.2 & A negative test result & $14(67 \%)$ & $7(33 \%)$ & $66.7 \%$ \\
\hline 10.3 & An unclear test result or test failure & $12(57 \%)$ & $9(43 \%)$ & $90.5 \%$ \\
\hline \multicolumn{5}{|c|}{ Other } \\
\hline 11 & Indicates where users can ask questions & $17(81 \%)$ & $4(19 \%)$ & $95.2 \%$ \\
\hline 12 & Provides information on storage conditions & $19(90 \%)$ & $2(10 \%)$ & $95.2 \%$ \\
\hline \multicolumn{5}{|c|}{ Section C. Information source } \\
\hline 1 & $\begin{array}{l}\text { Describes what organisation is responsible for the } \\
\text { development and distribution of the test }\end{array}$ & $20(95 \%)$ & $1(5 \%)$ & $90.5 \%$ \\
\hline 2 & Presents disclaimer in the consumer information & $19(90 \%)$ & $2(10 \%)$ & $57.1 \%$ \\
\hline
\end{tabular}

\section{Data extraction and analysis}

The checklist for assessing the quality of instruction leaflets on self-testing consisted of 25 items, each reflecting a specific quality criterion which was considered an essential feature of good quality consumer information. The items were subdivided into three groups: (A) product description - seven items regarding the features of the product under evaluation; (B) content - 16 items regarding the content of the instruction leaflet on the practical use of the self-test; and (C) information source - two items about the origin of the instruction leaflet. Items were assessed using a dichotomous 
scale with answering options $0=$ the information is not included and $1=$ the information is included. All instruction leaflets were reviewed by two researchers (JG and $\mathrm{MI}$ ), and any disagreements were resolved in consensus meetings. See Table 5.4.

\section{Results}

A total of 21 instruction leaflets were analysed, 11 of which were in Dutch and 10 in English. We selected instruction leaflets included in test kits that tested for one of seven different diseases or conditions, namely Chlamydia $(n=2)$, urinary tract infections $(n=2)$, syphilis $(n=2)$, diabetes $(n=3)$, Candida $(n=3)$, total cholesterol $(n=5)$, and cholesterol ratio $(n=4)$. The number of quality criteria that were met ranged from 6 to 23 for a total of 25 proposed quality items, with a mean score of 17.1 (SD=3.8).

\section{Compliance with quality criteria}

\section{Section A}

All instruction leaflets provided pictures as well as text to clarify the self-testing procedure. Approximately $80 \%$ of the instruction leaflets provided a date at which the information had last been updated. Only one instruction leaflet provided scientific references for the claims about the reliability of the test (Table 5.4).

\section{Section B}

All leaflets provided information on how the test should be used, including the interpretation of the test result. Information on alternative test options was lacking from all leaflets. Almost all leaflets listed the content of the test kit (81\%), and provided information on the expiration date of the test (86\%), the health condition the test was designed to detect (90\%), what the test measured (95\%), when to use the test $(86 \%)$, how to contact the service department of the test manufacturer $(81 \%)$, and how to store the test (90\%). The vast majority of the leaflets (95\%) provided information on what to do in case of a positive result. However, one third of the leaflets did not provide information on the actions that should be taken when a negative or inconclusive test result was obtained (33\% and $43 \%$ ).

Approximately half of the leaflets described the likelihood of obtaining correct positive or correct negative results, whereas $86 \%$ described the likelihood of getting a falsepositive or a false-negative result. Information on the target group was only provided in $52 \%$ of the leaflets and was more often reported in English leaflets than in Dutch leaflets (70\% and $36 \%$ ). Only $46 \%$ of Dutch leaflets included an FAQ-section as compared to $70 \%$ of the English leaflets. Half of the English tests provided an indication if the test had been performed correctly, whereas $82 \%$ of the Dutch tests provided this indication (Table 5.4). 


\section{Section C}

Almost all instruction leaflets provided at least the name of the manufacturer of the self-test (95\%) and included a disclaimer excluding responsibility for any consequences related to the use of the self-test ( $90 \%$; Table 5.4 ).

\section{Discussion}

To the best of our knowledge, no research to date has examined the use of and needs for information among self-testers or the consumers' perceived quality of information accompanying home test kits, while independently assessing the quality of consumer information using a checklist of quality criteria. This study was a first attempt to gain more insight into these factors and to provide directions for future research. The information needs that were reported by consumers who had used a self-test were in line with the topics that were most frequently read in the instruction leaflets, namely instructions for performing the test, the reliability of the test result, the disease or risk factor identified by the test, and the meaning of the test result. According to the respondents, the information in the instruction leaflets was of moderate to good quality and they reported that the information had been helpful in using the self-test correctly.

Our quality assessment of consumer information by means of the checklist showed that the instructions for carrying out the test, the disease or risk factor assessed by the test, and the meaning of the test result were provided in most information leaflets. Although some information on the reliability of the test result was presented, it was very limited. Whereas $86 \%$ of the leaflets indicated the likelihood of obtaining incorrect test results, only $52 \%$ of the leaflets mentioned the likelihood of correct results. It must be noted that we merely assessed whether a particular aspect mentioned in the criterion was present in the leaflet, but did not evaluate its completeness or quality. Most information on false-positive or false-negative results was very limited and only consisted of a brief statement such as 'false-positive or falsenegative results may occur'.

These results are unfortunately not surprising. The essential requirements described in the European In-Vitro Diagnostic guidelines relate to the analytical, diagnostic, and clinical validity of self-tests. ${ }^{16,17}$ Manufacturers of low-risk self-tests are allowed to determine for themselves whether their product meets these essential requirements of the IVD guidelines and are allowed to provide their product with a CE (Conformitée Européenne) mark as a stamp of quality. This leads to claims of extraordinary test performances that are based on comparisons between the self-test and an unknown reference test. The CE mark does not provide information on the diagnostic value of the test and conceals the likelihood of false-positive and false-negative test results. ${ }^{16,25}$ 
Information on the interpretation of the test result was provided in all information leaflets. However, no indication of the likelihood of false-positive and false-negative test results was offered, consumers are unable to correctly interpret their test result. Where information on the reliability of the test result was provided, it was phrased as 'laboratory tests have indicated that this test is reliable in $99 \%$ of the cases'. These socalled reliability claims provide very limited information on the diagnostic value of the test. $^{16}$

The results of our quality assessment by means of a checklist demonstrated that information on alternative test options was lacking from all leaflets and information on the target group of the self-test was given in only $52 \%$ of the leaflets. This information is one of the things that are essential for consumers to make an informed decision about using a self-test.

\section{Study limitations and strengths}

The Flycatcher Internet panel enabled us to reach a large sample of Dutch Internet users. This panel of Internet users differs in some respects from the general Dutch population in that panellists are slightly younger, more often female and more highly educated. ${ }^{2}$ However, since self-tests are often bought via the Internet, we consider the use of this Internet panel as an acceptable option.

The current study was conducted to gain more insight into the use of and needs for information among self-testers as well as into the quality of the consumer information accompanying home test kits. We assessed these factors by means of two independent studies and we were therefore not able to match the information leaflets that were used by the consumers to the information leaflets that were assessed by using the checklist. However, there are two main manufacturers of self-tests in the Netherlands and we might assume that most home self-tests that were used, were produced by those manufacturers. The leaflets of the home tests under investigation were mainly from those two producers. Therefore, we might assume that there is a significant overlap between the leaflets under investigation and the home tests used by our participants.

The process of developing our checklist to assess the quality of the consumer information accompanying self-tests could have been optimized by using a large-scale Delphi study but financial and logistic limitations meant we had to restrict ourselves to a small Delphi study among the experts of our research team. Additionally, the quality criteria and the coding method we used directly influenced the validity of our findings. We coded whether the aspect mentioned in the quality criterion was present in the leaflet but did not evaluate it for completeness or sufficiency. We decided not to prioritize quality aspects, in view of the lack of an empirical basis for prioritization. In the absence of specific quality guidelines for information leaflets included in home test 
kits, we based our checklist on results of previous research (Grispen JEJ, Ickenroth MHP, Ronda G, Hurenkamp L, De Vries NK, Van der Weijden T, Submitted), ${ }^{2,5,23,24}$ the IPDAS criteria for decision aids, ${ }^{18,19}$ the Discern criteria for judging the quality of written consumer information on treatment choices, ${ }^{20,21}$ and the Dutch regulations for content of IVD patient information. ${ }^{16,17}$ We consider our checklist to have sufficient face validity, to be evidence-based, and to be well-founded in theory, and therefore conclude that our observations on the quality of information leaflets included in home test kits appear valid.

\section{Practical implications and future research}

Although the advantages and disadvantages of self-testing are currently not clear, selftesting is an existing phenomenon that is likely to become more popular in the future. It is therefore essential that appropriate consumer information is developed, to provide a solid basis for informed choices about self-testing. The current study was a first attempt to assess the actual quality of the information leaflets included in self-test kits by means of a checklist of quality criteria. However, since we chose to code only whether the aspect mentioned in a criterion was indeed present in the information leaflets or not, our quality assessment was limited. Our checklist should be extended with specific quality criteria scored on, for instance, a 5-point Likert scale, accompanied by a detailed description, to obtain a more complete picture of the quality of information leaflets.

In the present study, information needs were identified after the consumers had used a self-test. This may have resulted in a biased view of the information needs, since these could have been influenced by the actual use of the consumer information when performing the self-test. Future research should be aimed at determining the consumers' information needs before they use a self-test and to indentify the consumers' actual use of the information after they have performed a self-test, to determine if consumers' information needs and their use of information correspond.

Additionally, besides identifying consumers' information needs and use it is important to simultaneously assess the level of health literacy of the average self-test user. The effectiveness of an information leaflet does not only depend on the quality of the information but also on the level of skills people have to understand and use the information that is provided. Therefore we have to determine if the information leaflet corresponds to the level of health literacy of its users. ${ }^{26}$

Furthermore, to gain more insight into the implications of self-test use in the medical practice, it is important to investigate the opinion of GPs towards self-testing and to indentify how often they are confronted with patients who made an appointment based on their self-test result and, in line with this, to identify how GPs respond to these patients. Therefore, future research should be aimed at identifying the GPs' 
opinions on self-testing and their experiences with patients who used a self-test by means of semi-structured interviews.

In view of the biased and optimistic presentation of data on reliability, validity and diagnostic value to potential consumers, European legislation concerning quality criteria for self-tests and the accompanying consumer information needs to be extended and enforced more strictly. Self-test producers need to be monitored by an independent external committee to check if the claims made by the self-test kits are truthful and are not manipulated to disguise unfavourable properties. Only if the legislation on self-tests and the accompanying information leaflets is adapted and producers are forced to comply with these legislations, will consumers be able to make an informed decision on the use of a self-test.

\section{Conclusions}

Overall, instruction leaflets were of reasonable quality and met most medical guidelines. However, we only scored whether certain required information aspects were present, but not whether this information was sufficient or complete. A closer inspection of some criteria showed that information on certain aspects, such as reliability was insufficient. European legislation on self-tests needs to be adapted and enforced more strictly in order to provide consumers with a complete overview of the properties of self-tests. A complete overview of all available information about selftests may enable consumers to make informed decisions about using or not using a particular test. 


\section{References}

1. Ryan A, Wilson S, Greenfield S, Clifford S, McManus RJ, Pattison HM. Range of self-tests available to buy in the United Kingdom: an Internet survey. J Public Health 2006;28:370.

2. Ronda G, Portegijs P, Dinant GJ, Buntinx F, Norg R, Van der Weijden T. Use of diagnostic self-tests on body materials among Internet users in the Netherlands: prevalence and correlates of use. BMC Public Health 2009;9:100.

3. Ryan A, Greenfield S, Wilson S. Prevalence and determinants of the use of self-tests by members of the public: a mixed methods study. BMC Public Health 2006;6:193.

4. Grispen JEJ, Ickenroth MHP, De Vries NK, Dinant GJ, Ronda G, Van der Weijden T. Improving behaviour in self-testing (IBIS): Study on frequency of use, consequences, information needs and use, and quality of currently available consumer information (protocol) BMC Public Health 2010;10.

5. Ickenroth MHP, Ronda G, Grispen JEJ, Dinant G, De Vries N, Van der Weijden T. How do people respond to self-test results? A cross-sectional survey BMC Family Practice 2010;11.

6. Borriello SP. Science, medicine, and the future. Near patient microbiological tests. BMJ 1999;319:298301.

7. Campbell S, Klein R. Home Testing To Detect Human Immunodeficiency Virus: Boon or Bane? J Clin Microbiol 2006;44:3473-6.

8. Frith L. HIV self-testing: a time to revise current policy. Lancet 2007;369:243-5.

10. Franck M, Foulon V, Van Vaerenbergh L. ABOP, the automatic patient information leaflet optimizer: evaluation of a tool in development. Patient Education and Counseling 2011;83:411-6.

11. Humphris G, Duncalf M, Holt D, Field E. The experimental evaluation of an oral cancer information leaflet. Oral Oncology 1999;35:575-82.

12. Pander Maat $\mathrm{H}$, Lentz L. Improving the usability of patient information leaflets. Patient Education and Counseling 2010;80:113-9.

13. Beaver K, Luker K. Readability of patient information booklets for women with breast cancer. Patient Education and Counseling 1997;31:95-102.

14. Dickinson D, Raynor D, Duman M. Patient information leaflets for medicines: using consumer testing to determine the most effective design. Patient Education and Counseling 2001;43:147-59.

15. Datta AK, Selman TJ, Kwok T, Tang T, Khan KS. Quality of information accompanying on-line marketing of home diagnostic tests. Journal of the Royal Society of Medicine 2008;101:34-8.

16. Health Council of the Netherlands. Annual report on screening for disease 2007 - The self-testing of body samples. The Hague: Health Council of the Netherlands; 2007.

17. Wielders JPM, Loeber JG, Bartels PCM. Praktische consequenties van IVD-Richtlijn voor laboratoria, kansen en beperkingen [Practical consequences of IVD guidelines for laboratories, opportunities and limitations]. Nederlands Tijdschrift voor Klinische Chemie en Labgeneeskunde 2004;29:209-13.

18. Elwyn G, O'Connor A, Stacey D, Volk R, Edwards A, Coulter A, et al. Developing a quality criteria framework for patient decision aids: online international Delphi consensus process. BMJ 2006;333: 417-23.

19. Elwyn G, O'Connor AM, Bennett C, Newcombe RG, Politi M, Durand MA, et al. Assessing the quality of decision support technologies using the International Patient Decision Aid Standards instrument (IPDASi). PlosOne. 2009;4:e4705.

20. Charnock D, Shepperd S, Needham G, Gann R. DISCERN: an instrument for judging the quality of written consumer health information on treatment choices. Journal of Epidemiology and Community Health. 1999;53:105-11.

21. Charnock D, Shepperd S, Rose P, Lucassen A. Discern Genetics Quality Criteria. 2006.

22. Van Drongelen AW, De Vries CGJCA, Pot JWGA. Assessment of files of in vitro diagnostic devices for self-testing. Bilthoven, the Netherlands: National Institute for Public Health and the Environment (RIVM); 2008.

23. Grispen JEJ, Ronda G, Dinant GJ, de Vries NK, van der Weijden T. To test or not to test: A crosssectional survey of the psychosocial determinants of self-testing for cholesterol, glucose, and HIV. BMC Public Health. 2011;11:112.

24. Ickenroth MH, Grispen JE, Ronda G, Tacken M, Dinant GJ, de Vries NK, et al. Motivation and experiences of self-testers regarding tests for cardiovascular risk factors. Health Expectations. 2011. 
25. Michel CE, Saison FG, Joshi H, Mahilum-Tapay LM, Lee HH. Pitfalls of internet-accessible diagnostic tests: inadequate performance of a CE-marked Chlamydia test for home use. Sexual Transmitted Infections. 2009;85:187.

26. Car J, Lang B, Colledge A, Ung C, Majeed A. Interventions for enhancing consumers' online health literacy Cochrane Database of Systematic Reviews. 2011. 


\section{CHAPTER 6}

Educating consumers in self-testing: lessons learned from the development of an online decision aid on glucose and cholesterol self-testing

Martine Ickenroth, Janaica Grispen, Gaby Ronda, Geert-Jan Dinant, Nanne de Vries, Trudy van der Weijden

Submitted for publication 


\section{Abstract}

\section{Background}

Consumers are able to test themselves for conditions such as diabetes and high cholesterol. Since these tests on body materials can be performed without professional counselling, independent information should be directly provided to potential consumers on the pros, cons and possible pitfalls of self-testing. The aim of this study was to develop a decision aid (DA) that stimulates informed choice and meets consumers' needs and expectations.

\section{Methods}

A DA was developed based on previous research and medical practice guidelines. The first prototype was assessed on its contents and usability by semi-structured interviews with experts $(n=13)$, followed by usability tests with end-users $(n=10)$ leading to improvements of the DA in an iterative process.

\section{Results}

Comments of the experts were grouped into four themes: general comments, textual remarks, technical errors and lay-out. End-user comments were mainly consistent with the experts' opinion. Important considerations that were identified were whether providing this information without direct professional counselling is safe, whether a ranking of available tests should be provided, and how strong a warning on self-testing should be given.

\section{Conclusions}

Important considerations on how to inform consumers on self-testing were discussed, and led to important changes in the decision aid. Future research will have to assess the actual use of the DA when accessible for the general public, and its effects on knowledge and attitude towards self-testing. 


\section{Introduction}

Diagnostic self-tests, i.e. tests on body materials to diagnose a disease or a risk factor, that are available to consumers without the involvement of health professionals, are frequently used. Internet surveys showed that self-tests are available for 24 conditions including cancer, chronic conditions and infections. ${ }^{1,2}$ In 2008, 18 percent of the respondents in an online survey in the Netherlands had ever performed a diagnostic self-test on body materials, for example to detect diabetes, high cholesterol, allergies or Chlamydia. ${ }^{3}$ Forty-four percent of these tests had been performed as home tests: the test was performed without any professional support or counselling. Other ways of self-testing are the so-called 'streetcorner tests', 'direct access' and 'home collect' selftests. ${ }^{4}$

Diagnostic self-tests have been subject of discussion in recent years, for there are important pros and cons that make it difficult to decide whether self-testing is per definition a 'good' or a 'bad' thing." Self-testing fits in our current view of people taking responsibility for their health and consumers indicate several benefits of selftesting, for example their privacy or not having to see a doctor which saves time. ${ }^{7,8}$ On the other hand, the negative sides of self-testing are not to be ignored: the unnecessary costs and distress when further investigations follow a false positive result, or false reassurance after a false negative result. ${ }^{9}$ Moreover, even valid results can lead to inappropriate follow-up behaviour, for example providing a 'certificate of health' when the test result is negative. ${ }^{10,11}$ Despite all these considerations, consumers often respond to the test result rather straightforward: seeing a doctor when the test result is positive, and feeling reassured after a normal test result. ${ }^{3,7}$ While most consumers seem to have a high level of confidence in self-tests ${ }^{7}$, most instruction leaflets included with self-tests do not elaborate on considerations such as the validity of test results and the possibility of false positive or negative results. ${ }^{12}$ The available information sources are usually biased by conflicts of interest; the information from the test device producers may be biased towards selling as many self-tests as possible, while the information from clinicians may be biased towards abandoning self-tests. Consumers should have access to independent information on the pros, cons and possible pitfalls of self-testing. In order to establish this, we developed a decision aid (DA) on self-testing for consumers and future consumers.

Decision aids have been developed to support patients in medical decision making. They have been used as adjuncts to counselling by practitioners, in order to help patients recognize the value-sensitive nature of the decision and help to clarify the value they place on the benefits, harms, and scientific uncertainties of an

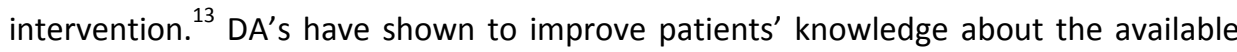
options, including watchful waiting, and to reduce decisional conflict. ${ }^{13}$ Because 
consumers perform self-tests without professional counselling, the challenge in a decision aid on self-testing is to support autonomy, to guide consumers in the decision to self-test or not, support in the different phases in testing, provide knowledge about the pitfalls of self-testing, and helping them weigh the positive and negative sides of self-testing, while not ignoring that in some cases medical advice should be sought, independent of the result of the self-test.

The aim of our study was to develop a decision aid that meets consumers' needs and expectations, while the medical contents and scientific background of the decision aid remain reliable and well founded. In this article, we will describe the development of the DA, as well as important considerations when informing consumers on self-testing.

\section{Methods}

\section{Development of the decision aid}

In the development of our decision aid we distinguished two important phases: the content specification and the design phase. ${ }^{14}$ As part of the design phase, usability testing was performed to assess and further improve the first version of the decision aid.

\section{Content specifications phase}

In this phase, the experiences and information needs of people who had ever performed a self-test, or with an intention to do a self-test, were explored, and the quality of available information on self-testing was assessed. ${ }^{15}$ The Health Belief Model $(\mathrm{HBM})^{16}$ served as a theoretical framework for these studies. The HBM is a psychological model which explains engagement in health related behaviour and describes six constructs that contribute to the decision whether to engage in certain behaviour or not: perceived severity, perceived susceptibility, perceived benefits, perceived barriers, cues to action and self-efficacy. ${ }^{16}$

We combined the results of our previous research ${ }^{3,4,7,12,15,17}$ with current medical practice guidelines on screening for diabetes and cardiovascular disease as input for the first draft of the decision aid. To inform and guide consumers in their decision whether to do a self-test or not, all aspects of the HBM were covered in this version: information on why people chose to do a self-test (cues to action), information on diabetes and cardiovascular disease and indications for doing a test, including a personal risk calculator (perceived susceptibility and severity), how to perform a selftest and what to do with the result (self-efficacy), and information on the pros and cons of self-testing (perceived benefits and barriers). 


\title{
Design phase
}

The content specification phase resulted in a storyboard. An expert specialized in plain language and communication reviewed our draft of the web text and the storyboard of the website. The contents of the first draft of the decision aid are shown in Table 6.1. To stimulate consumers to consider the pros and cons of self-testing, we designed a value clarification tool. ${ }^{18}$ Two techniques for value clarification were included: weighing the pros and cons of self-testing, in which consumers can agree or disagree with the statements given, after which the weighing scales shift towards self-testing or consulting a doctor. Second, consumers can choose their three most important reasons in favour of or against self-testing, which are depicted next to the results of the weighing scales. ${ }^{19}$

Table 6.1 Contents of the first draft of the decision aid.

\begin{abstract}
A homepage which gives an introduction to visitors of the website. A warning is given that the information provided on the website is not suitable for people who are already being treated for diabetes or cardiovascular disease.
\end{abstract}

General information on self-testing, including information on the different kinds of self-tests available, the reliability of self-tests in general and eleven cues what to check before doing a self-test.

Information about cholesterol self-testing: information about risk factors for cardiovascular disease, the role of cholesterol as a risk factor in cardiovascular disease, an interactive tool to determine personal risk for cardiovascular disease, information on the different kinds of cholesterol tests (tests for total cholesterol and HDL cholesterol), how these self-tests have to be performed, and what to do with the test result, including advise when to see a doctor, and information on lifestyle changes.

Information about diabetes self-testing, similar to the information regarding the cholesterol self-test, including an interactive tool to assess personal risk for developing diabetes.

Frequently asked questions (FAQ)

A value clarification tool to weigh the pros and cons of self-testing. This tool first shows 14 propositions on self-testing, of which 7 represent advantages of self-testing, and the other 7 the disadvantages of selftesting. Examples of these propositions are: 'I think it is an advantage that I can do the test whenever I want to', or 'I think that it is a disadvantage of self-testing that I have to get a blood sample myself'. People can indicate whether they agree, disagree or feel neutral about these propositions. When they indicate they agree with a proposition, the weighing scales depicted next to the propositions start shifting towards doing a self test or seeing a doctor. After respondents have filled out all the propositions, they are asked which propositions are most important to them. They are given advise whether they prefer seeing a doctor or doing a self-test.

A sitemap, disclaimer and contact information.

\section{Usability testing}

For the usability testing, interviews in which expert opinion was obtained were combined with a user-based testing method, in which end-users used the website while thinking aloud. ${ }^{20,21}$ Changes to the decision aid were made in an iterative 
process, based on the experts' and end-users' comments. In case of divergent opinions, the issues were discussed in the project team until consensus was achieved. Experts were selected from various stakeholder groups: general practitioners, researchers in the field of cardiovascular risk and prevention, experts in health promotion, ICT and communication policy officers from a health insurance company, staff members of Diagned (Dutch organisation of manufacturers and importers of invitro diagnostics) and the Dutch Consumers Organisation. The experts were invited to view the decision aid, and subsequently being interviewed by one of the researchers (see Table 6.2 for the interview scheme), or approached by email to answer specific questions on the functionality of the website, as well as to provide a general opinion on the contents of the decision aid. The interviews were audiotaped and written out, and subsequently, together with the email answers, analysed using a simple thematic content analysis. ${ }^{22}$

Table 6.2 Interview schemes.

\begin{tabular}{ll}
\hline & Experts \\
\hline 1 & Is the information provided correct? \\
3 & Is the information provided in a sensible way? \\
4 & Is this a proper way of providing information to consumers? \\
\hline 1 & What can be improved? \\
2 & End-users \\
3 & What were your expectations of the decision aid? \\
4 & Do you consider the information provided on the decision aid to be balanced? \\
5 & Do you think the weighing scales are useful? \\
6 & Are the texts easy to read, or too difficult? \\
7 & Is the amount of information provided in the decision aid sufficient? \\
\hline
\end{tabular}

Participants for the end-user usability tests were recruited by announcements in the Maastricht University Hospital. The announcement asked for people over 18 years of age and explained the aim of the study and the incentive for participating (a gift voucher). People could respond by email or telephone. Respondents were screened for age, gender, educational level and level of Internet use in order to recruit a heterogeneous sample. Respondents were invited until saturation was reached.

The usability tests were carried out in the usability laboratory at Maastricht University using Morae software (http://www.techsmith.com/morae.asp) and were performed by one of the researchers (MI). Informed consent was obtained and participants were asked to fill out a short questionnaire with general characteristics. Next, participants were instructed conform the think aloud method. ${ }^{20}$ They were asked to navigate freely on the website while thinking aloud and while completing three tasks that were given 
in written form (Table 6.3). Morea software simultaneously recorded participants' navigation through the website and their comments. Markers were included in the recording when important comments were made or when technical errors were found. When navigation through the website was completed, a short interview was held with the participants (interview scheme provided in Table 6.2). The comments of the endusers during the usability tests, marks made in the Morae software and the results of the interviews were compared with the comments of the experts.

Table 6.3 Tasks for the end-user usability test.

\begin{tabular}{ll}
\hline Task number & Description \\
\hline 1 & $\begin{array}{l}\text { You are searching for the symptoms of diabetes. Try to find this information on the } \\
\text { website. } \\
\text { You are searching for more information on cholesterol, and about "good" and "bad" } \\
\text { cholesterol. Try to find this information on the website. } \\
\text { You are considering doing a cholesterol self-test, but you are not sure whether the test is } \\
\text { useful. Try to find out your personal risk, and if a cholesterol test is useful for you. } \\
\text { You are considering doing a diabetes self-test, but you are not sure whether the test is } \\
\text { useful. Try to find out your personal risk, and if a diabetes test is useful for you. } \\
\text { You have bought a cholesterol self-test, and you would like to have more information on } \\
\text { how to perform the self-test. Try to find this information on the website. } \\
\text { You are considering buying a diabetes self-test, and you would like to have more } \\
\text { information on how to perform the test. Try to find this information on the website } \\
\text { You are searching for more information on what to do to avoid cardiovascular disease. Try } \\
\text { to find this information on the website } \\
\text { You have performed a cholesterol self-test, but you do not know what to do with the test } \\
\text { result. Try to find this information on the website } \\
\text { You have performed a diabetes self-test, but you do not know what to do with the test } \\
\text { result. Try to find this information on the website } \\
\text { You would like to know more about the reliability of self-tests. Try to find this information } \\
\text { on the website } \\
\text { You are still in doubt whether to do a self-test, or to visit a doctor. Try to compare the pros } \\
\text { and cons of a self-test for yourself on the website. }\end{array}$ \\
\hline 10 &
\end{tabular}

\section{Results}

\section{Participants}

In October 2010, 15 experts from Maastricht University were invited to view our decision aid, of which 11 responded positively and were interviewed within one week. We received feedback from two of the external experts (staff members of a health insurance company and Diagned).

Ten participants reviewed the decision aid during the end-user usability tests. Our sample included people of different ages (range 19- 64 years), educational level and 
Internet experience (Table 6.4). The end-user usability tests were executed in October and November 2010 and in April 2011.

Table 6.4 Personal characteristics of the participants in the end-user usability tests

\begin{tabular}{|c|c|c|c|c|c|c|}
\hline Participant & Age & Gender & Education & $\begin{array}{c}\text { Hours per } \\
\text { week on the } \\
\text { Internet }\end{array}$ & $\begin{array}{c}\text { Ever } \\
\text { performed } \\
\text { self-test } \\
\end{array}$ & $\begin{array}{c}\text { Considering } \\
\text { doing a } \\
\text { self-test }\end{array}$ \\
\hline 1 & 62 & $\mathrm{M}$ & Intermediate vocational education & 7 & No & No \\
\hline 2 & 38 & M & Higher vocational education & $25-30$ & No & Yes \\
\hline 3 & 56 & $\mathrm{~F}$ & Higher vocational education & 15 & No & Yes \\
\hline 4 & 29 & $\mathrm{~F}$ & Primary school & 7 & No & No \\
\hline 5 & 49 & M & Higher vocational education & 7 & No & No \\
\hline 6 & 60 & $\mathrm{~F}$ & Intermediate vocational education & 20 & Yes & Yes \\
\hline 7 & 19 & $\mathrm{~F}$ & Higher secondary education & 30 & No & Yes \\
\hline 8 & 53 & $\mathrm{~F}$ & Higher vocational education & 25 & Yes & Yes \\
\hline 9 & 64 & $\mathrm{~F}$ & Lower secondary education & 8 & No & Yes \\
\hline 10 & 22 & $\mathrm{M}$ & Higher secondary education & 15 & No & No \\
\hline
\end{tabular}

\section{Results from the expert opinion}

The comments of the experts could be grouped into one of the following themes: general comments, textual remarks, technical errors and the lay-out of the decision aid.

\section{General comments}

The neutrality of the central decision at stake was discussed: whether it should aim for a free choice between self-testing or seeing a doctor, or on the contrary, whether it should contain a stronger warning about self-testing, and a stronger emphasis on the role of a doctor. Suggestions were made to inform people on the dilemmas in selftesting and the goal of the website. Other general comments were made on the use of the interactive cardiovascular risk tool (for example is it medically sound to use these risk calculators and what advice should be given based on the results) and on the use of the value clarification tool (e.g. should it give you an advise whether to do a self-test or not, or should people only weigh pros and cons for themselves and draw their own conclusions?). Some of the experts asked for a ranking of the various types of available tests, with data on for example reliability and user-friendliness.

\section{Textual remarks, technical errors and lay-out}

Most of the comments of the experts concerned remarks regarding the contents of the website, e.g. parts of texts that were regarded as medically not sound, or descriptions that were too complex. Several of the experts indicated that more information should be provided on the general limitations of diagnostic testing. The information on the reliability of tests was found insufficient. Further, they missed a clear introduction on 
how to use the value clarification tool, and the statements that were used in the weighing scales were not always clear. Several technical errors were observed, such as hyperlinks that malfunctioned, the appearance of too many scrollbars, and the impossibility to increase the size of the text. Comments on the lay-out of the decision aid were related to the position of the menu, the font used, and the use of colours and images.

\section{Results from the end-user usability tests and changes to the decision aid}

In general, participants had no problems understanding the texts; they found the information provided on the decision aid to be balanced, and said it met their expectations.

The first three end-users usability tests identified similar problems as identified by the experts and concerned similar topics or text parts, and their opinions and suggestions on how to improve were mainly consistent. Major changes were made, resulting in the addition of a text that explains the reason for the development of the decision aid, explaining the different views on self-testing, and a stronger instruction on the importance and timing of visiting a doctor. An important change regarded the core decision at stake, most clearly visible in the value clarification tool: instead of weighing the pros and cons of a self-test versus consulting a doctor, we now ask people to weigh the pros and cons of doing a self-test or not. The value clarification tool no longer provided a direct advice whether to do a self-test or to see a doctor, but instead aims at weighing pros and cons, without giving advice. We realise that this has led to some of the end-users being disappointed. Nevertheless, during the final usability tests, most end-users indicated they thought the warnings on the pitfalls in self-testing were clear, but they still felt free in making their choice. Technical problems were solved, and lay-out and texts were improved.

During the following seven end-users usability tests minor changes were still needed, e.g. hyperlinks that malfunctioned and words or parts of texts that were still unclear. Some of the comments did not lead to changes, i.e. because of different opinions among participants in the usability tests, because changes would not be medically sound, or because of technical limitations.

\section{Discussion}

The phenomenon of diagnostic self-testing has led to many debates, and many pros and cons of self-testing have been described. By designing a decision aid on selftesting, we have made efforts to translate this debate into neutral information. Our 
aim was to design a decision aid that stimulates consumers to make a choice that is in line with their values. This means that both doing or not doing a self-test can be suitable choices.

The development process of a decision aid on diagnostic self-testing has confronted us with challenging dilemmas because a DA for consumers outside health care is different from the 'traditional' DAs on screening options used within the doctor patient relation. ${ }^{13}$ In self-testing, consumers do not consult a doctor at all. Since the decision aid offers health related advice such as information on personal risk, and how to interpret a test-result, it should be safe to use without additional professional counselling. We found these issues also addressed in our usability tests. Experts and end-users raised the issue whether self-testing is safe, and whether the decision aid included sufficient warning about the pitfalls of self-testing, especially since there are situations in which consulting a doctor is recommended, for example when having complaints or being at high risk for developing cardiovascular disease. Also, usability testing of the decision aid led to discussion about whether or not the decision aid encourages or discourages self-testing. The general opinion of experts as well as endusers was that a diagnostic self-test could never replace consulting a clinician. This discussion led to stronger statements concerning the limitations of self-tests on the website and the role of the clinician.

Second, we were not able to meet one of the needs; to help choose 'the best self-test' using a ranking of the available tests on quality criteria. While decision aids mostly present probabilities on positive or negative outcomes ${ }^{23}$, these numbers are often not available for diagnostic self-testing devices. Self-tests are provided in various formats by different companies in a market that changes constantly. Often, information about the exact validity and reliability of the tests is not provided ${ }^{12}$ and, to our knowledge, there are no studies on the use of specific self-tests for cholesterol and diabetes in which the chance of an adverse outcome is assessed. Therefore, we were unable to provide this information. Although consumers as well as some experts would have preferred more information or even quality rankings of tests, we did not want to become commercially involved in any way; therefore we decided not to provide such rankings.

Since the goal of the decision aid is to stimulate an informed choice, consumers should have sufficient knowledge not only regarding the reliability of diagnostic self-tests in general, but also about the different phases in testing, in order to decide whether a self-test for a certain disease is important to them. The decision aid aims to guide consumers through these phases in testing: 'Do I need the test?' (i.e. 'Am I at-risk for developing the disorder?'); 'How to perform the test?'; 'How to interpret the result?' (i.e. 'What follow-up steps to take?'). It can be debated whether the additions made based on the usability tests, which have led to quite extensive information, and also 
the fact that during the usability tests the take-home message of the website has become more subtle and includes more warnings, might affect the actual use of the website when consumers access the decision aid online. Further research will have to assess whether people visit these specific pages and in which domains knowledge increase is found.

\section{Study strengths and limitations}

Strengths of the development of the decision aid are the theoretical framework and the thorough development of the decision aid in an iterative process, involving experts and end-users. In this study, we gained a more in-depth understanding of the way people use our website and what problems they encountered in using the website and its interactive tools by using a think aloud method in combination with video and audio recordings.

Almost all experts we invited to view the website were experts employed the same university as the project team. Although the background of the experts was diverse, it is unclear whether involvement of more experts might have elicited other views. Furthermore, we only asked the experts to view the website once, and have not asked for their feedback after improvements had been made.

\section{Conclusions}

The development and usability testing of a decision aid on self-testing has provided useful insights into the use of the DA and the reasoning of experts and end-users concerning its contents. It has led to debate on how to inform consumers on selftesting and led to important changes in the decision aid. The development of this decision aid still has to pass through a final step: field testing of the decision aid. The actual use will have to be assessed by using weblog files when the decision aid is accessible for the general public on the Internet. Also, further studies will have to assess the actual effect of the decision aid on for example knowledge, attitude towards self-testing, worry, uptake of self-tests and follow-up behaviour after self-testing. ${ }^{24}$ 


\section{References}

1. Ryan A, Wilson S, Greenfield S, Clifford S, McManus RJ, Pattison HM. Range of self-tests available to buy in the United Kingdom: an Internet survey. J Public Health (Oxf). 2006;28:370-4.

2. Weijden T, Ronda G, Norg R, Portegijs P, Buntinx F, Dinant GJ. Diagnostische zelftests op lichaamsmateriaal: aanbod, validiteit en gebruik door de consument [Diagnostic self-tests on body materials: availability, validity and frequency of use]. Maastricht: Maastricht University, School for Public Health and Primary Care (Caphri); 2007.

3. Ickenroth MH, Ronda G, Grispen JE, Dinant GJ, de Vries NK, van der Weijden T. How do people respond to self-test results? A cross-sectional survey. BMC Fam Pract. 2010;11:77.

4. Ronda G, Portegijs P, Dinant GJ, Buntinx F, Norg R, Van der Weijden T. Use of diagnostic self-tests on body materials among Internet users in the Netherlands: prevalence and correlates of use. BMC Public Health. 2009;9:100.

5. Campbell S, Klein R. Home testing to detect human immunodeficiency virus: boon or bane? J Clin Microbiol. 2006;44:3473-6.

6. Spielberg F, Levine RO, Weaver M. Self-testing for HIV: a new option for HIV prevention? The Lancet Infectious Diseases. 2004;4:640-6.

7. Ickenroth MH, Grispen JE, Ronda G, Tacken M, Dinant GJ, de Vries NK, et al. Motivation and experiences of self-testers regarding tests for cardiovascular risk factors. Health Expect. 2011 Oct 28.

8. Ryan A, Ives J, Wilson S, Greenfield S. Why members of the public self-test: an interview study. Family Practice. 2010;27:570-81

9. Walensky RP, Paltiel AD. Rapid HIV testing at home: does it solve a problem or create one? Annals of Internal Medicine. 2006;145:459-62.

10. Tymstra T, Bieleman B. The psychosocial impact of mass screening for cardiovascular risk factors. Family Practice. 1987;4:287-90.

11. Ryan A, Greenfield S, McManus R, Wilson S. Self-care--has DIY gone too far? Br J Gen Pract. 2006;56: 907-8.

12. Grispen JE, Ickenroth $\mathrm{MH}$, de Vries NK, van der Weijden T, Ronda G. Quality and use of consumer information provided with home test kits: room for improvement. Health Expect. 2012 Jul 19.

13. O'Connor AM, Bennett CL, Stacey D, Barry M, Col NF, Eden KB, et al. Decision aids for people facing health treatment or screening decisions. Cochrane database of systematic reviews (Online). 2009(3):CD001431.

14. Elwyn G, Kreuwel I, Durand MA, Sivell S, Joseph-Williams N, Evans R, et al. How to develop web-based decision support interventions for patients: A process map. Patient education and counseling. 2010 Jun 1.

15. Grispen JE, Ickenroth MH, de Vries NK, Dinant GJ, Ronda G, van der Weijden T. Improving behaviour in self-testing (IBIS): Study on frequency of use, consequences, information needs and use, and quality of currently available consumer information (protocol). BMC Public Health. 2010;10:453.

16. Janz NK, Champion VL, Strecher VJ. The Health Belief Model. In: Glanz K RB, Lewis FM, ed. Health behavior and health education: Theory, research, and practice 3 ed San Francisco: Jossey-Bass 2002: 45-66.

17. Grispen JE, Ronda G, Dinant GJ, de Vries NK, van der Weijden T. To test or not to test: a cross-sectional survey of the psychosocial determinants of self-testing for cholesterol, glucose, and HIV. BMC Public Health. 2011;11:112.

18. Abhyankar P, Bekker HL, Summers BA, Velikova G. Why values elicitation techniques enable people to make informed decisions about cancer trial participation. Health Expect. 2010;14 Suppl 1:20-32.

19. van der Pligt J, de Vries NK, Manstead ASR, van Harreveld F. The importance of being selective: weighing the role of attribute importance in attitudinal judgment. Advances in experimental social psychology: Academic Press 2000.

20. Jaspers MW. A comparison of usability methods for testing interactive health technologies: methodological aspects and empirical evidence. International journal of medical informatics. 2009;78: 340-53.

21. Bastien JM. Usability testing: a review of some methodological and technical aspects of the method. Int J Med Inform. 2010;79:e18-23. 
22. Green J, Thorogood N. Qualitative methods for health research. London: SAGE publications Ltd 2004.

23. Elwyn G, O'Connor AM, Bennett C, Newcombe RG, Politi M, Durand MA, et al. Assessing the quality of decision support technologies using the International Patient Decision Aid Standards instrument (IPDASi). PloS One. 2009;4:e4705.

24. Ickenroth MH, Grispen JE, de Vries NK, Dinant GJ, Elwyn G, Ronda G, et al. A single-blind randomised controlled trial of the effects of a web-based decision aid on self-testing for cholesterol and diabetes. Study protocol. BMC Public Health. 2012;12:6. 


\section{CHAPTER 7}

A single-blind randomised controlled trial of the effects of a web-based decision aid on self-testing for cholesterol and diabetes. Study protocol

Martine Ickenroth*, Janaica Grispen*, Nanne de Vries, Geert-Jan Dinant, Glyn Elwyn, Gaby Ronda, Trudy van der Weijden *Authors contributed equally to this work BMC Public Health 2012;12:6 


\section{Abstract}

\section{Background}

Self-tests, tests on body materials to detect medical conditions, are widely available to the general public. Self-testing does have advantages as well as disadvantages, and the debate on whether self-testing should be encouraged or rather discouraged is still ongoing. One of the concerns is whether consumers have sufficient knowledge to perform the test and interpret the results. An online decision aid (DA) with information on self-testing in general, and test specific information on cholesterol and diabetes self-testing was developed. The DA aims to provide objective information on these self-tests as well as a decision support tool to weigh the pros and cons of self-testing. The aim of this study is to evaluate the effect of the online decision aid on knowledge about self-testing, informed choice, ambivalence and psychosocial determinants

\section{Methods}

A single blind randomised controlled trial in which the online decision aid 'zelftestwijzer' is compared to short, non-interactive information on self-testing in general. The entire trial will be conducted online. Participants will be selected from an existing Internet panel. Consumers who are considering doing a cholesterol or diabetes self-test in the future will be included. Outcome measures will be assessed directly after participants have viewed either the DA or the control condition. Weblog files will be used to record participants' use of the decision aid.

\section{Discussion}

Self-testing does have important pros and cons, and it is important that consumers base their decision whether they want to do a self-test or not on knowledge and personal values. This study is the first to evaluate the effect of an online decision aid for self-testing.

\section{Trial registration}




\section{Background}

Self-tests on body materials are widely available to the general public. ${ }^{1,2}$ These tests give consumers the opportunity to test themselves on medical conditions without consulting a health professional first. Self-tests are available for conditions such as diabetes, high cholesterol, kidney disorders, Chlamydia or prostate cancer. ${ }^{1,2}$ In a recent study among Dutch Internet users, $18 \%$ of the respondents had ever performed a self-test and $66 \%$ of all respondents considered to use a self-test in the future. ${ }^{3}$ Tests can be performed at home ('home tests'), in which the consumer is responsible for all aspects of the test: execution, interpretation and follow-up behaviour. These tests can be bought on the Internet and are available in drugstores or pharmacies. Other ways of self-testing are 'streetcorner' tests, in which a test is performed by trained personnel in public places (for example in a supermarket), or 'direct access' and 'home collect' tests, in which a sample is taken at a laboratory or at home, is analysed in a laboratory and the results are sent to the consumer by mail or email.

Self-testing does have advantages as well as disadvantages, and the debate on whether self-testing should be encouraged or rather discouraged is still ongoing. ${ }^{4-7}$ Self-testing can be considered as an easy way for consumers to gain more insight in their health status, it might lead to early detection of disease, and fits in with our current views on patient autonomy. On the other hand, there are concerns about selftesting, for example whether consumers have sufficient knowledge to enable appropriate use of self-tests, such as insight in indications for testing, and whether they consider the possibility of obtaining false positive or false negative results. Consumers who perform a self-test often perform these tests for reassurance, because the test is offered by an organisation at no costs, or out of curiosity ${ }^{8,9}$, and respond quite straightforward to the test result: they generally have a high level of confidence in self-tests, visit a doctor in case of an abnormal test result and are reassured by a negative test result. ${ }^{2,9}$ Consumers with an intention towards self-testing also perceive these benefits of self-testing, although they experience several barriers as well, such as doubts concerning the reliability of self-tests and not knowing how to interpret the test result.(Grispen et al.: An intention to self-testing: a qualitative study regarding consumers' considerations and information needs about self-testing, submitted)

To support consumers in deciding whether they want to perform a self-test or not, objective information on self-tests could be provided to stimulate consumers to weigh the pros and cons of self-testing. Their decision should be based on knowledge as well as personal values, in which these personal values are related to intention, for example, a positive attitude should lead to a positive intention; a so-called informed choice. Consumers with an intention towards self-testing indicated they experienced benefits as well as barriers in self-testing. In other words, they experienced feelings of 
ambivalence towards self-testing. ${ }^{10}$ If these feelings are not resolved and people have to make a decision, they experience feelings of discomfort. Therefore, ambivalent attitude holders have the urge to integrate these feelings into one response; they want to 'choose sides'. ${ }^{10}$ To support patients in making a choice that is the best choice in their specific situation, for example for patients facing treatment and screening decisions, decision aids have been developed. These decision aids have shown to improve people's knowledge of options and reduce difficulty in decision making. ${ }^{11}$

We developed a web-based decision aid on self-testing (http://www.zelftestwijzer.nl), which provides information on self-tests in general, and test specific information on self-tests for diabetes and cholesterol. The web-based decision aid was based on clinical practice guidelines, previous research on self-testing ${ }^{3,9,12,13}$, the International Patient Decision Aid Standard (IPDAS) ${ }^{14,15}$, and the Health Belief Model (HBM) ${ }^{16}$. The decision aid provides information on self-testing, as well as a value clarification tool to weigh the pros and cons of self-testing. The aim of this study is to investigate the effect of the web-based decision aid on knowledge about self-testing, informed choice, ambivalence and psychosocial concepts.

\section{Theoretical framework}

\section{Health Belief Model}

The Health Belief Model $(\mathrm{HBM})^{16}$ was used as the theoretical framework during the development of the decision aid and will be used in its evaluation as well. According to the HBM, an individual's decision to engage in health-related behaviour is based on their evaluation of the severity of and the susceptibility to a particular condition or illness and the belief that a certain action is effective in reducing their susceptibility to or the severity of this condition. Furthermore, individuals are only inclined to engage in health-related behaviour if they perceive more benefits than barriers associated with that behaviour and if certain cues (for example in self-testing: having a neighbour with diabetes, or the offering of free tests) are present that trigger action. Finally, selfefficacy, the individual's confidence in his or her capability to successfully perform a certain action, is an important concept within the HBM.

Besides the concepts of the HBM, additional concepts of the Theory of Planned Behaviour (TPB) ${ }^{17}$ were used in the development and evaluation of the decision aid, namely subjective norm, anticipated regret, moral obligation and response efficacy. These concepts have been shown to contribute to the explanation of health-related behaviour. $^{18-22}$

\section{Ambivalence}

In previous research we found that individuals who intend to perform a cholesterol or diabetes self-test perceived strong benefits as well as strong barriers towards using a 
self-test. (Grispen et al.: An intention to self-testing: a qualitative study regarding consumers' considerations and information needs about self-testing, submitted) Individuals who hold both strong positive and negative beliefs or feelings towards a certain action or attitude object are considered to be ambivalent. ${ }^{10}$ An important distinction needs to be addressed concerning the ambivalence concept, namely the difference between potential ambivalence ${ }^{23}$ and felt ambivalence ${ }^{24}$. Potential ambivalence concerns the coexistence of beliefs that are associated with incongruent evaluations related to a certain behaviour or attitude object. Individuals do not necessarily have to be aware of this incongruence and therefore potential ambivalence can be implicit. Felt ambivalence refers to simultaneously having positive and negative emotions towards a certain behaviour or attitude object. For felt ambivalence to occur, the individual needs to be aware of his conflicting feelings between the two sides of the behaviour or attitude object. These conflicting feelings lead to psychological discomfort which is experienced as being unpleasant. Ambivalent attitude holders are motivated to solve this psychological discomfort by integrating their conflicting feelings in one evaluate response. When this is achieved, ambivalence and the related psychological discomfort are solved. . $^{10,25}$

\section{Study aim and research questions}

The principal aim of the proposed study is to evaluate the effect of the decision aid on knowledge about self-testing. The following research questions were formulated:

1. Do consumers who have been exposed to the decision aid have more knowledge about self-testing than the control group?

2. Do consumers who have been exposed to the decision aid more often make an informed choice in self-testing than consumers in the control group?

3. Do the intervention and control groups differ in level of attitudinal ambivalence?

4. What is the effect of the decision aid on the psychosocial factors that predict selftest use for diabetes and cholesterol?

5. Is there a difference between the intervention and control group in follow-up behaviour three months after the use of the decision aid?

\section{Methods}

\section{Study design}

A single-blind randomised controlled trial in which the online decision aid will be compared to short, non-interactive information on self-testing in general (non-testspecific). The entire trial will be conducted online. 


\section{Ethical approval}

The study was reviewed by The Medical Ethical Committee of Maastricht University Medical Centre. They had no objection to the study proceeding and because the study evaluates usual care and no patient recruitment was required, formal approval was not deemed necessary.

\section{Setting and participants}

Participants will be recruited from an existing Internet panel in the Netherlands that is managed by Flycatcher, an ISO-certified institute for online research associated with Maastricht University. Currently, the panel consists of approximately 14,000 active members between 12 and 96 years of age (http://www.flycatcher.eu). Members of the panel are recruited online, by written invitation, face to face contacts or by intermediaries. All individuals aged 12 years or older and who have an email address can apply for the panel. Compared with the Dutch population, the panellists are younger, have a higher level of education and are more often female. The total panel is representative of the Dutch Internet population. Panel members receive invitations to participate in online questionnaires approximately eight times per year, and receive an incentive when they have completed a certain number of questionnaires. Variables of the panel members such as age, sex and level of education are provided by Flycatcher.

\section{Inclusion and exclusion criteria}

Panel members aged 18 or older, with an intention to use a diabetes and/ or a cholesterol self-test in the future will be invited to participate in the randomised controlled trial. An intention will be defined as a consumer indicating to maybe, probably, or definitely intending to use a self-test in the future. People who report that they are already diagnosed with diabetes and/or a cardiovascular disease will be excluded from this study.

\section{Randomisation}

Participants will be assigned to one of two groups (having an intention towards doing a cholesterol or towards doing a diabetes self-test). If participants have an intention to do both, they will be assigned to the test towards which they have the strongest intention. Within each group, randomisation over experimental conditions (and invitation to view either the decision aid or the control condition) will be performed by Flycatcher using SPSS. Participants will be blinded for randomisation. 


\section{Intervention}

The $\mathrm{HBM}^{16}$, IPDAS criteria ${ }^{14,15}$ and the results of previous quantitative and qualitative studies $^{3,9,12,13}$ provided input for the development of the decision aid http://www.zelftestwijzer.nl. The medical information in the decision aid is based on current clinical practice guidelines on screening for diabetes and cardiovascular disease. After the first versions of the decision aid had been developed, the content and usability of the decision aid were assessed by professionals as well as by end users. An iterative procedure was used to improve the decision aid. The core components of the decision aid are described in Box 7.1. Respondents in the intervention group will be asked to view the decision aid.

Box 7.1

Core components of the decision aid.

- A homepage which gives an introduction on how to use the website, and an explanation about the contents of the website. Visitors are asked to read the disclaimer, and a warning is given that the information provided on the website is not suitable for people who are already being treated for diabetes or cardiovascular disease.

- General information on self-testing, including information on the different kinds of self-tests, the reliability of self-tests in general and eleven cues what to check before doing a self-test.

- Information about cholesterol self-testing: information about risk factors for cardiovascular disease, the role of cholesterol as a risk factor in cardiovascular disease, an interactive tool to determine personal risk for cardiovascular disease, information on the different kinds of cholesterol tests (tests for total cholesterol and HDL cholesterol), how these self-tests have to be performed and what to do with the test result, including advise when to see a doctor, and information on lifestyle changes.

- Information about diabetes self-testing, similar to the information related to the cholesterol self-test, including an interactive tool to assess your personal risk for developing diabetes.

- Frequently asked questions (FAQ)

- An interactive tool to weigh the pros and cons of self-testing. This tool first shows 12 propositions on self-testing, of which six represent advantages of a self-testing, and the other 6 the disadvantages of self-testing. Examples of these propositions are: 'I think it is an advantage that I can do the test whenever I want to', or 'I think that it is a disadvantage of self-testing that I have to get a blood sample myself'. People can indicate whether they agree, disagree or feel neutral about these propositions. When they indicate they agree with a proposition, the weighing scales depicted next to the propositions starts shifting towards doing a self test of not doing a self-test. After respondents have filled out all the propositions, they are asked which propositions are most important to them. They are explained that the tool is not meant to give an advise on whether to do a self-test or not, but is aimed at clearing out their personal values on self-testing.

- A sitemap, disclaimer and contact information.

\section{Control condition}

A placebo control condition was designed consisting of general information on selftesting. An existing control condition was not available, since there is no usual care in self-testing. Our intervention is the first decision aid that aims at people with an intention towards self-testing, and, to the best of our knowledge, is the first noncommercial website that provides test specific information on cholesterol and diabetes 
self-testing. The control condition will consist of a pdf file of one page which gives general information on self-testing (definition of a self-test and the types of self-tests that are available). It does not include test specific information or interactive elements that are included in the original decision aid since these are distinguishing features of our decision aid.

\section{Methods of data collection}

An overview of all questionnaires and measures is provided in Table 7.1 and Figure 7.1. Questionnaire 1 will be sent to a random sample of the Flycatcher panel and is aimed at selecting consumers with an intention towards self-testing for diabetes and cholesterol. The questionnaire will consist of questions on personal characteristics (including medical history of cardiovascular disease and diabetes, and risk factors), and intention towards doing a cholesterol or diabetes self-test.

Table 7.1 Outcome measures and timing of data collection.

\begin{tabular}{|c|c|c|c|}
\hline Construct & Measures & No. of items & Questionnaire* \\
\hline \multicolumn{4}{|l|}{ Primary outcome } \\
\hline "'Knowledge & $\begin{array}{l}\text { Knowledge questionnaire based on } \\
\text { information provided in the decision } \\
\text { aid }\end{array}$ & $\begin{array}{l}21 \text { Statements } \\
\text { (True/false/ don't } \\
\text { know) }\end{array}$ & 2 \\
\hline \multicolumn{4}{|l|}{ Secondary outcomes } \\
\hline Attitude & Marteau ${ }^{26}$ & 4 & 1,2 \\
\hline Ambivalence & Felt ambivalence ${ }^{24}$ & 3 & 1,2 \\
\hline Follow-up behaviour & $\begin{array}{l}\text { Uptake of self-tests, visiting a doctor, } \\
\text { changing lifestyle. }\end{array}$ & 7 & 3 \\
\hline \multirow[t]{2}{*}{ Intention } & $\begin{array}{l}\text { Intention towards self-testing, seeing } \\
\text { a doctor, changing lifestyle }\end{array}$ & 3 & $1,2,3$ \\
\hline & Stages of change ${ }^{27}$ & 1 & $1,2,3$ \\
\hline \multirow[t]{9}{*}{ Psychosocial determinants } & Perceived benefits and barriers & 14 & 2 \\
\hline & Self-efficacy & 3 & 2 \\
\hline & Response-efficacy & 4 & 2 \\
\hline & $\begin{array}{l}\text { Perceived susceptibility/risk } \\
\text { perception }^{28}\end{array}$ & 3 & $1,2,3$ \\
\hline & Cues to action & 1 & 2 \\
\hline & Perceived severity & 1 & 2 \\
\hline & Anticipated regret & 1 & 2 \\
\hline & Moral obligation & 2 & 2 \\
\hline & Subjective norm & 1 & 2 \\
\hline
\end{tabular}

*Questionnaire 1: baseline. Questionnaire 2: directly after seeing intervention or control condition. Questionnaire 3: three months after viewing intervention or control condition.

Questionnaire 2 will be sent after participants have been assigned to the intervention or control condition and have been exposed to this condition. Participants with an intention to do a cholesterol self-test will receive questions on cholesterol self-testing, 
participants with an intention to do a diabetes self-test will receive a similar questionnaire, but addressing the diabetes self-test.

Three months after participants have viewed the decision aid or the control condition, they will be sent questionnaire 3, which includes questions on self-test use in the past three months, intention towards doing a self-test, visiting a doctor or changing lifestyle.

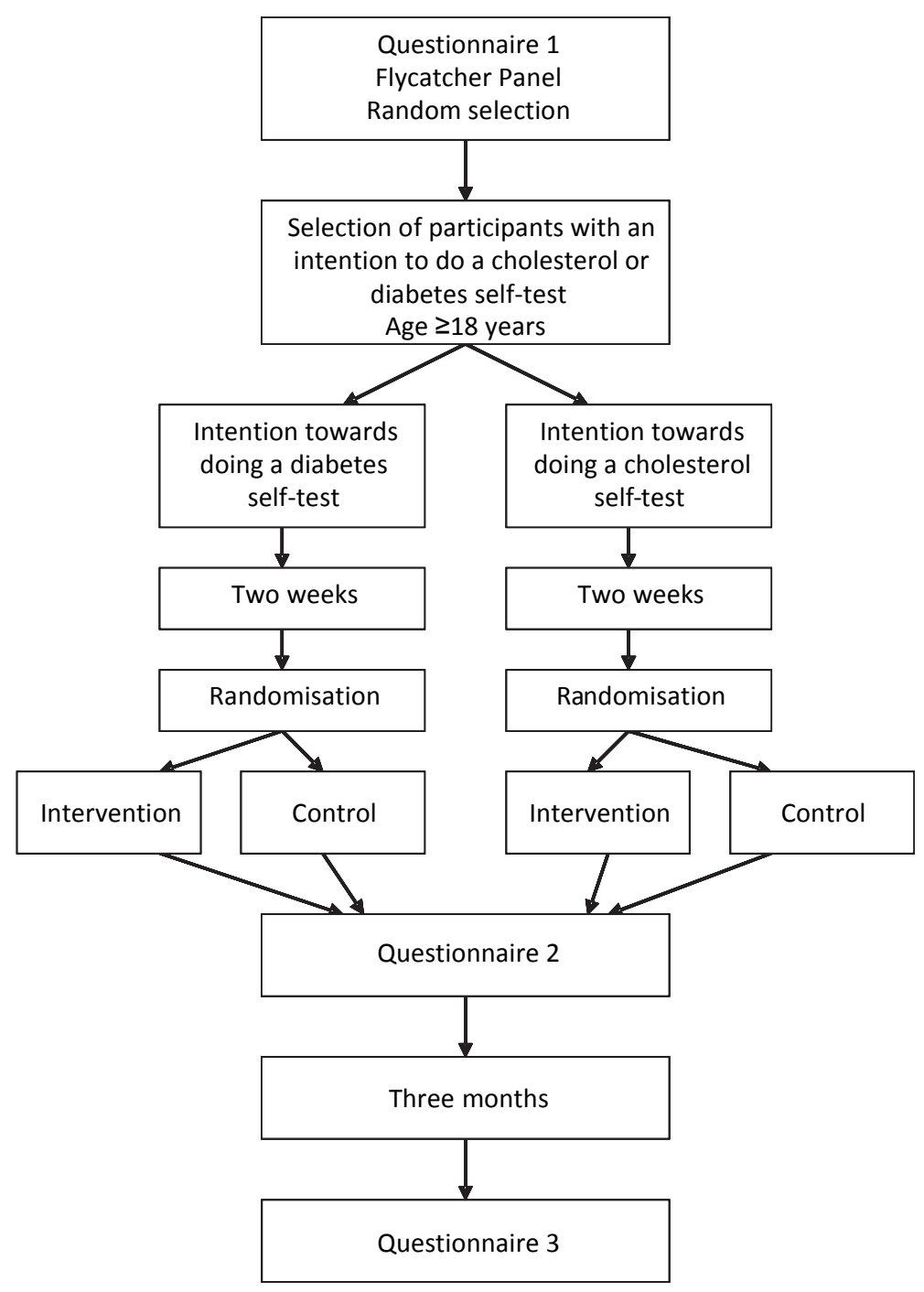

Figure 7.1 Selection of participants and randomisation. 


\section{Measures}

\section{Primary outcome}

1. Knowledge. Knowledge questions are based on the themes that are addressed in the decision aid. It includes questions on the condition, indications for testing, such as symptoms and risk factors, what the test measures, how to interpret the test result, and questions on the validity of the self-test. These aspects of self-testing were deemed important by health professionals and were indicated as well by endusers. ${ }^{9}$ (Grispen et al.: An intention to self-testing: a qualitative study regarding consumers' considerations and information needs about self-testing, submitted) The knowledge quiz consists of 20 true/ false statements. Knowledge questions are test specific, and differ between the cholesterol and diabetes self-test.

\section{Secondary outcome measures}

2. Intention. Intention to do a self-test in general and the intention to do a self-test for diabetes and cholesterol. Intention will be assessed with a single question using a 5-point Likert scale with answering options ranging from 1='definitely not' to $5=$ 'definitely will'. Further, intention to visit a doctor and intention to change lifestyle will be assessed.

Intention will also be measured using the stages of change algorithm. ${ }^{27}$ Stages of change will give more detailed insight in the strength of the participants' intention towards doing a self-test and will be measured by asking participants in what time frame they think they will perform a self-test.

3. Attitude. Attitude towards self-testing for diabetes or cholesterol will be measured using a four item scale developed by Marteau. ${ }^{26}$ Participants are asked to respond to the following questions on a 7-point Likert scale: I think self-testing is: harmful beneficial; unimportant - important; bad thing - good thing; unpleasant - pleasant. Responses to the scale are used to classify people as having a positive or a negative attitude. Scores range from 4 to 28 , with higher scores referring to a more positive attitude towards self-testing. Whether the participant has a positive or negative attitude towards self-testing will be determined using the median of the scores of the participants. $^{26}$

4. Ambivalence. Felt ambivalence will be assessed using a 3 item scale as described by Priester and Petty. ${ }^{24}$

5. Psychosocial determinants. Possible determinants of self-test use were derived from the Health Belief Model $(\mathrm{HBM})^{16}$, as well as several concepts of the Theory of Planned 
Behavior (TPB) ${ }^{17}$ and will be assessed after participants have viewed the decision aid or control condition.

6. Behaviour. Behaviour will be measured three months after the intervention. Participants will be asked whether they have performed a self-test for cholesterol or diabetes, and whether they have visited a doctor or have changed their lifestyle in the past three months, in response to having viewed the decision aid. If they have performed a self-test, they will be asked what the result of the self-test was (normal test result, abnormal test result) and the actions taken based on this test result.

\section{Process evaluation}

Message acceptance will be measured on an eight item scale, for example, 'The information provided on the website is very realistic/ realistic/ neutral/ not realistic/ not realistic at all'. ${ }^{29}$ Participants will be asked to comment on the strong and weak features of the decision aid. Weblog files of each participant will be collected to assess use of the website, time spent on the website and use of each page of the website.

\section{Sample size}

According to a Cochrane review by O'Connor et al. on the efficacy of decision aids, there is an average absolute increase of $15 \%$ in knowledge scores when decision aids are compared to usual care. When more detailed decision aids are compared to simpler decision aids, knowledge increases with $5 \% .{ }^{11}$ Since we will compare our decision aid to general, non test specific information on self-testing, we expect an increase in knowledge of $15 \%$ (intervention group knowledge score $70 \%$, control group $55 \%$ ). Our sample size will be based on a power of $80 \%$ to detect a hypothesized increase in knowledge of $15 \%$ at a significance level of $5 \%$ (two-sided). Power analysis showed 175 respondents would be needed in each of the four groups. ${ }^{30}$ Based on previous research, a completion rate of $60 \%$ on the first questionnaire, and $80 \%$ on questionnaire 2 is expected. ${ }^{3}$ Intention towards doing a cholesterol and/ or a diabetes self-test in 2008 was $42 \%$. Based on these results, a minimum of 3472 respondents would have to be invited for the first questionnaire. Since we do not know intention rate in 2011, and an unknown number of participants will be excluded because of having cardiovascular disease or diabetes, we decided to invite 6000 panel members for the first questionnaire.

\section{Statistical analysis}

Knowledge will be treated as primary outcome measure, whereas intention, attitude, ambivalence and psychosocial variables are the secondary outcome measures. To 
compare knowledge levels and level of ambivalence between the intervention and control group, we will use linear regression analysis. The effect of the decision aid on the psychosocial factors that predict self-test use will be assessed using logistic regression analysis. Follow-up behaviour after three months will be compared using logistic regression analysis.

Based on the method proposed by Marteau and colleagues, informed choice will be measured by combining the constructs knowledge, attitudes and behaviour into a composite measure of informed decision making. ${ }^{26}$ Informed choice in our study will be defined as having sufficient knowledge, and attitude being in line with intention (positive attitude and a positive intention to do a self-test, or a negative attitude and a negative intention to self-test). As a cut off point for having sufficient knowledge, a score of $50 \%$ (number of correct answered questions 10 or above) will be considered. Individual scores will be corrected for guessing using Abbotts' formula. ${ }^{31,32}$ A positive intention towards self-testing is defined as a participant indicating to maybe, probably or definitely consider performing a self-test in the future. To classify participants as having a positive or negative attitude towards self-testing, the median score will be used. The median score of the participants and scores above will indicate a positive attitude, whereas scores below the median score will be considered as a negative attitude. $^{26}$ The percentage of people with an informed choice in the control and intervention group will be compared using logistic regression analysis.

\section{Discussion}

This paper describes the protocol for a randomised controlled trial to evaluate the effect of an online decision aid for self-testing on diabetes and cholesterol. Since selftesting on these conditions can be beneficial but can have negative implications as well, the goal of the decision aid 'zelftestwijzer' was not to increase or decrease uptake of these tests, but to enhance knowledge levels and to guide the decision making process. Self-test uptake in the past often seemed to be associated with offering of free tests and media campaigns stressing the importance of testing, and consumers responding quite straightforward, being curious about testing and wanting to be reassured on their health status. ${ }^{9}$ Although these strategies seemed to increase uptake levels, consumers will often not have considered important pitfalls of self-testing. ${ }^{3}$ Also, consumers with an intention to self-testing experience several barriers to selftesting, especially a lack of knowledge about interpreting the results.(Grispen et al.: An intention to self-testing: a qualitative study regarding consumers' considerations and information needs about self-testing, submitted) For this reason, the primary outcome of this study is knowledge about self-testing. We expect knowledge levels of participants who have viewed the decision aid to increase. Being aware of the pitfalls 
of self-testing, but also of the positive effects of self-testing, consumers should be enabled to make a choice regarding self-testing they think is the best choice for them. We expect levels of informed choice to increase, and levels of ambivalence to decrease. We will measure actual uptake of self-tests 3 months after viewing the decision aid, to assess if there are changes in uptake of tests between the intervention and the control group.

\section{Strengths and limitations}

The online decision aid has been developed in a thorough, iterative process, and is considered to be a sound and user-friendly provider of information on self-testing. By using an Internet panel, the online decision aid can be tested among a large group of individuals with an intention towards self-testing. The use of individual weblog files will provide the opportunity to assess how long each participant has viewed the decision aid, and which pages of the decision aid they have visited.

Most decision aid evaluation studies compare the decision aid to usual care, or to simpler versions of the decision aid. Since there is no usual care in self-testing, we decided to provide the control group with a control intervention that consists of only general information on self-testing, without any specific information on diabetes and cholesterol. This minimal information is the same information as was already provided in the instruction section of the baseline questionnaire, so this is the maximum contrast in information provided between intervention and control group possible. The fact that the participants were blind for the trial conditions is a strength, minimising the Hawthorne effect.

The measure of informed choice often includes actual behaviour instead of intention. In our study, measuring behaviour (uptake of tests after seeing the information) would ask for selecting consumers who are at the point of purchasing a self-test. Since selftests are provided in several websites and shops, it would be almost impossible to gather a group of consumers large enough for a trial. Besides these practical reasons, the fact that we invited consumers who are still considering doing a test, instead of being in a shop, at the point of purchasing the test, gives consumers more time to read information on self-testing and thoroughly consider the pros and cons of these tests. Therefore, we chose to invite consumers with a positive intention towards self-testing to view the decision aid, although we know these people are not actually faced with a decision that needs to be made.

Inviting consumers who are not faced with an actual decision that needs to be made can affect the generalisability of our data. Participants in our trial might read other information on the decision aid than consumers who are close to buying a self-test. On the other hand, participants are encouraged to read the complete decision aid, and know they will receive an incentive if they have viewed the decision aid and have filled 
out questions in the questionnaire provided afterwards. The actual use of the decision aid will also be affected by its usability and attractiveness to visitors. Although the decision aid was developed using usability tests to assess user friendliness of the decision aid, the results of the process evaluation such as information on message acceptance and weblog files, will be of use for optimising and implementing the decision aid after the trial. 


\section{References}

1. Ryan A, Wilson S, Greenfield S, Clifford S, McManus RJ, Pattison HM. Range of self-tests available to buy in the United Kingdom: an Internet survey. J Public Health (Oxf). 2006;28:370-4.

2. CVZ-rapport. Diagnostische zelftests op lichaamsmateriaal. Aanbod, validiteit en gebruik door de consument [Diagnostic self-tests on bodymaterial. Supply, validity, and use by the consumer]. 2007.

3. Ickenroth MH, Ronda G, Grispen JE, Dinant GJ, de Vries NK, van der Weijden T. How do people respond to self-test results? A cross-sectional survey. BMC Fam Pract. 2010;11:77.

4. Pavlin NL, Gunn JM, Parker R, Fairley CK, Hocking J. Implementing chlamydia screening: what do women think? A systematic review of the literature. BMC Public Health. 2006;6:221.

5. Ryan A, Greenfield S, McManus R, Wilson S. Self-care--has DIY gone too far? Br J Gen Pract. 2006; 56:907-8.

6. Nielen MM, Schellevis FG, Verheij RA. The usefulness of a free self-test for screening albuminuria in the general population: a cross-sectional survey. BMC Public Health. 2009;9:381.

7. Campbell S, Klein R. Home testing to detect human immunodeficiency virus: boon or bane? J Clin Microbiol. 2006;44:3473-6.

8. Ryan A, Ives J, Wilson S, Greenfield S. Why members of the public self-test: an interview study. Family Practice 2010.

9. Ickenroth MH, Grispen JE, Ronda G, Tacken M, Dinant GJ, de Vries NK, van der Weijden T: Motivation and experiences of self-testers regarding tests for cardiovascular risk factors. Health Expect. 2011.

10. Van Harreveld F, Van der Pligt J, De Liver YN. The agony of ambivalence and ways to resolve it: Introducing the MAID model. Personality and Social Psychology Review. 2009;13:45-61.

11. O'Connor AM, Bennett CL, Stacey D, Barry M, Col NF, Eden KB, Entwistle VA, Fiset V, Holmes-Rovner $M$, Khangura $S$ et al. Decision aids for people facing health treatment or screening decisions. Cochrane database of systematic reviews (Online) 2009(3):CD001431.

12. Ronda G, Portegijs P, Dinant GJ, Buntinx F, Norg R, Van der Weijden T. Use of diagnostic self-tests on body materials among Internet users in the Netherlands: prevalence and correlates of use. BMC Public Health. 2009;9:100.

13. Grispen JE, Ronda G, Dinant GJ, de Vries NK, van der Weijden T. To test or not to test: a cross-sectional survey of the psychosocial determinants of self-testing for cholesterol, glucose, and HIV. BMC Public Health. 2011;11:112.

14. Elwyn G, O'Connor A, Stacey D, Volk R, Edwards A, Coulter A, Thomson R, Barratt A, Barry M, Bernstein $S$ et al. Developing a quality criteria framework for patient decision aids: online international Delphi consensus process. BMJ (Clinical Research ed. 2006;333:417.

15. Elwyn G, O'Connor AM, Bennett C, Newcombe RG, Politi M, Durand MA, Drake E, Joseph-Williams N, Khangura S, Saarimaki $A$ et al. Assessing the quality of decision support technologies using the International Patient Decision Aid Standards instrument (IPDASi). PloS One. 2009;4:e4705.

16. Janz NK CV, Strecher VJ. The Health Belief Model. In Health behavior and health education: Theory, research, and practice 3 ed Edited by Glanz K RB, Lewis FM. San Francisco: Jossey-Bass. 2002:45-66.

17. Ajzen I. The theory of planned behavior. Organizational Behavior and Human Decision Pocesses. 1991; 50:179-211.

18. Armitage CJ, Conner M. Efficacy of the Theory of Planned Behaviour: A meta-analytic review. Br J Soc Psychol. 2001;40:471-99.

19. Conner M, Armitage CJ. Extending the theory of planned behavior: A review and avenues for further research. J Appl Soc Psychol. 1998;28:1429-64.

20. Kok G, de Vries H, Mudde AN, Strecher VJ. Planned health education and the role of self-efficacy: Dutch research. Health Educ Res. 1991;6:231-8.

21. Sheeran P, Orbell S. Augmenting the Theory of Planned Behavior: Roles for Anticipated Regret and Descriptive Norms 1. J Appl Soc Psychol. 1999;29:2107-42.

22. Strecher VJ, DeVellis ME. The role of self-efficacy in achieving health behavior change. Health Educ Behav. 1986;13:73-92.

23. Kaplan KJ. On the ambivalence-indifference problem in attitude theory and measurement: a suggested modification of the semantoc differential technique. Psychological Bulletin. 1972;77:361-72. 
24. Priester JR, Petty RE. The Gradual Treshold Model of ambivalence: Relating the positive and negative bases of attitudes to subjective ambivalence. Journal of Personality and Social Psychology. 1996; 71:431-49.

25. Jonas K, Broemer P, Diehl M. Attitudinal ambivalence. European Review of Social Psychology. 2011; 11:35-74.

26. Marteau TM, Dormandy E, Michie S. A measure of informed choice. Health Expect. 2001;4:99-108.

27. Dijkstra A, Roijackers J, De Vries H. Smokers in four stages of readiness to change. Addictive Behaviors. 1998;23:339-50.

28. Lipkus IM, Kuchibhatla M, McBride CM, Bosworth HB, Pollak KI, Siegler IC, Rimer BK. Relationships among breast cancer perceived absolute risk, comparative risk, and worries. Cancer Epidemiol Biomarkers Prev. 2000;9:973-5.

29. Van 't Riet J, Ruiter RAC, Werrij MQ, Candel MJJM, de Vries H. Distinct pathways to persuasion: the role of affect in message-framing effects. Eur J Soc Psychol. 2010;40:1261-76.

30. Lipsey ML. Design sensitivity. Statistical power for experimental research. Newbury Park, California: SAGE Publications. 1990.

31. Nunnally JC, Bernstein IH. Psychometric theory. third edition. New York: McGraw-Hill. 1994.

32. van den Berg $M$, Timmermans $D R$, Ten Kate $L P$, van Vugt JM, van der Wal G. Are pregnant women making informed choices about prenatal screening? Genet Med. 2005;7:332-8. 


\section{CHAPTER 8}

Effects of a web-based decision aid on knowledge and informed choice regarding diagnostic self-testing for cholesterol and diabetes. A single-blind randomised controlled trial

Martine Ickenroth, Janaica Grispen, Nanne de Vries, Geert-Jan Dinant, Gaby Ronda, Trudy van der Weijden Submitted for publication 


\section{Abstract}

\section{Objectives}

To assess the effect of a decision aid on diagnostic self-testing for cholesterol or diabetes among consumers with an intention to take these tests.

\section{Design}

A single-blind randomised controlled trial.

\section{Participants}

1259 consumers with an intention to use a diagnostic cholesterol or diabetes self-test were selected from an existing Dutch Internet panel. They were excluded if they had already been diagnosed with diabetes or cardiovascular disease, or if they were younger than 18 years of age. Based on these criteria, 122 participants were excluded. Response rate in the cholesterol arm was $76.4 \%(217 / 284)$ in the intervention group versus $84.5 \%(240 / 284)$ in the control group $(p=0.020)$. Corresponding numbers in the diabetes arm were $78.6 \%(224 / 285)$ and $84.9 \%$ (241/284) respectively (ns). Participants were blinded for randomisation.

\section{Intervention}

An online decision aid offering general information on self-testing and test-specific information on cholesterol and diabetes self-testing, including indications for testing, how to perform the test and interpreting the result. The placebo condition consisted of a limited information sheet.

\section{Main outcome measures}

Knowledge and informed choice.

\section{Results}

Multiple regression analysis showed that the knowledge level in the diabetes arm was higher in the intervention group than in the control group (B 0.657; 95\%Confidence Interval, 0.011 to 1.303), as was the number of participants with an informed choice (OR 1.672; $95 \% \mathrm{Cl}, 1.134$ to 2.465). No differences were found in the cholesterol arm.

\section{Discussion}

The decision aid led to improvements in knowledge and informed choice in the diabetes intervention group compared to the control group, but did not have any effects in the cholesterol intervention group. The decision aid should be further tested among consumers who are actually about to purchase a test. Consumers who are considering doing a diabetes self-test should have access to independent information on self-testing and be encouraged to read this information, since this leads to more knowledge and informed choice. 


\section{Background}

Diagnostic self-tests, tests on body materials such as blood tests to measure one's glucose level, or tests on urine to detect urinary tract infections, are currently directly available to consumers. Chemists and Internet sites offer home tests, i.e. tests that can be completely performed at home, without any professional counselling, producing a direct result. Other modes of self-testing are streetcorner tests, in which a test is offered in a public place such as a supermarket, or direct-access or home-collect tests, in which a laboratory is directly accessible to consumers. ${ }^{1}$ These self-tests on body materials are available for over 24 conditions, including cancer, chronic conditions and infections. ${ }^{2}$ Dutch research has shown that $18 \%$ of the respondents in an online questionnaire had ever performed a diagnostic self-test. ${ }^{3}$

Cholesterol and diabetes self-tests are two of the most commonly used diagnostic selftests in the Netherlands. ${ }^{3}$ These tests fit in with our current views on patient autonomy, and might be part of preventive strategies, such as early disease detection. Consumers have indicated that they perform these tests out of curiosity, because they are looking for reassurance, or because they do not want to consult a doctor when they do not have any complaints. ${ }^{4,5}$ On the other hand, negative side effects should not be ignored. Previous research showed that the information provided with self-tests explains how to perform the test and how to interpret the result, but often lacks information and warnings about possible false-negative or false-positive results. ${ }^{6}$ Moreover, interpreting the results, especially when assessing cardiovascular risk, is not merely a question of being ill or not, and can be a challenging task.

Since diagnostic self-testing does have advantages as well as disadvantages, it is important that consumers who are considering taking these tests have sufficient knowledge about how to perform and interpret the test, and are also aware of the pros and cons of self-testing. To support consumers in their decision whether they want to do a self-test or not, we developed a web-based decision aid on self-testing for diabetes and cholesterol (http://www.zelftestwijzer.nl). ${ }^{7}$ Patient decision aids (DAs) have been developed to support patients when facing a decision about screening or treatment, and have been shown to improve patients' knowledge about treatment options and to reduce decisional conflict. ${ }^{8}$ DAs aim to help patients recognise the value-sensitive nature of the decision and help to clarify the value they place on the benefits, harms and scientific uncertainties.

The web-based DA we developed provides information on self-testing in general, as well as specific information on self-tests for diabetes and cholesterol. It offers instructions on the way to perform the test, as well as indications for performing a test, risk factors for diabetes and cardiovascular disease, and the interpretation of the 
result. Visitors of the website can use a value clarification tool to weigh the pros and cons of self-testing.

We hypothesised that the decision aid would increase knowledge about self-testing, and support consumers in making a decision that represents the best choice for them personally. Doing a self-test or not doing it can both be suitable options, as long as the choice is congruent with the consumer's attitude towards self-testing, and the consumer has sufficient knowledge about self-testing.

The aim of our study was to investigate the effect of the decision aid on knowledge about self-testing and on informed choice. ${ }^{7}$ We addressed the following research questions, for the diabetes and cholesterol tests separately: 1. Do consumers who have been exposed to the decision aid have more knowledge about self-testing than the control group? 2. Are consumers who have been exposed to the decision aid more likely to make an informed choice in self-testing than consumers in the control group? 3. Are there differences in follow-up behaviour between consumers who have been exposed to the decision aid and those in the control group?

\section{Methods}

\section{Design}

A single-blind randomised controlled trial was designed. ${ }^{7}$ The entire trial was conducted online, and participants were selected from an existing Internet panel. Two groups were distinguished: participants with an intention to do a diagnostic diabetes self-test and those with an intention to do a diagnostic cholesterol self-test. Both groups were randomly assigned to either visiting the web-based decision aid or a control condition involving short, non-interactive and non-test specific information on self-testing. Analysis was performed separately for both groups (diabetes and cholesterol). This trial has been registered in the Dutch Trial Register: NTR 3149.

\section{Ethical approval}

The study was reviewed by the Medical Ethics Committee of Maastricht University Medical Centre. They had no objection to the study procedure, and since the study evaluates usual care and no patient recruitment was required, formal approval was not deemed necessary.

\section{Participants}

Participants were recruited from an existing Internet panel in the Netherlands, managed by Flycatcher, an ISO-certified institute for online research associated with Maastricht University. The entire panel consists of approximately 14,000 active 
members. All individuals who have an email address and are aged 12 years or older can apply for the panel. Compared with the Dutch population, the panellists are younger, have a higher level of education and are more often female. The panel as a whole is representative of Dutch people who have access to the Internet.

\section{Inclusion and exclusion criteria}

A random sample of the Flycatcher panel was sent a questionnaire on their previous use of self-tests and their intention to use a diagnostic cholesterol or diagnostic diabetes self-test in the future (questionnaire 1). Panellists aged 18 years or older and indicating an intention to use a cholesterol or diabetes self-test were invited for participation in the trial. Panellists who reported that they had already been diagnosed with cardiovascular disease or diabetes were excluded from the study.

\section{Intervention and control conditions}

The web-based decision aid www.zelftestwijzer.nl was based on results of previous quantitative and qualitative studies ${ }^{1,3,4,9}$, as well as on the Health Belief Model ${ }^{10}$ and the International Patient Decision Aid Standards (IPDAS) criteria ${ }^{11,12}$. The medical contents were based on current clinical practice guidelines on screening for diabetes and cardiovascular disease. The website was analysed and further developed by performing usability tests involving experts as well as end users. A placebo control condition was designed consisting of a single pdf document containing general information on self-testing.

\section{Randomisation}

Participants were first assigned to two groups (diabetes or cholesterol self-test, based on the intention they expressed in the initial questionnaire). Within each group, randomisation to the experimental and control condition (and invitation to either view the decision aid or the control condition) was performed by Flycatcher using SPSS. Participants were blinded for randomisation.

\section{Measures}

Immediately after participants had viewed either the decision aid or the control condition, they received an online questionnaire (questionnaire 2) for the following measurements:

\section{Knowledge}

The knowledge questionnaire consisted of 20 true / false / don't know statements, based on the themes addressed in the decision aid. It included questions on the disease, risk factors, how to perform the self-test, how to interpret the test result, and 
questions on the validity of the self-test. The knowledge questions were test-specific (i.e. relating to cholesterol or diabetes). Correct answers were given one point, one point was subtracted for each incorrect answer. This method corrects scores obtained by guessing (Abbotts' formula ${ }^{13,14}$ ). The knowledge score was considered sufficient if the participant scored 10 points or more. The knowledge questionnaires have been published as online additional files with our protocol article (http://www. biomedcentral.com/1471-2458/12/6/additional). ${ }^{7}$ One question was removed from each of the questionnaires, since these questions were answered correctly by all participants in a pre-test.

\section{Intention}

Intention to take a test was assessed using a single question on a 5-point Likert scale ('definitely not', 'probably not', 'maybe', 'probably will' or 'definitely will'). Intention ranging from 'maybe' to 'definitely will' was regarded as a positive intention.

\section{Attitude}

Attitude towards doing a cholesterol or diabetes self-test was measured using a 4-item scale, asking the following questions: I think a self-test is 'harmful -beneficial', 'unimportant-important', 'bad thing-good thing', 'unpleasant-pleasant', on a 7-point Likert scale. ${ }^{15}$ Scores could range from 4 to 28 , with higher scores indicating a more positive attitude. The median score of the participants was used as a cut-off value to determine whether an individual participant had a positive (median score or above) or negative attitude towards self-testing. ${ }^{15}$

\section{Informed choice}

Informed choice was measured by combining the constructs of knowledge, attitude and intention into a composite measure of informed decision making. ${ }^{15,16}$ In order to have an informed choice, a participant should have sufficient knowledge, and their attitude must be in line with their intention, e.g. a positive attitude and a positive intention to self-test, or a negative attitude combined with a negative intention to selftest.

\section{Follow-up behaviour}

Participants were sent a third questionnaire three months after the second questionnaire, asking whether they had performed a self-test, their follow-up behaviour after performing the test and their current intention towards self-testing. ${ }^{7}$

\section{Process evaluation}

Time spent on the website was measured by recording the time between the moment the participants clicked on the link to the decision aid and the moment they closed the website. Information acceptance was measured using an 8-item questionnaire (for 
example 'I think the information is not at all convincing-very convincing' or 'I think this information is not at all relevant-very relevant'), using a 5-point Likert scale. ${ }^{17} \mathrm{~A}$ mean score was computed, with higher scores indicating a higher degree of acceptance of the information. Participants were also asked to rate their perception of the overall quality of the website on a scale from zero to ten. ${ }^{7}$

\section{Sample size and statistical analysis}

Knowledge was treated as the primary outcome measure. Based on a review of the effect of decision aids, we expected an absolute knowledge difference of $15 \%$ between the intervention and control groups. ${ }^{8}$ Our sample size was based on a power of $80 \%$ at a significance level of 5\% (two-sided). Power analysis showed that 175 respondents would be needed in each group. ${ }^{18}$ Based on response rates and levels of intention in previous research, we calculated that 3472 respondents would have to be invited for the first selecting questionnaire. ${ }^{7}$ Since these numbers were based on responses to surveys without an experimental condition, we expected to have additional drop-outs and decided to invite 6000 panellists to ensure the minimum number of 175 respondents in each group. All participants who fully completed the second questionnaire were included in the analysis.

Basic descriptive statistics were used to describe the respondents' characteristics and their follow-up behaviour, and t-tests and chi square tests were applied to describe differences between the intervention and control groups. Knowledge and informed choice were compared between the intervention and control groups by first performing a bivariate analysis. This was followed by multiple regression analysis, with knowledge and informed choice as outcome variables and condition (intervention=1, and control=0) as the main independent variable. Gender (male=1, female=0), educational level, age, and the interaction terms of these variables with condition were also included as independent variables in the analysis. All variables were first included in the model, after which non-significant interaction terms were excluded, starting with the least significant interaction term. If significant interactions were found, subgroup analyses were performed. Differences were considered to be statistically significant if $p<0.05$. Analyses were performed with SPSS (Version 19).

\section{Results}

Response to questionnaire 1 was $63 \%(n=3800)$. Of these respondents, 1259 (33.1\%) indicated having an intention to do a cholesterol or diabetes diagnostic self-test, 320 of whom were only interested in doing a diabetes self-test, 453 only in doing a cholesterol self-test, and 486 had an intention to do both tests (Figure 8.1). After 
exclusion of participants under 18 years of age and participants already diagnosed with diabetes or cardiovascular disease, 1137 participants were eligible for the trial. They were assigned to the diabetes or cholesterol group. If participants had an intention to perform both tests, they were assigned to the test for which they expressed the strongest intention. If intention was equal, we randomly assigned them to one of the groups, with the aim of creating equally sized groups. Since the group of people with an intention to do a diabetes self-test was smaller, more panellists with a double intention were randomised to the diabetes arm.

\section{Response and participants' characteristics}

Response in the cholesterol intervention group to questionnaire 2 (immediately after being exposed to the decision aid) was lower than in the control group (control 84.5\%, intervention 76.4\%, $p=0.020$ ). A similar trend was seen in the diabetes arm, though not statistically significant $(p=0.065)$. Participants' characteristics are shown in Table 8.1. There were no significant differences in gender, age or educational level between the intervention and control conditions. Response to questionnaire 3 (three months follow-up) and socio-demographic characteristics did not differ significantly between the intervention and control groups.

\section{Knowledge}

Knowledge scores in the diabetes arm ranged from -3 to 19 (mean 10.16, SD 3.65). Results of the bivariate analysis showed that participants who had been exposed to the decision aid attained higher knowledge levels than the control group, with a mean absolute knowledge score of 10.5 (SD 3.56) versus 9.81 (SD 3.71)( $p=0.031$ ), and a percentage with sufficient knowledge of $67.0 \%$ versus $53.5 \%$, ( $p=0.003$ ) (Table 8.2 ). In the cholesterol arm, scores ranged from -4 to 18 (mean 8.50, SD 4.16), with no significant difference between the intervention and control groups. Further analysis showed that a significant difference in knowledge level in the diabetes arm was found for the items on information about the disease and risk factors for diabetes, but not for the items more specifically addressing self-testing (performing the self-test, interpretation of the test results and test reliability). (Table 8.3)

Linear regression analysis showed that in the diabetes arm, intervention condition was a significant predictor of knowledge $(\mathrm{B}=0.657 ; 95 \% \mathrm{Cl}, 0.011$ to 1.303$)$, as were gender $(\mathrm{B}=-1.114 ; 95 \% \mathrm{Cl},-1.792$ to -0.437 ) and educational level (low versus high, $\mathrm{B}=-2.282$; $95 \% \mathrm{Cl},-3.169$ to -1.396$)$. The only significant determinant of knowledge in the cholesterol group was educational level. (Table 8.4) 


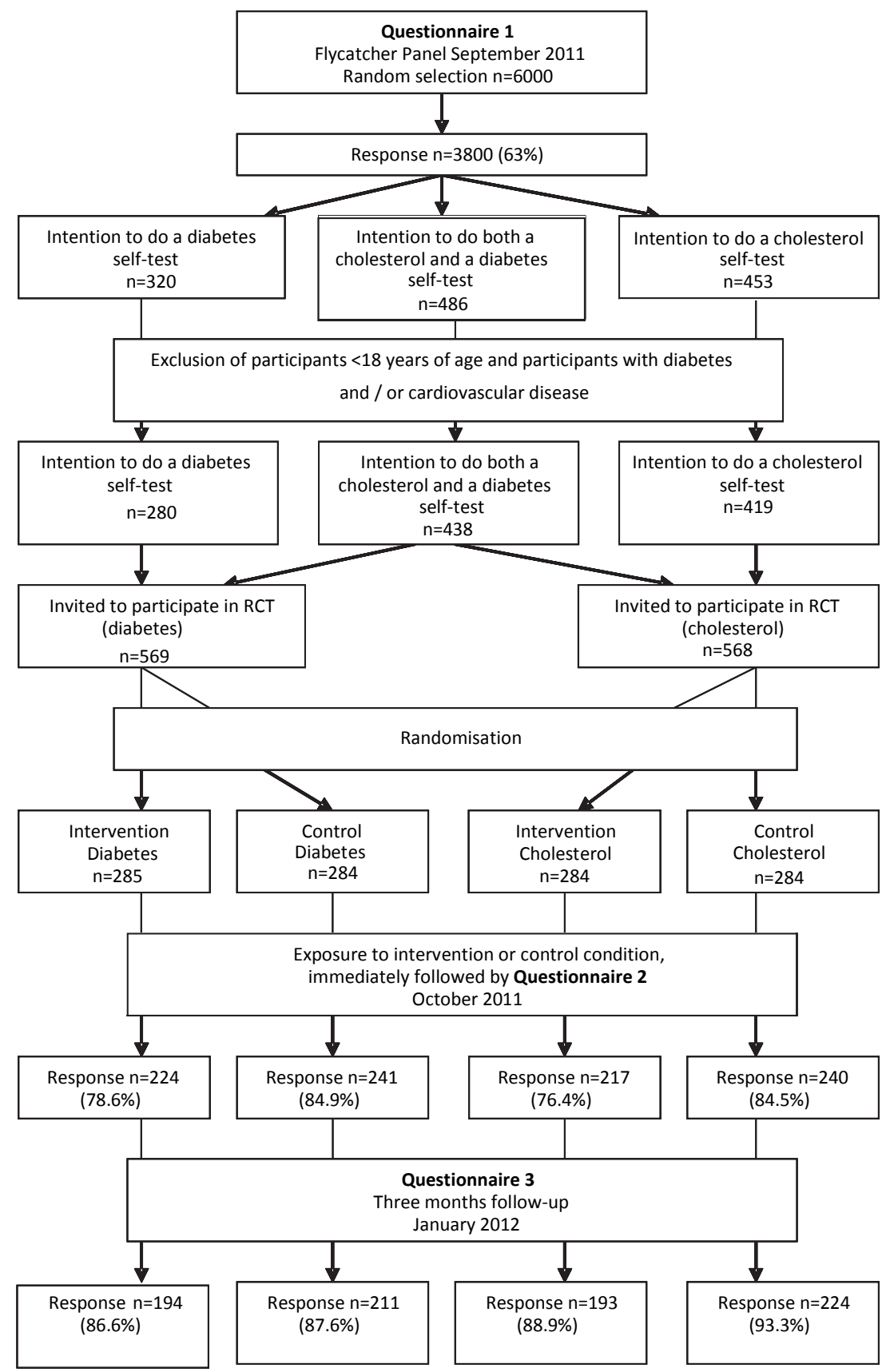

Figure 8.1 Selection, randomisation and response. 


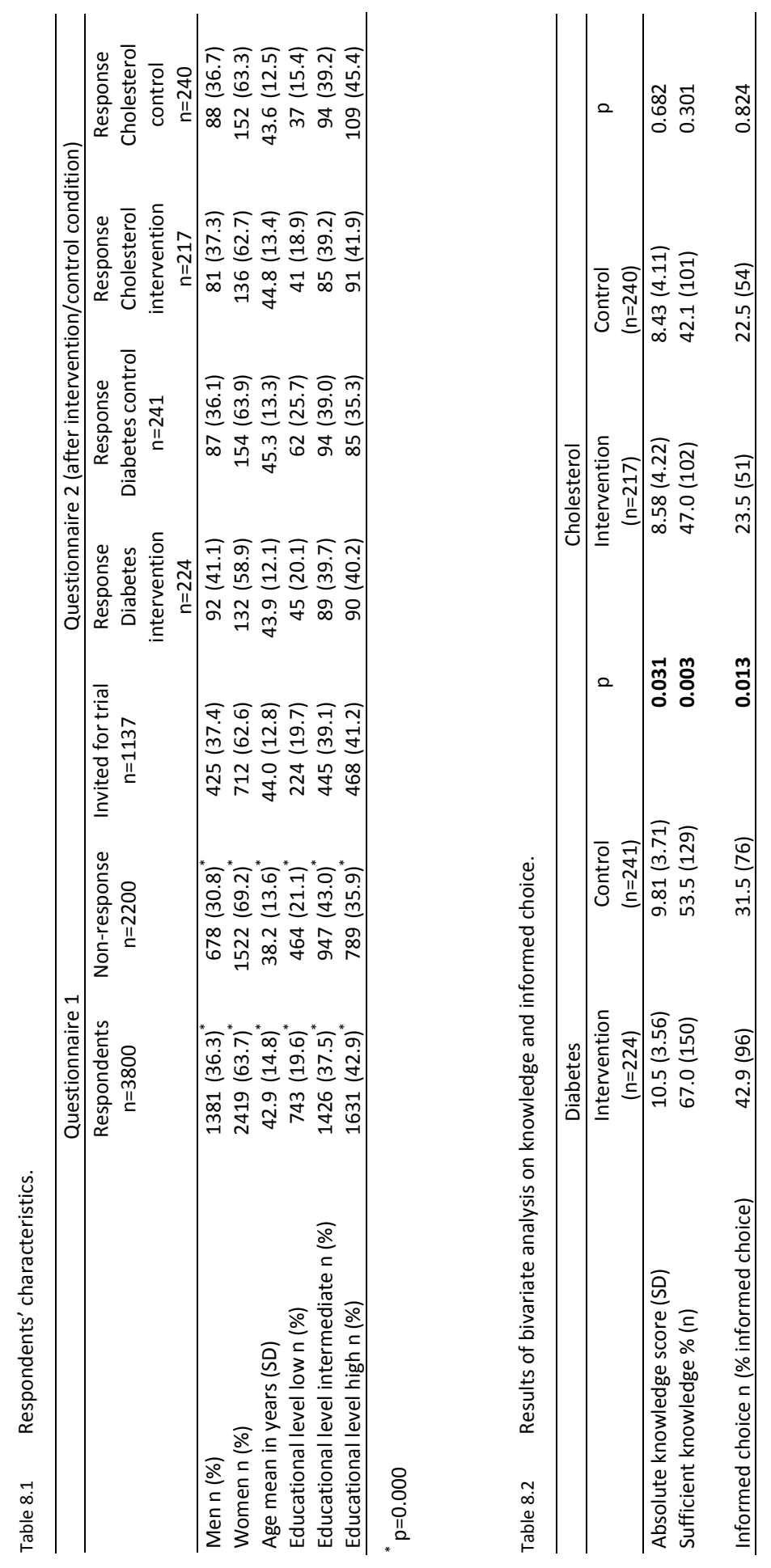


Table $8.3 \quad$ Knowledge scores per item.

\begin{tabular}{|c|c|c|c|c|c|c|}
\hline Test item & $\begin{array}{l}\text { Number } \\
\text { of items }\end{array}$ & $\begin{array}{c}\text { Absolute score } \\
\text { Intervention } \\
\text { Group }\end{array}$ & $\begin{array}{c}\text { \% score } \\
\text { Intervention } \\
\text { Group }\end{array}$ & $\begin{array}{c}\text { Absolute } \\
\text { score Control } \\
\text { group }\end{array}$ & $\begin{array}{l}\text { \% score } \\
\text { Control } \\
\text { Group }\end{array}$ & $p$ \\
\hline \multicolumn{7}{|l|}{ Diabetes } \\
\hline 1. Disease & 4 & 2.84 & 71.0 & 2.60 & 64.9 & 0.040 \\
\hline 2. Risk factors & 3 & 2.34 & 78.0 & 2.12 & 70.5 & 0.019 \\
\hline $\begin{array}{l}\text { 3. Performing the } \\
\text { self-test }\end{array}$ & 4 & 1.95 & 48.8 & 1.74 & 43.5 & 0.087 \\
\hline $\begin{array}{l}\text { 4. Interpretation of } \\
\text { the test result }\end{array}$ & 3 & 1.29 & 43.0 & 1.27 & 42.3 & 0.846 \\
\hline 5. Test reliability & 6 & 2.12 & 35.3 & 2.09 & 34.8 & 0.842 \\
\hline \multicolumn{7}{|l|}{ Cholesterol } \\
\hline 1. Disease & 4 & 1.63 & 40.7 & 1.76 & 44.0 & 0.334 \\
\hline 2. Risk factors & 2 & 0.93 & 46.5 & 0.86 & 42.9 & 0.465 \\
\hline $\begin{array}{l}\text { 3. Performing the } \\
\text { self-test }\end{array}$ & 3 & 0.80 & 26.7 & 0.70 & 23.2 & 0.306 \\
\hline $\begin{array}{l}\text { 4. Interpretation of } \\
\text { the test result }\end{array}$ & 5 & 3.12 & 62.5 & 3.11 & 62.2 & 0.910 \\
\hline 5. Test reliability & 6 & 2.10 & 34.9 & 2.00 & 33.3 & 0.579 \\
\hline
\end{tabular}

Table 8.4 Results of multiple regression analysis on knowledge and informed choice.

\begin{tabular}{|c|c|c|c|}
\hline \multicolumn{4}{|l|}{ Linear regression analysis } \\
\hline Knowledge (diabetes) & $B^{6}(95 \%$ Confidence Interval) & Beta & $\mathrm{p}$ \\
\hline${\text { Intervention/ } \text { control }^{1}}^{1}$ & $.657(.011$ to 1.303$)$ & .090 & 0.046 \\
\hline Gender $^{2}$ & $-1.114(-1.792$ to -.437$)$ & -.149 & 0.001 \\
\hline Educational level low versus high ${ }^{3}$ & $-2.282(-3.169$ to -1.396$)$ & -.263 & 0.000 \\
\hline Educational level intermediate versus high ${ }^{4}$ & $-.589(-1.323$ to .146$)$ & -.079 & 0.116 \\
\hline Age & $-.004(-.030$ to .022$)$ & -.012 & 0.788 \\
\hline Knowledge (cholesterol) & $B^{6}(95 \%$ Confidence Interval) & & \\
\hline 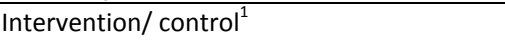 & $.254(-.499$ to 1.007$)$ & .031 & 0.508 \\
\hline Gender $^{2}$ & $-.194(-.992$ to .6040 & -.023 & 0.633 \\
\hline Educational level low versus high ${ }^{3}$ & $-2.273(-3.382$ to -1.165$)$ & -.206 & 0.000 \\
\hline Educational level intermediate versus high ${ }^{4}$ & $-1.181(-2.015$ to -.348$)$ & -.139 & 0.000 \\
\hline Age & $-.012(-.043$ to .018$)$ & -.038 & 0.438 \\
\hline \multicolumn{4}{|l|}{ Logistic regression analysis } \\
\hline Informed choice (diabetes) & $\mathrm{OR}^{7}$ (95\% Confidence Interval) & & \\
\hline 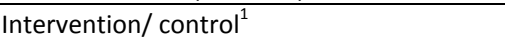 & 1.672 (1.134 to 2.465$)$ & & \\
\hline Gender $^{2}$ & $.450(.296$ to .685$)$ & & \\
\hline Educational level low versus high ${ }^{3}$ & $.628(.366$ to 1.078$)$ & & \\
\hline Educational level intermediate versus high ${ }^{4}$ & $.887(.572$ to 1.347$)$ & & \\
\hline Age & $.996(.981$ to 1.012$)$ & & \\
\hline Informed choice (cholesterol) ${ }^{5}$ & $\mathrm{OR}^{7}$ (95\% Confidence Interval) & & \\
\hline 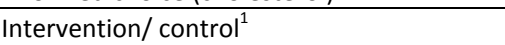 & $1.063(.685$ to 1.648$)$ & & \\
\hline Gender $^{2}$ & .984 (.620 to 1.564$)$ & & \\
\hline Educational level low versus high ${ }^{3}$ & $.722(.379$ to 1.376$)$ & & \\
\hline Educational level intermediate versus high ${ }^{4}$ & .667 (.409 to 1.088$)$ & & \\
\hline Age & $1.007(.989$ to 1.025$)$ & & \\
\hline
\end{tabular}

${ }^{1}$ Intervention group $=1$, control group $=0 ;{ }^{2}$ Male=1, Female $=0 ;{ }^{3}$ Low educational level=1, high educational level $=0 ;{ }^{4}$ Intermediate educational level $=1$, high educational level $=0 ;{ }^{5}$ Model without interaction effects; ${ }^{6} \mathrm{~B}$ : regression coefficient; ${ }^{7}$ OR: Odds Ratio. 


\section{Informed choice}

In the diabetes intervention group, $42.9 \%$ of the participants had an informed choice concerning diabetes self-testing, compared to $31.5 \%(p=0.013)$ in the control group. In the cholesterol arm, there was no difference between the intervention and control group (23.5\% versus $22.5 \%$; $\mathrm{p}=0.824$ ). (Table 8.2 )

Our multiple logistic regression analysis showed that in the diabetes arm, intervention (OR 1.672; $95 \% \mathrm{Cl}, 1.134$ to 2.465 ) and gender (OR $0.450 ; 95 \% \mathrm{Cl}, 0.296$ to 0.685 ) were independent determinants of having an informed choice (Table 8.4) Analysis of the data in the cholesterol group showed significant interaction effects of group with educational level and of group with age. Subgroup analysis revealed that older (>43 years) respondents with a high educational level in the cholesterol intervention group were more likely to reach an informed choice than older ( $>43$ years) respondents with a high educational level in the control group, but this difference was not statistically significant (OR 2.374; $\mathrm{p}=0.058$ ).

\section{Follow-up behaviour after three months}

At three months follow-up, 32 participants in the diabetes arm had performed a diabetes self-test during the past three months (intervention group 12 (6.2\%) and control group 20 (9.5\%), while 9 participants in the cholesterol arm had performed a cholesterol self-test $(5[1.0 \%]$ in the intervention group and 4 [1.8\%] in the control group)(Table 8.5 ). Thirty-six participants had visited a doctor. Since the number of participants who had actually performed a self-test or had visited a doctor was low, we decided not to perform further statistical analysis on these numbers.

Intention to perform a diagnostic cholesterol or diabetes self-test remained high. In the diabetes control group, $97.2 \%$ of the respondents had a positive intention at three months, versus $93.3 \%$ in the intervention group, with a mean intention score of 3.68 versus 3.61. In the cholesterol arm, these numbers were $93.3 \%$ and $93.8 \%$ for the control and intervention groups, respectively, and a mean intention score of 3.51 was found in the intervention group versus 3.54 in the control group. (Table 8.5)

\section{Process evaluation}

\section{Time spent on website}

In the diabetes intervention group, time spent on the decision aid ranged from 7 to 14,531 seconds. We excluded one participant from the process analysis based on the excessive time this respondent spent on the website (14,531 seconds). After excluding this participant, the mean time spent on the website was 169 seconds (range 7- 2989 seconds, SD 284). We performed multiple regression analysis within the intervention group to determine whether time was a significant contributor to knowledge or 
informed choice (independent variables: time spent on website, gender, age and educational level), but this showed no significant effect of time. The same was found in the cholesterol group: no significant contribution of the time spent on the website. Time spent on the website in this group ranged from 12 to 2352 seconds (mean $194 \mathrm{~s}$, SD 315). The difference between the cholesterol and diabetes arms in the time spent on the website was not statistically significant $(p=0.377)$.

\section{Information acceptance}

The mean score on information acceptance was 3.71 in the cholesterol intervention group (SD 0.034) and 3.67 in the diabetes intervention group (SD 0.037) $(p=0.390)$. The average rating for the website was 7.08 in the cholesterol group and 7.04 in the diabetes group $(p=0.753)$.

Table $8.5 \quad$ Follow-up at 3 months.

\begin{tabular}{lcccc}
\hline & $\begin{array}{c}\text { Diabetes } \\
\text { intervention } \\
\mathrm{n}=194\end{array}$ & $\begin{array}{c}\text { Diabetes control } \\
\mathrm{n}=211\end{array}$ & $\begin{array}{c}\text { Cholesterol } \\
\text { intervention } \\
\mathrm{n}=193\end{array}$ & $\begin{array}{c}\text { Cholesterol } \\
\text { control } \\
\mathrm{n}=224\end{array}$ \\
\hline Performed self-test & $12(6.2)$ & $20(9.5)$ & $2(1.0)$ & $4(1.8)$ \\
- Diabetes (\%) & $4(2.0)$ & $2(0.9)$ & $5(2.6)$ & $4(1.8)$ \\
- Cholesterol (\%) & $6(3.1)$ & $7(3.3)$ & $8(4.1)$ & $5(2.2)$ \\
- Other self-test & $13(6.7)$ & $5(2.4)$ & $8(4.1)$ & $10(4.5)$ \\
Visited doctor (\%) & $7(3.6)$ & $5(2.4)$ & $5(2.6)$ & $8(3.6)$ \\
Other health professional (\%) & & & & 3.54 \\
Intention & 3.61 & 3.68 & 3.51 & 93.3 \\
- mean intention & 93.3 & 97.2 & 93.8 & \\
- \% positive intention & & & & \\
\hline
\end{tabular}

\section{Discussion}

This study investigated the effects of an online decision aid for cholesterol and diabetes diagnostic self-testing on knowledge and informed choice. We found that the knowledge level in the diabetes arm was higher in the intervention group than in the control group, as was the number of participants with an informed choice. No significant differences were found in the cholesterol arm. Intention to use a self-test, defined as a participant indicating that they would maybe, probably of definitely perform a self-test in the future remained high at 3 months follow-up, while the number of participants who had actually performed a self-test during the three months of follow-up ranged from 6.2 to 9.5 percent in the diabetes arm, and only 1.8 to 2.6 percent in the cholesterol groups.

It is unclear why no effect on knowledge and informed choice was found in the cholesterol arm. A possible explanation could be that it is easier to inform people 
about diabetes than about cholesterol. Diabetes is a disease, with clear risk factors, and the result of the test will indicate whether or not someone has this disease. In contrast, cholesterol is a risk factor, and has to be interpreted in the light of multiple other risk factors. Explaining the consequences of a particular cholesterol level to a patient is a more challenging task, let alone providing this information on a website. Another explanation might be that people are already better informed about cholesterol, since not only doctors but also the media and the producers of products that claim to lower cholesterol levels have provided ample information about cholesterol. The latter explanation is, however, not confirmed by the average knowledge level in the cholesterol groups, which was lower than in the diabetes groups, although the knowledge questionnaires were not completely equal. Further analysis showed that the difference in knowledge level between the diabetes intervention and control groups was found in the items concerning general information about the disease and risk factors. The knowledge scores for the items which were more related to diagnostic testing, such as how to perform the test and the validity of the test, were also higher in the intervention group, but this difference did not reach statistical significance. Participants may have only viewed the first pages of the website, and since they were not actually on the verge of performing the test, may have disregarded the pages on how exactly to perform and interpret a self-test. Further analysis of weblog data might improve our understanding of the way participants used the website, and whether they had actually viewed the test-specific information.

\section{Strengths and limitations}

We selected participants for the trial from an existing Internet panel. The advantages of this panel are the high response rates and the possibility to recruit a large group of participants. However, the use of this panel also has its limitations. People in the panel are on the whole more highly educated compared to the general population in the Netherlands, and women are overrepresented. This may have led to an overestimation of the knowledge level. Furthermore, most of the participants in the trial had indicated they were considering doing a self-test in the future, but most of them were not actually about to buy a self-test. We considered the option of selecting only consumers who were actually on the verge of buying a test, but since tests are often offered through the Internet and multiple shops, we assumed we would not be able to reach sufficient consumers for a trial.

A non-response analysis of the first questionnaire showed that that non-responders were more likely to be female, were younger, and were more likely to have a low or intermediate educational level. There was a difference in response rate between the control and intervention groups, which might be due to the fact that panellists in the 
intervention group were asked to view the website, which would take more time than viewing the short control condition document, so panellists may have decided not to continue to the actual questionnaire.

We chose to measure informed choice using the method described by Marteau et al. ${ }^{15}$ In our study, however, the informed choice measure differed from the originally described measure, since we did not measure actual behaviour (taking the test), but instead measured intention. This decision was based on the assumption that few people would actually do a test in the following three months, since we selected participants who were not actually about to purchase a test.

Although the number of participants with an informed choice was higher in the intervention group, it was still less than $50 \%$ in the diabetes arm, and only around $23 \%$ in the cholesterol groups. Two important questions arise from these findings. First, how can this percentage be compared to that found for other interventions intended to increase informed choice, and second, how should this percentage be evaluated in terms of implications for further research and daily practice?

\section{Comparison with other studies}

Informed choice is a composite measure of knowledge and value-based choice. In a systematic review on the effect of decision aids, Stacey et al. described a mean difference in knowledge of 13.77 out of 100 when comparing decision aids with usual care. Informed choice was more often seen after exposure to a decision aid with explicit values clarification than after exposure to a decision aid without explicit values clarification, with a relative risk of $1.25 .{ }^{19}$ Compared to this review, we found less difference in knowledge, although the difference in informed choice score between the intervention and control groups in the diabetes arm in our study was higher than the average increase found in the review. The smaller difference in knowledge can be explained by our finding that knowledge did differ as regards general information about diabetes, but not as regards self-test specific items such as how to perform the test, probably because participants did not spend enough time on the website to view all this information, or were not actually being confronted with doing the self-test and were not in need of this information. The effect on the actual uptake of tests was not a primary goal of our study, since we did not intend to increase or reduce the uptake of tests. Other studies have shown that providing more detailed information on screening for diabetes did not lead to increased or decreased test use. ${ }^{20}$

\section{Implications for daily practice and future research}

The goal of our research project was to guide consumers in self-testing, and help them make a well-informed choice, since it is still unclear whether diagnostic self-testing is 
beneficial in terms of getting people to actually diagnose themselves at an earlier stage and preventing further complications, or whether self-testing has adverse health consequences, for example in the case of false-negative results or by providing an excuse to continue unhealthy behaviour after a normal test result is found ('certificate of health' $)^{21}$. There appeared to be an increase in the number of participants in our diabetes intervention group who visited a doctor based on the information provided by the decision aid, and a reduction in the use of self-testing, although the numbers are too small to draw conclusions about follow-up behaviour. Increasing awareness of risk factors and one's susceptibility to a disease is already an important step in the early diagnosis of disease, and as such should probably be stimulated. Since participants were not actually on the verge of taking a self-test, our decision aid should be further tested among participants who are actually about to perform the test, to evaluate its effect on their interpretation of the test result and their follow-up behaviour. Nevertheless, the increase in knowledge in the diabetes arm underlines the need to make objective information available to consumers, and to stimulate them to read this information before purchasing a test. The number of participants with sufficient knowledge and informed choice in our cholesterol arm was low. Further development of the decision aid, based on weblog analysis and participants' feedback, may improve the information about cholesterol self-testing, and may lead to higher knowledge levels, to ensure a responsible use of these tests.

\section{Conclusions}

Knowledge about diagnostic cholesterol and diabetes self-testing was limited. An online decision aid for diagnostic self-testing was found to improve knowledge and informed choice in consumers with a positive intention to use diabetes diagnostic selftests, though no effect was found for cholesterol self-testing. Further testing of the decision aid among consumers who are about to purchase a test is needed to assess whether knowledge about self-test specific aspects, such as interpreting the test results, can be improved. In any case, since it proved possible to improve knowledge and informed choice regarding self-testing, future diabetes self-testers should be encouraged to make use of a decision aid before purchasing a test. 


\section{References}

1. Ronda G, Portegijs P, Dinant GJ, Buntinx F, Norg R, Van der Weijden T. Use of diagnostic self-tests on body materials among Internet users in the Netherlands: prevalence and correlates of use. BMC Public Health. 2009;9:100.

2. Ryan A, Wilson S, Greenfield S, Clifford S, McManus RJ, Pattison HM. Range of self-tests available to buy in the United Kingdom: an Internet survey. J Public Health (Oxf). 2006;28:370-4.

3. Ickenroth MH, Ronda G, Grispen JE, Dinant GJ, de Vries NK, van der Weijden T. How do people respond to self-test results? A cross-sectional survey. BMC Fam Pract. 2010;11:77.

4. Ickenroth MH, Grispen JE, Ronda G, Tacken M, Dinant GJ, de Vries NK, et al. Motivation and experiences of self-testers regarding tests for cardiovascular risk factors. Health Expect. 2011.

5. Ryan A, Ives J, Wilson S, Greenfield S. Why members of the public self-test: an interview study. Fam Pract. 2010.

6. Grispen JE, Ickenroth $\mathrm{MH}$, de Vries NK, van der Weijden T, Ronda G. Quality and use of consumer information provided with home test kits: room for improvement. Health Expect. 2012.

7. Ickenroth MH, Grispen JE, de Vries NK, Dinant GJ, Elwyn G, Ronda G, et al. A single-blind randomised controlled trial of the effects of a web-based decision aid on self-testing for cholesterol and diabetes. Study protocol. BMC Public Health. 2012;12:6.

8. O'Connor AM, Bennett CL, Stacey D, Barry M, Col NF, Eden KB, et al. Decision aids for people facing health treatment or screening decisions. Cochrane Database Syst Rev. 2009(3):CD001431.

9. Grispen JE, Ronda G, Dinant GJ, de Vries NK, van der Weijden T. To test or not to test: a cross-sectional survey of the psychosocial determinants of self-testing for cholesterol, glucose, and HIV. BMC Public Health. 2011;11:112.

10. Janz NK, Champion VL, Strecher VJ. The Health Belief Model. In: Glanz K RB, Lewis FM, editor. Health behavior and health education: Theory, research, and practice. 3 ed. San Francisco: Jossey-Bass, 2002: 45-66.

11. Elwyn G, O'Connor A, Stacey D, Volk R, Edwards A, Coulter A, et al. Developing a quality criteria framework for patient decision aids: online international Delphi consensus process. BMJ. 2006;333: 417.

12. Elwyn G, O'Connor AM, Bennett C, Newcombe RG, Politi M, Durand MA, et al. Assessing the quality of decision support technologies using the International Patient Decision Aid Standards instrument (IPDASi). PLoS One. 2009;4:e4705.

13. Nunnally JC, Bernstein IH. Psychometric theory. third ed. New York: McGraw-Hill, 1994.

14. van den Berg M, Timmermans DR, Ten Kate LP, van Vugt JM, van der Wal G. Are pregnant women making informed choices about prenatal screening? Genet Med 2005;7:332-8.

15. Marteau TM, Dormandy E, Michie S. A measure of informed choice. Health Expect. 2001;4:99-108.

16. Michie S, Dormandy E, Marteau TM. The multi-dimensional measure of informed choice: a validation study. Patient Educ Couns. 2002;48:87-91.

17. Van 't Riet J, Ruiter RAC, Werrij MQ, Candel MJJM, de Vries H. Distinct pathways to persuasion: the role of affect in message-framing effects. Eur. J. Soc. Psychol. 2010;40:1261-76.

18. Lipsey ML. Design sensitivity. Statistical power for experimental research. Newbury Park, California: SAGE Publications, 1990.

19. Stacey D, Bennett CL, Barry MJ, Col NF, Eden KB, Holmes-Rovner M, et al. Decision aids for people facing health treatment or screening decisions. Cochrane Database Syst Rev. 2012(10):CD001431.

20. Marteau TM, Mann E, Prevost AT, Vasconcelos JC, Kellar I, Sanderson S, et al. Impact of an informed choice invitation on uptake of screening for diabetes in primary care (DICISION): randomised trial. BMJ. 2010;340:c2138.

21. Tymstra T, Bieleman B. The psychosocial impact of mass screening for cardiovascular risk factors. Fam Pract. 1987;4:287-90. 


\section{CHAPTER 9}

General discussion 


\section{General discussion}

In this thesis, we studied the use of diagnostic self-tests. To start with, quantitative and qualitative studies provided insight in self-test behaviour: why people use self-tests, which information they use and want, the interpretation of test results and follow-up behaviour. Also, the quality of consumer information provided in instruction leaflets that come with home tests was assessed. These studies led to the development of an online decision aid www.zelftestwijzer.nl. Finally, the effects of the decision aid on knowledge and informed choice were investigated in a randomised controlled trial.

In this chapter we discuss the overall conclusions and methodological aspects of these studies along the following themes: 1 ) trends in frequency of diagnostic self-testing, 2) reasons for self-testing, 3) the use and quality of existing information materials, information needs, and legislation concerning self-testing, 4) consumers' response to self-test results and follow-up behaviour and 5) the development and effect of the decision aid www.zelftestwijzer.nl.

\section{Trends in frequency of self-testing}

The number of consumers who had ever performed a diagnostic self-test was assessed by distributing online surveys among the Flycatcher Internet panel. ${ }^{1-3}$ We sent a questionnaire on the lifetime use of diagnostic self-tests to the panel in 2006, and repeated this survey in 2008 and 2011. Table 9.1 shows the top nine of the most frequently used self-tests in 2006 . We added the self-test for kidney disease to this list of self-tests, since this test was the second most used test in 2008. Because we conducted the surveys among a random sample of the Flycatcher panel, respondents may have participated multiple times in the surveys. To make a fair comparison of the use of self-tests through the years, we selected all new respondents who answered to the questionnaires for the first time in either 2008 or 2011 ( $n=1803$ and $n=1864$ respectively). While the general frequency of self-testing seems to be stable with overall scores moving from $16 \%$, to $17 \%$ and back to $16 \%$, various trends in types of self-testing seem to exist.

First, there are changes in the use of glucose and cholesterol diagnostic tests over the years 2006- 2011. Self-tests for diabetes and cholesterol were performed less often in 2008 and 2011, while the percentage of true home tests seems to rise in the case of diabetes self-testing, but seems to diminish in cholesterol self-testing. These changes in frequency correspond with national Dutch campaigns on prevention of diabetes and cardiovascular disease held in the previous years. We will discuss this in more detail below. 
Table 9.1 Participants who had ever performed a self-test and \% of tests performed as true home tests.

\begin{tabular}{lcccccc}
\hline & \multicolumn{3}{c}{$\begin{array}{c}\text { \% of participants who had ever } \\
\text { performed a self-test }\end{array}$} & \multicolumn{2}{c}{$\begin{array}{c}\text { \% of self-tests, performed as true } \\
\text { home tests }\end{array}$} \\
\hline & $\begin{array}{r}2006 \\
\mathrm{n}=7919\end{array}$ & $\begin{array}{c}2008^{*} \\
\mathrm{n}=1803\end{array}$ & $\begin{array}{c}2011^{*} \\
\mathrm{n}=1864\end{array}$ & 2006 & 2008 & 2011 \\
\hline Total & 16 & $\mathbf{1 7}$ & $\mathbf{1 6}$ & & & \\
Diabetes & 6.2 & 4.8 & 4.0 & 30 & 59 & 55 \\
Cholesterol & 5.4 & 3.9 & 2.7 & 25 & 21 & 14 \\
Allergies & 2.0 & 1.5 & 1.1 & 14 & 22 & 19 \\
Urinary tract infection & 1.9 & 1.5 & 2.0 & 21 & 37 & 46 \\
Aids/ hiv & 1.8 & 1.3 & 1.2 & 6 & 8 & 5 \\
Anaemia & 1.7 & 1.2 & 1.7 & 7 & 18 & 7 \\
Ovulation & 1.6 & 0.8 & 1.0 & 92 & 100 & 100 \\
Chlamydia & 1.4 & 1.6 & 2.6 & 5 & 3 & 10 \\
Glandular fever & 1.3 & 0.7 & 0.5 & 16 & 23 & 20 \\
Kidney disease & 0.7 & 4.2 & 2.2 & 36 & 93 & 86 \\
Other (not specified) & 1.7 & 2.3 & 2.7 & 71 & 55 & 46 \\
\hline
\end{tabular}

* respondents who answered to the questionnaire for the first time in either 2008 or 2011

Secondly, a mass media campaign in 2006 on the early detection of kidney disease, with postal distribution of free home tests to detect albuminuria that could be ordered on a mouse click via the campaign website, resulted in $7.8 \%$ of the Dutch adult population ordering the test in the first 30 days of the campaign ${ }^{4}$. This explains the rise in testing for kidney disease between 2006 and 2008.

Thirdly, one other test seems to have become more popular over the past few years: the Chlamydia test. From 2007 onwards, a pilot project on the offering of free, anonymous Chlamydia tests to 16 to 29 year-old by post, organised by the municipal health services, was executed, inviting the target group to respond by sending in a selftaken swab for analysis.

The influence of media campaigns and the offering of free tests on the frequency of self-testing was confirmed in our qualitative study, and was also found in an interview study in the UK. ${ }^{5,6}$ Participants in these studies indicated that they often performed a self-test because the test was offered for free or promoted to them. It made them realise they might be at risk, they became curious and took the test to find reassurance.

Before 2006, cholesterol and diabetes tests were frequently offered in the form of streetcorner tests by fund raising societies such as the Dutch Heart Foundation and the Dutch Diabetes Foundation, in order to increase public awareness of diabetes and cardiovascular disease, and with the aim of early detection of the condition. The offering of these tests was part of public campaigns on the prevention of cardiovascular disease and diabetes. Also, home tests to test for diabetes and high 
cholesterol have become directly available to consumers and are offered by for example chemists and on the Internet. ${ }^{7}$ In the light of these developments, the Dutch College of General Practitioners, in collaboration with the Dutch Heart Foundation, the Dutch Kidney Foundation and the Dutch Diabetes Foundation, developed a clinical practice guideline on the cardiovascular 'health check'. This guideline describes the screening of patients at risk for cardiovascular disease and encourages consumers to have themselves screened by their general practitioner (GP). ${ }^{8}$

(http://www.hartstichting.nl/professionals/programmas/passie_voor_preventie/proje cten_passie_voor_preventie/project_preventieconsult/). Analysis of the effects of a health check program showed that cardiometabolic disorders could be effectively detected at a primary health care centre. ${ }^{9}$

If these trends continue, one would expect the number of self-testers to decrease over the following years, since less streetcorner tests are provided, while at the same time more opportunistic screening in primary care is provided. Also, if consumers are more aware of the fact that GP's will perform screening, they will feel they have a 'valid' reason to visit their GP for asking for tests without having any complaints. ${ }^{5}$

On the other hand, home self-tests are still offered by commercial companies, and there is ample opportunity to have blood samples taken and analysed by professional laboratories. In the light of new developments, such as the provisional ideas to have patients pay for a consultation at their GP, more emphasis on patients' own responsibilities concerning their health, home tests and direct-access tests might become more popular. Further monitoring of the trends in of self-testing will still be needed to detect future changes in self-test behaviour. Additionally, the self-tests that are performed by consumers might probably more often be home tests, in which all aspects of the test are in the hands of the consumer: the indication for testing, performing the test, correctly interpreting the result and deciding on the follow-up. More education is needed to ensure safe use.

\section{Methodological considerations}

By distributing online questionnaires among the Flycatcher panel, we were able to reach a considerably large group of consumers. At the start of the questionnaire, respondents were informed on our definition of a self-test. We do not know if all respondents have correctly interpreted this explanation. For example, people with diabetes, who monitor their glucose level at home, might have considered this test as a diagnostic self-test. In the 2008 and 2011 questionnaire, we put more emphasis on our definition of a diagnostic self-test, by repeating it on every page of the questionnaire, instead of only explaining this at the start of the survey. This may have led to a more appropriate interpretation of diagnostic self-tests versus self-tests used 
for monitoring a chronic disease. In 2008, we asked respondents whether they had diabetes, and found that of the respondents who had performed a diabetes self-test $(n=232), 22$ (9.5\%) indicated having diabetes, although some of them might have discovered the disease by doing the self-test (of the 232 diabetes self-testers, 48 had found an abnormal result). In 2006, $12.5 \%$ (61/488) of the diabetes self-testers indicated having diabetes.

The percentage of respondents who had performed a self-test for kidney disease in our survey is lower than the number of people who had ordered the test. ${ }^{4}$ This may be clarified by various reasons. Probably, not all consumers who ordered the test did actually perform it. Next, the Flycatcher panel is not completely representative for the Dutch population, with panellists being somewhat more highly educated and more often female. (www.cbs.nl) The fact that the Flycatcher panel is not completely representative for the Dutch population implies that the numbers on self-testing that we found might differ from the frequency of self-testing in the general Dutch population, considering that self-testers are more often women, older than nontesters and that highly educated women more often perform tests compared to those with a lower education. ${ }^{1}$ While the respondents in our 2008 questionnaire had an average age of 40 years, and $64 \%$ of them were female, Nielen et al. report that the mean age of the respondents who had performed an albuminuria self-test was 53 years, and $54 \%$ was female. ${ }^{4}$ This may explain why we found a lower number of self-testers for albuminuria.

\section{Reasons for self-testing}

Our studies provided more insight in why people perform glucose or cholesterol selftests. As described above, reasons to perform a self-test are often influenced by the (free) offering of tests, and the promotion of self-tests in the media. During our studies, consumers indicated several other reasons why they had engaged in selftesting. We found the following factors which influence the decision whether to selftest or not.

If one would like to discourage self-testing, consumers should be informed on the responsibilities of their GP. Consumers indicated they turned to self-testing because they thought that they should only consult their GP when having specific complaints. Asking for a blood test without having any physical symptoms was not regarded as a 'valid reason' to consult a GP. More information about the possibilities for screening in primary care, for example in the recently developed cardiovascular 'health check' could encourage consumers to visit their GP instead of self-testing. Consumers should also be more aware of the possibility that self-tests can give false negative or false 
positive results. Self-testers often do not doubt the reliability of self-tests, since they think these tests are also used by professionals, and otherwise would not be allowed to be distributed. Furthermore, consumers indicated they would not self-test if selftests became expensive.

To encourage self-testing, the importance of screening should be stressed, while promoting the test in (social) media or by offering the test in public places. As explained above, consumers often chose for self-testing in an impulsive manner, when they coincidentally come across these tests, and realise they might discover an important disease or risk factor, or seek reassurance. Consumers indicate they purchase self-tests when they think the test is easy to use and is easily accessible. They think they should have easy access to information about indications for doing a test, how to perform the test, the reliability of the test result, the disease or risk factor identified by the test and the meaning of the test result and further actions. With this information, they will feel empowered to correctly perform the test.

Our findings are based on research on self-testing for cardiovascular risk factors. The determinants for self-testing are different for each specific self-test ${ }^{10}$, thus the recommendations described above may not be generalisable to all self-tests.

While the Royal Dutch Medical Association (KNMG) disapproves of self-testing, and recommends to always consult a doctor independent of the test result (http://knmg.artsennet.nl/Nieuws/Nieuwsarchief/Nieuwsbericht-1/Ga-niet-af-opzelftest.htm), consumers do see the advantages of self-testing and draw their conclusions based on the result. When considering diabetes and cholesterol selftesting, should these tests be discouraged, maybe forbidden, or do the positive effects outweigh the negative sides of self-testing? We will discuss this in more detail below.

The most frequently used tests in 2011, glucose, cholesterol, urine albumin, and Chlamydia, are often used for screening in persons who do not have health related complaints. High cholesterol does not give any direct symptoms, and also diabetes, Chlamydia and kidney disease often go unnoticed. The emphasis on prevention and screening can also be seen in a broader perspective and changes in health care globally. During the last decades, medicine has changed from doctors principally treating disease and symptoms, to putting more emphasis on prevention and early diagnosis. And not only health professionals and policy makers have become more directed towards prevention. Consumers have become more aware of their susceptibility to disease and are empowered to take responsibility for their health status, encouraged by public campaigns. Another important development is the current Medicine 2.0 movement: people have access to health related information through the Internet. The development of Medicine 2.0 offers new possibilities to 
empower consumers and patients, and should not be ignored, but instead its benefits should be used. ${ }^{11}$ Consumers can become more responsible for their health, and shared decision making is stimulated, for example by patients preparing themselves before visiting a doctor, or finding information in addition to the information provided by their doctor.

In addition to the earlier mentioned reasons to engage in self-testing, other pros of self-testing that are important to consumers were found, for example not having to make an appointment with the GP, which saves time. Some consumers wish to avoid waiting at the doctor's office, or to go to a laboratory service to have their blood sample taken. They think it is more convenient to perform the test at home. The aspect of having more privacy was not mentioned in our studies on reasons for glucose or cholesterol self-testing, although this might be due to the nature of the tests we studied, and might apply more to for example Chlamydia testing. The campaigns on self-testing were directed at making consumers more aware of certain risk factors, and stimulating a healthy lifestyle. Further, research among consumers with an intention to self-test showed that consumers want to be empowered, and feel it is their own responsibility to assess their health status. (Grispen et al., Considerations and information needs of people intending to use a self-test for cholesterol and diabetes: a qualitative study, submitted). The positive effect of self-testing, which could be the early discovery of disease or risk factors, and more awareness of these conditions and the importance of a healthy lifestyle should not be overlooked.

Nevertheless, there are also concerns about the use of self-tests. The chance of false positive or false negative results is often mentioned as a main pitfall in self-testing. In the case of diabetes, it is important that self-testers are aware of the fact that when having certain complaints, they should always contact a doctor. The chance of receiving a false negative result when performing the screening test, could lead to delayed diagnosis of the disease. Another reason to criticize self-testing is the 'certificate of health' effect, which means that consumers feel they are free to go on with their unhealthy lifestyle when a test gives a normal result (for example not changing unhealthy dietary habits when one's cholesterol level is normal, or continue smoking). ${ }^{12}$ However, this effect could also occur when consumers visit their GP. It is important that information about cholesterol self-testing also explains about the other risk factors for cardiovascular disease, and gives information about the importance of a healthy lifestyle, independent of the test result. We found that self-testers were not worried after receiving an abnormal result. Those who tested positive on diabetes, high cholesterol or albuminuria were relieved that they discovered the condition in 
time, and thought that now early treatment could be started, in which case the chance of developing complications is low.

When weighing the pros and cons of self-testing from the point of view of policy makers and health professionals, it is important to know which persons self-test, for a self-test might be more beneficial if it is used among people at risk for the condition the self-test is aimed at, and not being aware of this risk. Consumers would benefit from the self-test if they discover a certain condition that they would otherwise not have found, for example asymptomatic disease. On the other hand, one could argue that those truly at risk should consult a doctor. For example when assessing cardiovascular risk, multiple risk factors need to be assessed, instead of merely performing a cholesterol self-test. Those who are healthy and looking for reassurance might profit from self-testing, because it reassures them and can stimulate to continue their healthy lifestyle. It is still unclear whether the worried well, or rather those truly at risk engage in self-testing, since studies produced contradictory results. Ronda et al. found that self-tests were often performed by consumers who are already engaged in health related behaviour, such as the use of dietary supplements, but on the other hand, reported a lower health status and a higher BMI. ${ }^{1}$ In our qualitative study, participants reported being already aware of a healthy lifestyle, and trying to adhere to this. A study by Deutekom et al. on participants in cholesterol streetcorner testing showed that most consumers participating in the test were healthy and did not have risk factors. ${ }^{13}$

After weighing these pros and cons, we think that self-testing for diabetes and cholesterol may be a valid option, on the condition that the following crucial information is communicated in neutral and comprehensive way: in case of complaints, always consult your doctor; the chance of false positive and false negative results; that other risk factors for cardiovascular disease need to be taken into account to interpret the test result; and the importance of a healthy lifestyle. By providing this information, an informed choice in self-testing should be stimulated, and in this way can be a valid option to consumers.

\section{Information and legislation}

Our studies showed that self-testers who had performed a home test had read the information that comes with the test, and they indicated it had helped them to perform the test and interpret the result. They found the information easy to understand and sufficient. On the other hand, our analysis of the instruction leaflets revealed that information about the validity of the test and what to do with a normal 
or inconclusive test result often was insufficient. Consumers often assume that selftests are highly reliable, based on the fact that the test was authorized for distribution in the Netherlands. Packages often indicate that the self-test is easy to use and reliable. The requirements concerning the reliability of a self-test, and the minimum information that should be provided are described in the 'Besluit in-vitro diagnostica', based on European Union legislation. It states that a new in-vitro diagnostics for selftest use should be reported to a governmental body (CIBG). The manufacturer of the self-test submits a report in which the facts on reliability are described. There are no exact minimal claims on for example sensitivity and specificity, the only requirements are that the self-test should perform to such a degree that safe use can be ensured, and that the claims made in the manufacturers' reports are reproducible. The law also states that the instruction leaflet should mention the risk for false positive or false negative test results, although this does not have to be elaborated on in detail. The latter can lead to discussion on the amount of information required in the instruction leaflet. It should not be too elaborate, since consumers might not be able to understand this information, but should probably be more than only mentioning the possibility that a false positive or false negative test result may occur. Future research should focus on the amount and nature of information about reliability of self-tests that is comprehensible for self-testers, and that will lead to the best interpretation of the test result. Another point of concern is that the instruction leaflets often do not elaborate on what to do when obtaining a normal or inconclusive test result. This information is required by law, and this law should be followed more strictly. Because manufacturers of self-tests do not provide all information about the validity and reliability of the test in the instruction leaflet, it is advisable to make the official test reports of self-tests accessible to the general public. This will also allow the development of an overview of all self-tests available from different manufacturers, with a description of the strong and weak points of each test.

\section{Future research}

The next challenge will be how to bring important information to the attention of future self-testers, especially since many self-testers indicate that they do not feel a need for extra information. If they would feel such an information need, they would most preferably find this information on the Internet, provided by a reliable organisation. Especially our findings that self-testers thought the information provided was sufficient showed that it will be difficult to have consumers read important additional information about self-testing. It also implies that the instruction leaflets should be monitored more closely, and should comply strictly to regulations. 


\section{Consumers' response to self-test results and follow-up behaviour}

So far, we have mainly weighed the pros and cons of self-testing. Given the availability of self-tests on cholesterol and diabetes and the pros and cons, we concluded that selftesting may be a valid option on the condition that consumers have access to reliable information. Our studies showed that in general, self-testers are easily reassured by a normal result, and will not consult a GP. On the other hand, after receiving an abnormal result, most consumers do consult a doctor or other health professional. It is still unclear what the exact consequences of self-testing are. We do not know whether for example self-testing for cholesterol has led to more patients who are at risk for developing cardiovascular disease consulting their general practitioner, who can reduce the risks on cardiovascular events by treating their risk factors. In the case of screening for cardiovascular risk factors, some researchers have investigated the direct effects of self-testing on medical outcomes. Analysis of the streetcorner testing for cholesterol showed that mainly healthy consumers took these tests. Eleven percent of the participants had an elevated cholesterol level (>6.5) and were advised to visit their GP. Based on the risk factors that were assessed using a questionnaire, $22 \%$ of them would not need treatment (taking medication), because they had no other risk factors. ${ }^{13}$ De Borst et al. evaluated the effect of the albuminuria self-test campaign in $2006 .{ }^{14}$ They found an increasing number of newly diagnosed kidney complaints and disease in the year after the program, with the highest risks found in patients without risk factors for kidney disease. However, there were many false positive results (one in five testers received a positive test result), and only $25 \%$ of those who tested positive had visited their GP within 8 weeks of performing the test. In total 193 of over 71,000 self-testers were newly diagnosed with kidney disease, diabetes or hypertension. ${ }^{4}$ This shows that self-testing resulted in an increase in unnecessary medical investigations, and that there is a need for more regulation, and for appropriate information on the reliability of tests and on how to respond to the test result.

\section{Methodological considerations and future research}

To assess follow-up behaviour, we used online questionnaires and performed interviews with self-testers. Actions taken based on the test result were self-reported, and might be influenced by respondents giving sociable desirable answers. Also, the self-tests had been performed up to two years earlier, which might have made the responses less reliable.

To assess the effect of self-tests on health, extensive research would be needed. Selftesters would have to be monitored, the result of the self-test and the interpretation of this result should be compared to a golden standard, and long term effects should 
be assessed, such as changes in lifestyle, early disease detection and medical consumption.

\section{Development and effect of the decision aid www.zelftestwijzer.nl}

Based on the studies which gave more insight in self-test behaviour, we developed the decision aid www.zelftestwijzer.nl. The decision aid provides information about selftesting in general, such as important considerations before purchasing a self-test, and gives test-specific information about cholesterol and diabetes self-testing. Input for the decision aid was not only derived from the results of previous studies, but also experts and end-users were involved in the development of the website. It led to many discussions on the information that should be given on the website. The essential part of a decision aid is the weighing of two or more options (for example whether to perform screening or not), that may be more or less equal in outcome, and that have different pros and cons, benefits and side effects. In the case of self-testing, consumers have to decide whether to self-test without professional counseling, consult a doctor, or do nothing. During the development of our decision aid, the most important question was whether visiting a GP or doing a self-test could be represented as equal options. These considerations were not only mentioned within the project team, but also by end-users and experts. From a GP's perspective, one could argue that people who have health related questions and consider to take a blood test, should first consult a doctor, who is trained on the indications for testing and the interpretation of a test result in the light of certain symptoms or other risk factors. On the other hand, when considering the benefits of self-testing, and the current movements towards more patient participation and empowerment, self-testing may be a suitable option. Nevertheless, as described earlier, there are important pitfalls in self-testing that can not be ignored. It is important that when people have certain complaints, they should see a doctor, since they might experience symptoms caused by a different disease than the disease they tested for. During the development of the website, we added critical remarks and warnings about the use of self-tests on the website, and have also formulated the opinion of the Royal Dutch Medical Association (KNMG): they discourage the use of self-tests. The possibility of consulting a GP is mentioned first on the website, followed by the possibility to self-test. With these changes, we decided that the choice at stake should not be consulting a GP or doing a self-test, but instead changed this to doing a self-test or not. We realised that the tone of the website is not completely neutral on the choice whether to self-test or not, but we think, since the website as well as self-tests should be safe to use without professional counselling, information should be given with some caution. 


\section{Methodological considerations and future research}

There are several differences between our decision aid on self-testing compared to most other DA's. While most decision aids are used as an adjunct to professional counselling, our decision aid was built for use at home, without the need for direct involvement of for example a GP. Next, the decision aid does not give exact numbers on the probability of a certain outcome, which often is an important element of a decision aid. ${ }^{15}$ We do not have these numbers; not only the rates on diagnostic yields detecting specific diseases, but also data on the reliability of self-tests are lacking.

One could question why we chose to develop a decision aid, and not just provide plain information about self-testing, in which consumers are guided in the self-testing process ('do I have an indication for the test?', 'how to interpret the result' etc), including the pitfalls and benefits of self-testing, but without the value clarification tool we included to weigh the pros and cons separately. Some argue that only information (a so called 'option grid') might be sufficient to support good decision making ${ }^{16,17}$, though a meta-analysis showed that exposure to a decision aid with explicit value clarification compared to those without explicit value clarification resulted in a higher proportion of patients achieving an informed decision. ${ }^{18}$ The option grids seem to be useful when applied in clinical practice, combined with a consultation with a doctor. We think that, since the decision whether to self-test or not is often made at home, more information, including a value clarification tool is needed. In our decision aid, we used a list of the pros and cons to encourage value clarification, which is the most frequently used method in decision aids (http://ipdas.ohri.ca/IPDAS-Chapter-D.pdf).

We decided to develop test specific information on diabetes and cholesterol selftesting, since these tests are the most frequently used self-tests in the Netherlands. More tests can be added to the 'zelftestwijzer' in the future. In order to decide which tests can be added, the frequency of use of these tests needs to be taken into account, but most importantly the tests that are added to the website should have important pros which make the use of these tests defendable, and should be considered safe to use at home, without dangerous consequences. For example, cancer related self-tests and tests for HIV are not allowed to be sold over the counter in the Netherlands, and should be discouraged. Other tests that are approved for distribution will be more subject of discussion, for example Chlamydia testing, since missing this diagnosis will have more severe consequences. On the other hand, it is important that people at risk screen themselves, and they often prefer the privacy a self-test offers. Future research on how consumers use these tests will be needed before these tests can be added to the decision aid. 
To evaluate the effect of the decision aid, we chose knowledge and informed choice as main outcomes, since these are the most often used outcomes for analysing the effects of a decision aid. ${ }^{18}$ To measure knowledge, we used a knowledge test which was based on the contents of the decision aid and on expert opinion, since no standardized knowledge test was available. Marteau et al. describe three different approaches for quantifying the information needed to make an informed choice: expert-led, based on professional guidelines, consumer-led, or to determine knowledge associated with best psychological outcome. ${ }^{19}$ Our knowledge test was mainly expert led, and based on information in the decision aid. Future research should focus on which knowledge is related to the best outcome, psychological but also on medical outcomes such as prevention of disease or medical consumption.

Our goal was to evaluate follow-up behaviour after self-testing, but because of the small number of participants who had performed a self-test at a three month followup, no further analysis could be performed.

The results of the analysis of the randomised controlled trial to measure the effect of the decision aid showed that the level of knowledge increased in the diabetes arm, in which $67 \%$ of the participants who were randomised to the intervention group had gained sufficient knowledge. However, in the cholesterol arm, these numbers were only $47 \%$ and $42 \%$ for the intervention and control group respectively. Also the number of participants with an informed choice was low, despite the intervention: $43 \%$ in the diabetes arm and $23 \%$ in the cholesterol arm. When viewing these numbers, it might seem rather irresponsible to offer self-tests to consumers. We think that the level of knowledge and informed choice was this low since the participants in our trial were not actually at the verge of performing a self-test. This is confirmed by our findings that most knowledge increase was found in information about the disease, and not in the aspects of performing the self-test and interpreting the result. We think that consumers who are considering doing a test might be most interested in indications for the test, and not in how to exactly interpret the test result. Although we would like consumers to view all the information before purchasing a test, so they know all the aspects and pitfalls of the test, safe use can also be ensured when consumers find this information at the time they need it: when they have the test at home and are looking for more information about how to perform the test and what to do with the result. Additionally, we found that most instruction leaflets were clear on how to perform the test, so this will probably not lead to major problems. Nevertheless, future research should focus on how the decision aid was used, how consumers can be stimulated to read more information about the website, and most importantly, how to bring the existence of the website to attention of future selftesters. 
To provide extra information, the implementation of newly developed information, such as our decision aid, will be challenging, since self-testers often indicated they feel no extra information about self-testing is needed, and since they had no problems performing the self-test. The dissemination plan of the 'zelftestwijzer' involves the cooperation with organisations such as DiagNed (the Dutch organisation of manufacturers and importers of in-vitro diagnostics), the Dutch Consumers Organisation, Dutch patient organisations, and health insurance companies. Furthermore, the website should be easy to find when using 'google' to obtain more information about self-testing.

\section{Conclusions}

Diagnostic self-tests are performed by about $16 \%$ of the Dutch population, with most self-testers experiencing no adverse effects. It is a phenomenon that fits in the current changes in health care concerning more patient autonomy and empowerment, and also more focus on prevention and early disease detection. This makes the use of cholesterol and diabetes diagnostic self-tests an acceptable option that should not simply be rejected, on the condition that the following crucial information is communicated in neutral and a comprehensive way: in case of complaints, preferably consult your medical doctor; the chance of false positive and false negative results; that other risk factors for cardiovascular disease need to be taken into account to interpret the test result; and the importance of a healthy lifestyle.

While the overall frequency of self-testing seems to be stable, a relative increase in the use of home tests and direct-access laboratories is expected. Especially in case of home tests, in which all aspects of testing are in the hands of the consumer, information on the reliability of the specific self-tests and what to do with the result are of great importance, although we found that this part of information in instructions leaflets of the home tests is often lacking or incomplete. An online decision aid on diagnostic self-testing for diabetes can improve consumers' knowledge and stimulate an informed choice, consumers should be encouraged to view this information prior to and while performing the self-test. 


\section{References}

1. Ronda G, Portegijs P, Dinant GJ, Buntinx F, Norg R, Van der Weijden T. Use of diagnostic self-tests on body materials among Internet users in the Netherlands: prevalence and correlates of use. BMC Public Health. 2009;9:100.

2. Ickenroth MH, Ronda G, Grispen JE, Dinant GJ, de Vries NK, van der Weijden T. How do people respond to self-test results? A cross-sectional survey. BMC Fam Pract. 2010;11:77.

3. Ickenroth $\mathrm{MH}$, Grispen JE, de Vries NK, Dinant GJ, Elwyn G, Ronda G, et al. A single-blind randomised controlled trial of the effects of a web-based decision aid on self-testing for cholesterol and diabetes. Study protocol. BMC Public Health. 2012;12:6.

4. Nielen MM, Schellevis FG, Verheij RA. The usefulness of a free self-test for screening albuminuria in the general population: a cross-sectional survey. BMC Public Health. 2009;9:381.

5. Ickenroth MH, Grispen JE, Ronda G, Tacken M, Dinant GJ, de Vries NK, et al. Motivation and experiences of self-testers regarding tests for cardiovascular risk factors. Health Expect. 2011.

6. Ryan A, Ives J, Wilson S, Greenfield S. Why members of the public self-test: an interview study. Fam Pract. 2010.

7. CVZ-rapport. Diagnostische zelftests op lichaamsmateriaal. Aanbod, validiteit en gebruik door de consument [Diagnostic self-tests on bodymaterial. Supply, validity, and use by the consumer]. 2007.

8. Dekker JM, Alssema M, Janssen PG, Goudswaard LN. 'The Prevention Visit' module cardiometabolic risk. Huisarts Wet. 2011;54:138-55.

9. Godefrooij MB, van de Kerkhof RM, Wouda PJ, Vening RA, Knottnerus JA, Dinant GJ, Spigt MG. Development, implementation and yield of a cardiometabolic health check. Fam Pract. 2012;29:174-81

10. Grispen JE, Ronda G, Dinant GJ, de Vries NK, van der Weijden T. To test or not to test: a cross-sectional survey of the psychosocial determinants of self-testing for cholesterol, glucose, and HIV. BMC Public Health. 2011;11:112.

11. RVZ-rapport. Gezondheid 2.0 [Medicine 2.0]. The Hague: RVZ (Council for Public Health and Care), 2010.

12. Tymstra T, Bieleman B. The psychosocial impact of mass screening for cardiovascular risk factors. Fam Pract. 1987;4:287-90.

13. Deutekom M, Aziz Y, van Dis I, Stronks K, Bossuyt PM. [The Dutch National Cholesterol Test: participants mainly healthy]. Ned Tijdschr Geneeskd. 2008;152:2425-9.

14. de Borst J, Nielen MM, Verheij RA, Schellevis FG. Increased incidence of kidney diseases in general practice after a nationwide albuminuria self-test program. BMC Fam Pract. 2011;12:81.

15. Elwyn G, O'Connor AM, Bennett C, Newcombe RG, Politi M, Durand MA, et al. Assessing the quality of decision support technologies using the International Patient Decision Aid Standards instrument (IPDASi). PLoS One. 2009;4:e4705.

16. Labrecque M, Paunescu C, Plesu I, Stacey D, Legare F. Evaluation of the effect of a patient decision aid about vasectomy on the decision-making process: a randomized trial. Contraception. 2010;82:556-62.

17. Elwyn G, Lloyd A, Joseph-Williams N, Cording E, Thomson R, Durand MA, et al. Option Grids: shared decision making made easier. Patient Educ Couns. 2013;90:207-12.

18. Stacey D, Bennett CL, Barry MJ, Col NF, Eden KB, Holmes-Rovner M, et al. Decision aids for people facing health treatment or screening decisions. Cochrane Database Syst Rev. 2012(10):CD001431.

19. Marteau TM, Dormandy E, Michie S. A measure of informed choice. Health Expect. 2001;4:99-108. 
Summary 


\section{Summary}

Chapter one gives an introduction to the phenomenon of diagnostic self-testing. We define a diagnostic self-test as a test that is performed on body materials, such as blood or urine, without the involvement of a health professional. Four different modes of self-testing are described: home-tests, streetcorner testing, direct-access laboratories and home-collect testing. Previous research showed that these tests are available for 28 conditions, and that $16 \%$ of the respondents in an online survey had ever used a self-test. There are many pros and cons in self-testing, but the exact consequences are unknown. Few studies have been performed on why people selftest, how they interpret the results and what is their follow-up behaviour. The aim of the research project was to gain more insight into diagnostic self-testing behaviour, to assess consumers' follow-up behaviour after performing a self-test, and to improve consumers' knowledge in diagnostic self-testing and thereby stimulate an informed choice. The following research questions are addressed in this thesis: 1 ) Which selftests are currently used in the Netherlands, and is there a change in the frequency of self-testing in the period 2006-2011?, 2) What are consumers' reasons for using a selftest?, 3) What information do self-testers use, and what is the consumers' interpretation of the quality of this information?, 4) What is the consumers' response to self-test results in terms of confidence in the result, reassurance by the test result, and follow-up behaviour?, 5) What is the quality of the currently available information about a selected set of self-tests?, and 6) What is the effect of an online decision aid for self-testing on knowledge and informed choice?

In chapter 2, the protocol for the studies in chapter 3, 4 and 5 is described.

A cross-sectional study on the frequency of diagnostic self-testing was performed, with the aim of examining consumers' response to self-test results in terms of their confidence in the result, reassurance by the test result, and follow-up behaviour. This study is described in chapter 3. A random sample of 6700 Internet users in an existing Internet panel received an online questionnaire on the use of self-tests. A second questionnaire was sent to the respondents that were identified as self-testers in the first questionnaire $(n=703)$. We found that $18.1 \%$ of the respondents had ever performed a self-test, the most frequently used tests being those for diabetes (5.3\%), kidney disease (4.9\%), cholesterol (4.5\%), urinary tract infection (1.9\%) and HIV/ AIDS and Chlamydia (both 1.6\%). Respondents who had performed a self-test seemed to base their follow-up behaviour on the test result, they had confidence in the result, and were often reassured when the test result was negative. After an abnormal test result, most respondents sought medical care. 
Chapter 4 describes the results of an interview study among consumers who had performed a self-test for cardiovascular risk factors (glucose, cholesterol and albuminuria). Aim of this study was to gain more detailed insight in consumers' experiences with self-testing. Twenty consumers were interviewed, and data analysis was performed using a thematic content analysis. Regarding the reason for selftesting, three types of users were distinguished: those who engaged in self-testing when a test was offered, either with or without previous knowledge about the disease or risk factor, and those who had actively decided to test and had searched for a selftest themselves. Self-testers had generally experienced no problems performing the test or interpreting the result, and had considerable confidence in the result. They were easily reassured by a normal result, while an abnormal result did not automatically mean they consulted a doctor. Most participants did not feel a need for more information.

In chapter 5, the consumers' use of and needs for information about self-testing were examined, and the quality of consumer information provided with home test kits was assessed. A cross-sectional Internet survey among 305 self-testers assessed their use of and needs for information and their perception of the quality of consumer information provided with self-test kits. A meta-search engine was used to identify Dutch and English consumer information for home-diagnostic tests available online at the time of the study. The quality of this consumer information was evaluated using a checklist of quality criteria. The consumers' information needs were in line with the most frequently used information and the information was perceived as being of moderate to good quality. The information was mostly in agreement with clinical practice guidelines, although information on reliability and follow-up behaviour was limited. Approximately half of the instruction leaflets did not include information on the target group of the test. We concluded that, although generally of moderate to good quality, some aspects of the information provided were in many cases insufficient.

Chapter 6 describes the development of the decision aid (DA) 'zelftestwijzer'. The aim of this DA is to provide more information on cholesterol and diabetes self-testing, and to stimulate an informed choice in self-testing. It was developed based on previous research and medical practice guidelines. The first prototype was assessed on its contents and usability by semi-structured interviews with experts $(n=13)$, followed by usability tests with end-users $(n=10)$ leading to improvements of the DA in an iterative process. The comments of the experts were grouped into four themes: general comments, textual remarks, technical errors and lay-out. End-user comments were 
mainly consistent with the experts' opinion. Important considerations that were identified were whether providing this information without direct professional counseling is safe, whether a ranking of available tests should be provided, and how strong a warning on self-testing should be given. These considerations led to important changes in the decision aid.

In chapters 7 and 8, the protocol for and the results of a single-blind randomised controlled trial on the effect of the decision aid on knowledge and informed choice in diagnostic diabetes and cholesterol self-testing are described. We selected 1259 consumers with an intention to use a diagnostic cholesterol or diabetes self-test from an existing Dutch internet panel. Consumers were excluded if they had already been diagnosed with diabetes or cardiovascular disease, or if they were younger than 18 years of age. A total of 1137 participants were randomised towards viewing the decision aid, or a control condition consisting of a limited information sheet. Multiple regression analysis showed that the knowledge level in the diabetes arm was higher in the intervention group than in the control group, as was the number of participants with an informed choice. No differences were found in the cholesterol arm. We concluded that the decision aid led to improvements in knowledge and informed choice in the diabetes intervention group compared to the control group, but did not have any effects in the cholesterol intervention group.

In the final chapter, the overall conclusions and methodological aspects of the studies described in this thesis are discussed organized along the following themes: 1) trends in frequency of diagnostic self-testing, 2) reasons for self-testing, 3) use of information materials, the quality of the information material and legislation concerning selftesting and information required in self-testing, 4) consumers' response to self-test results and follow-up behaviour, and 5) the development and effect of the decision aid www.zelftestwijzer.nl.

The frequency of self-testing appears to be stable over the years 2006-2011, although the use of the specific self-tests seems to be influenced mainly by the offering of free tests and media campaigns promoting self-tests. Methodological considerations concerning the cross-sectional survey to assess the frequency of self-testing are the use of an Internet panel, which is not completely representative for the Dutch population, and whether respondents have correctly interpreted our definition of a diagnostic self-test.

Next, factors that influence the decision whether to self-test or not are described, followed by a discussion on the positive and negative sides of self-testing. We describe the phenomenon of self-testing in the light of global changes in medicine, such as the emphasis on prevention and the current Medicine 2.0 movement, after which we 
conclude that self-testing might be a suitable option to consumers, and should not simply be disapproved. Nevertheless, it is important that at least the following information is provided: when having complaints, a doctor should be consulted; the chance on false positive and false negative results; that other risk factors for cardiovascular disease are described; and the importance of a healthy lifestyle. We found that consumers base their follow-up behaviour on the test result, but the exact consequences on for example early diagnosis or on the other hand unnecessary further investigations, remains unknown. However, investigating these effects would imply extensive research in which all steps in the self-testing process, such as having an indication for testing, and comparing the test result to a golden standard, would have to be assessed.

We discuss the discrepancies between consumers' assessment of the quality of information provided with self-tests, the information that should be provided as stated by law, and our assessment of the instruction leaflets provided with home test kits. Consumers often indicate that they thought the information was sufficient, while our assessment shows that some important aspects of information were insufficient. Because consumers do not feel the need for extra information, the dissemination of information on self-testing will be challenging.

The final part of the general discussion focuses on the development and evaluation of the decision aid 'zelftestwijzer'. We discuss the changes made to the decision aid based on the usability testing, including why more warning on self-testing was added, and explain why we chose to develop a decision aid with a value clarification tool, instead of an option grid. After viewing the decision aid, the number of participants with an informed choice towards self-testing remains quite low: $43 \%$ in the diabetes arm and $23 \%$ in the cholesterol arm. We discuss that this might be due to the fact that participants were not actually at the verge of purchasing a self-test, and were less interested in information on for example how to exactly perform the test. We think that, although we prefer consumers to read all information before purchasing a test, a safe use can also be stimulated if consumers know where to find information on selftesting when they are actually performing the test. Nevertheless, future research should focus on how the decision aid was used, how consumers can be stimulated to read more information on the website, and most importantly, how to bring the existence of the website to the attention of future self-testers. 
Samenvatting 


\section{Samenvatting}

In de afgelopen jaren zijn er steeds meer diagnostische zelftests beschikbaar gekomen voor de Nederlandse consument. Met deze tests kan men zichzelf, zonder tussenkomst van een arts, testen op aandoeningen zoals bijvoorbeeld diabetes (suikerziekte) of een chlamydia infectie. Andere tests zijn gericht op het opsporen van risicofactoren voor aandoeningen zoals een verhoogd cholesterol (verhoogd risico op hart- en vaatziekten) of op vroege opsporing van kanker (zoals het meten van het PSA bij prostaatkanker). In dit proefschrift worden zelftests specifiek gedefinieerd als tests waarbij lichaamsmateriaal (bijvoorbeeld bloed, urine of speeksel) onderzocht wordt en waarbij het doel is om te bepalen of iemand een (verhoogd risico op een) aandoening heeft. Het gaat in dit proefschrift om diagnostische zelftests en niet om zelftests waarmee een bepaalde aandoening gecontroleerd kan worden, zoals bijvoorbeeld het meten van het glucose door mensen met diabetes. Eerder onderzoek uit 2006 liet zien dat voor de Nederlandse consument zelftests voor 28 verschillende aandoeningen beschikbaar zijn en dat er verschillende manieren bestaan om deze tests uit te voeren. Allereerst de zogenaamde 'thuistests', waarbij mensen een testpakket kopen waarmee ze de hele test zelf thuis kunnen uitvoeren. Andere mogelijkheden zijn tests die worden aangeboden in bijvoorbeeld de supermarkt of de sportschool, de zogenaamde 'streetcorner' tests, waarbij mensen direct het resultaat van de test te horen krijgen. Ook zijn er commerciële laboratoria, waar men op eigen kosten bloed kan laten prikken, of bijvoorbeeld speeksel of ontlasting naartoe kan sturen voor verder onderzoek.

Het bovengenoemde onderzoek uit 2006 liet zien dat 16\% van de deelnemers aan een online vragenlijst ooit een dergelijke zelftest had gedaan. Het is onduidelijk wat de gevolgen van zelftesten zijn. Voorstanders geven aan dat het belangrijk is dat mensen zelf verantwoordelijkheid nemen voor hun gezondheid, dat het past bij de groeiende informatiebehoefte van mensen over hun gezondheid (dat zich bijvoorbeeld uit in zoekgedrag op internet), en dat door middel van zelftests (risicofactoren voor) aandoeningen eerder kunnen worden opgespoord en zo aandoeningen of complicaties kunnen worden voorkomen. Tegenstanders wijzen echter op de gevaren van zelftesten: zijn de tests wel betrouwbaar, kunnen consumenten de resultaten goed interpreteren, en worden er geen onnodige, te dure tests gedaan?

Er zijn maar weinig studies gerapporteerd over de motivatie van consumenten om een zelftest te doen, hoe ze het resultaat van de test interpreteren en wat ze vervolgens met de uitslag doen. Het doel van dit onderzoeksproject was enerzijds beschrijvend, namelijk om meer inzicht te krijgen in het gedrag van mensen met betrekking tot diagnostisch zelftesten. Zo wilden we bijvoorbeeld het gedrag van consumenten na het 
doen van een zelftest in kaart te brengen. Anderzijds was het doel experimenteel, om de kennis van consumenten over zelftests verbeteren en daarmee een meer geïnformeerde keuze voor wel of niet zelftesten stimuleren. De volgende onderzoeksvragen worden in dit proefschrift behandeld:

1) Welke zelftests worden momenteel in Nederland gebruikt, en is er een verandering in de frequentie van zelftesten in de periode 2006-2011?;

2) Waarom doen consumenten een zelftest?;

3) Welke informatie wordt door consumenten gebruikt, en hoe beoordelen zij de kwaliteit van deze informatie?;

4) Wat doen consumenten met de uitslag van de test met betrekking tot vertrouwen in de uitslag, geruststelling en vervolggedrag?;

5) Wat is de kwaliteit van de consumenteninformatie die momenteel geleverd wordt bij een thuistest?;

6) Wat is het effect van consumenteninformatie in de vorm van een online keuzehulp over zelftesten op kennis en een geïnformeerde keuze?

Na deze algemene introductie, die in hoofdstuk 1 beschreven staat, wordt in hoofdstuk 2 uitgelegd hoe de studies in de volgende hoofdstukken (hoofdstuk 3 tot en met 6) zijn opgezet.

Hoofdstuk 3 beschrijft een vragenlijststudie naar de frequentie van zelftesten in Nederland en hoe consumenten omgaan met het resultaat van een zelftest: zijn ze gerustgesteld, hebben ze vertrouwen in de uitslag en wat doen ze vervolgens met die testuitslag? Voor deze studie werd gebruik gemaakt van het Flycatcher internet panel. Dit panel bestaat momenteel uit ongeveer 14.000 leden die tussen de 12 en 96 jaar oud zijn. Nieuwe panelleden worden online geworven, door middel van een schriftelijk uitnodiging, mond-tot-mondreclame of via intermediairen. Vergeleken met de Nederlandse populatie is het complete panel jonger, hoger opgeleid en bestaat uit meer vrouwen. Panelleden vullen enkele keren per jaar online vragenlijsten in en ontvangen daarvoor een cadeaubon. We stuurden 6700 consumenten uit dit internetpanel een vragenlijst toe, waarin gevraagd werd naar het gebruik van diagnostische zelftests volgens de definitie als hierboven gegeven. Vervolgens stuurden we de consumenten die aangaven ooit een zelftest te hebben gedaan een tweede vragenlijst, met daarin vragen over de specifieke zelftest die ze gedaan hadden. Ruim $18 \%$ van de consumenten die de vragenlijst hadden ingevuld had ooit een zelftest gedaan. De meest uitgevoerde testen waren de glucosetest voor het stellen van de diagnose diabetes (suikerziekte, 5,3\% van de consumenten had ooit een glucose zelftest voor diabetes gedaan), eiwit in de urine voor nierziekten $(4,9 \%)$, cholesterol $(4,5 \%)$, urineweginfectie (blaasontsteking, 1,9\%) en HIV/AIDS en Chlamydia (beide 1,6\%). 
Zelftesters leken hun vervolggedrag doorgaans direct te baseren op de uitslag van de zelftest, waarbij ze aangaven vertrouwen te hebben in de juistheid van de testuitslag, en waren meestal gerustgesteld door een normale testuitslag. Als de testuitslag afwijkend was zochten de meeste consumenten medische hulp.

Vervolgens werden de consumenten die in de vragenlijst hadden aangegeven dat ze een zelftest hadden gedaan voor diabetes, cholesterol of nierziekten uitgenodigd om deel te nemen aan een interview. We beschrijven de resultaten van deze studie in hoofdstuk 4. Het doel van deze studie was om meer inzicht te krijgen in de ervaringen van zelftesters. Twintig consumenten werden geïnterviewd, de interviews werden op geluidsband opgenomen en vervolgens woordelijk uitgeschreven en geanalyseerd.

In de interviews werden diverse beweegredenen voor zelftesten genoemd: veel consumenten deden de zelftest omdat deze (gratis) werd aangeboden en omdat ze op dat moment het gevoel hadden dat het belangrijk was de test te doen. Anderen kozen bewust voor een zelftest en gingen er zelf naar op zoek. In het algemeen hadden zelftesters geen problemen ervaren in het uitvoeren van de test of het interpreteren van de uitslag van de test en ze hadden veel vertrouwen in de uitslag. Ze waren gemakkelijk gerustgesteld door een normale uitslag. Bij een afwijkende uitslag werd echter niet altijd een arts geraadpleegd. De meeste zelftesters gaven aan dat ze geen behoefte hadden aan extra informatie bij het kiezen voor, uitvoeren en interpreteren van de zelftest.

In hoofdstuk 5 beschrijven we welke informatie zelftesters gebruiken en welke informatie zij belangrijk vinden. Ook werd de kwaliteit van de informatie in de bijsluiter van zelftests geanalyseerd. Consumenten die aangaven dat ze een thuistest hadden gedaan, werden in een online vragenlijst gevraagd naar hun gebruik van en behoefte aan informatie en hoe zij de informatie die wordt geleverd met de zelftest hadden ervaren. We zochten op internet naar de beschikbare bijsluiters van thuistests, zowel in het Nederlands als in het Engels. Vervolgens werd de kwaliteit van deze bijsluiters beoordeeld aan de hand van een checklist met kwaliteitscriteria die waren samengesteld op basis van literatuur en adviezen van experts. We vonden dat de informatie die zelftesters belangrijk vonden overeen kwam met de informatie die door hen gebruikt werd en dat ze de kwaliteit van de informatie beoordeelden als voldoende tot goed. Bij het beoordelen van de kwaliteit van de bijsluiters aan de hand van de kwaliteitscriteria vonden we dat de informatie in het algemeen overeenkomt met de geldende richtlijnen, hoewel de informatie over de betrouwbaarheid van de test en over wat te doen met het resultaat van de test (met name advies bij een normale of onduidelijke uitslag) vaak beperkt was. Ongeveer de helft van de bijsluiters vermeldde niet duidelijk de specifieke doelgroep voor de test. 
Gebaseerd op de onderzoeken die hierboven beschreven staan en op de huidige medische richtlijnen werd consumenteninformatie in de vorm van een online keuzehulp ontwikkeld, de zogenaamde 'zelftestwijzer'. Het doel van deze keuzehulp is om meer informatie te bieden over cholesterol en glucose zelftests en om consumenten te helpen een geïnformeerde keuze te maken over wel of niet zelftesten. Hoofdstuk 6 beschrijft de systematische ontwikkeling van de keuzehulp. Het eerste prototype werd beoordeeld door zowel consumenten als experts. We vroegen 13 experts om de website te bekijken en vroegen vervolgens in een persoonlijk interview om feedback. Ook voerden we onderzoek uit naar de bruikbaarheid van het prototype van de website. Tien willekeurige consumenten werden uitgenodigd om de website te gebruiken, waarbij hun kritische opmerkingen en spontane navigatiegedrag over de website werden vastgelegd. De resultaten hiervan werden gebruikt om de website te verbeteren. Het commentaar van de experts kon worden ingedeeld in vier thema's: algemene opmerkingen, tekstuele opmerkingen, technische fouten en lay-out. De feedback van de consumenten kwam grotendeels overeen met die van de experts. Belangrijke punten die naar voren kwamen waren: 'Is het veilig om deze informatie aan te bieden, zonder dat er directe professionele begeleiding is?', 'Moet er wel of geen overzicht van de verschillende beschikbare tests worden gegeven, met eventueel een beoordeling per test?', en 'Hoe sterk moet de waarschuwing met betrekking tot de nadelen van zelftesten zijn?'. Deze vragen leidden tot belangrijke wijzigingen in de keuzehulp.

In de hoofdstukken 7 en 8 beschrijven we het protocol voor en de resultaten van de studie naar het effect van de keuzehulp op kennis over zelftests en op de mate waarin de consument een geïnformeerde keuze maakt in het al dan niet willen aanschaffen van een cholesterol of glucose zelftest. Hiervoor voerden we een gerandomiseerd gecontroleerd experiment uit: de deelnemers die aangaven een intentie te hebben om een glucose of cholesterol zelftest te gaan doen werden door loting verdeeld in twee groepen. De eerste groep werd gevraagd om de online keuzehulp te bekijken, de tweede groep ontving als placebo-interventie een korte tekst met beknopte informatie over zelftests (wat is een zelftest en welke soorten tests zijn er beschikbaar). We selecteerden 1259 consumenten uit het internetpanel. Zij hadden allen aangegeven te overwegen om in de toekomst een cholesterol of glucose zelftest te gaan doen. Consumenten die jonger waren dan 18 jaar of die aangaven in het verleden gediagnosticeerd te zijn met een hart- of vaatziekte of diabetes werden uitgesloten van de studie. Kennis werd gemeten door middel van een 'kennisquiz', waarbij er 20 juist/ onjuist stellingen werden gegeven (bijvoorbeeld: 'De hoeveelheid bloed die gebruikt wordt bij het doen van een zelftest is van invloed op de juistheid van het testresultaat.'). Om te meten of deelnemers een geïnformeerde keuze maakten, werd 
de uitslag van de kennisquiz gecombineerd met hun attitude ten opzichte van zelftests en hun intentie om een zelftest te gaan doen. We spraken van een geïnformeerde keuze als consumenten voldoende kennis hadden, en als daarbij hun attitude overeenkwam met hun intentie. Bijvoorbeeld als iemand voldoende kennis had, een positieve attitude ten opzichte van zelftests, en ook van plan was een zelftest te gaan doen. Als consumenten te weinig kennis hadden, of als hun attitude niet overeenkwam met hun intentie (bijvoorbeeld een positieve attitude, terwijl men niet van plan was de test te gaan doen), was er geen sprake van een geïnformeerde keuze.

Analyse van de uitkomsten liet zien dat de deelnemers die de intentie hadden om een glucosetest te gaan doen meer kennis hadden na het doornemen van de keuzehulp in vergelijking met de deelnemers uit de tweede groep die slechts de korte tekst hadden gekregen. Ook was het aantal deelnemers met een geïnformeerde keuze hoger $(43 \%$ versus 32\%). Onder de deelnemers die aangaven dat ze overwogen ooit een cholesterol zelftest te gaan doen werd geen verschil gevonden in kennis en in een geïnformeerde keuze tussen de twee groepen ( $24 \%$ maakte een geïnformeerde keuze in de interventiegroep, versus $23 \%$ in de placebo groep).

In het laatste hoofdstuk worden de overstijgende conclusies en methodologische aspecten van de studies in de volgende thema's besproken: 1) trends in het gebruik van diagnostische zelftests, 2) redenen om een zelftest te doen, 3) het gebruik van informatie en de kwaliteit van informatie bij zelftests en wetgeving rondom zelftests, 4) vervolggedrag van consumenten na het doen van een zelftest en 5) de ontwikkeling en het effect van de keuzehulp 'zelftestwijzer".

Het aantal mensen dat een zelftest doet leek stabiel te blijven over de jaren 20062011, hoewel er wel een verschil leek te zijn tussen de verschillende tests. Dit werd voornamelijk beïnvloed door het aanbieden van gratis tests en media campagnes die zelftests aanbevelen. Methodologische aspecten met betrekking tot de studie waarin de frequentie van het zelftesten werd onderzocht zijn het gebruik van een internetpanel dat niet geheel representatief is voor de Nederlandse bevolking. Ook kan het zijn dat de deelnemers aan de studie onze omschrijving van wat een diagnostische zelftest is niet goed hebben begrepen. De consequentie van deze ruis is mogelijk dat de frequentie van zelftesten in werkelijkheid lager ligt dan de door ons genoemde getallen.

Vervolgens werden de factoren die de beslissing om wel of geen zelftest te doen beschreven, gevolgd door een discussie over de positieve en negatieve kanten van zelftesten. Hierbij werden actuele veranderingen in de geneeskunde meegenomen, zoals meer nadruk op het voorkómen van ziekte en het huidige Medicine 2.0, waarbij 
steeds meer mensen online informatie over ziekten en het voorkómen van ziekten opzoeken. Wij concludeerden dat zelftesten een optie is voor consumenten en niet principieel afgekeurd dient te worden. Het blijft belangrijk dat in ieder geval de volgende informatie gegeven wordt: dat mensen die gezondheidsklachten hebben geadviseerd moet worden een arts te raadplegen, dat er een kans is op ten onrechte afwijkende of ten onrechte niet afwijkende uitslagen, dat er nog andere risicofactoren zijn voor het krijgen van een hart- of vaatziekte en het belang van een gezonde leefstijl.

De exacte gevolgen van zelftesten op bijvoorbeeld het eerder ontdekken van een ziekte of juist te veel onnodige verdere onderzoeken, blijft onbekend. Dit zijn belangrijke klinisch-epidemiologische vragen die wij niet hebben kunnen beantwoorden. Als we dit zouden willen onderzoeken zou een uitgebreide studie moeten worden opgezet waarbij alle stappen in het zelftesten zoals: 'heeft iemand een indicatie voor de test?', en het vergelijken met de uitslag van de zelftest met een gouden standaard moeten worden onderzocht.

Voorts bespreken we het verschil tussen hoe consumenten de kwaliteit van de informatie bij zelftests beoordelen, de beoordeling hiervan door onderzoekers en wat er volgens de wet in de bijsluiters zou moeten staan. Consumenten gaven aan dat de informatie die nu aangeboden wordt voldoende is, terwijl volgens de beoordeling aan de hand van kwaliteitscriteria op sommige punten belangrijke informatie ontbrak. Omdat consumenten geen behoefte leken te hebben aan extra informatie, zal het een uitdaging zijn om extra informatie onder de aandacht van consumenten te krijgen.

Het laatste deel van de algemene discussie gaat over de ontwikkeling en de evaluatie van de keuzehulp 'zelftestwijzer'. We gaan nogmaals in op de keuzes die zijn gemaakt tijdens de ontwikkeling van de keuzehulp en waarom we hebben gekozen voor een keuzehulp in plaats van een meer eenvoudige 'option grid'. Bij de evaluatie van de keuzehulp vonden we dat het aantal mensen dat een geïnformeerde keuze maakte na het zien van de zelftestwijzer nog steeds laag was. Dit kan het gevolg zijn van het feit dat mensen niet direct op het punt stonden om de test te gaan doen en misschien minder geïnteresseerd waren in informatie over hoe ze de test precies moesten uitvoeren. Naar onze mening kan de test ook verantwoord gebruikt kan worden als consumenten weten waar betrouwbare informatie te vinden is, hoewel bij voorkeur consumenten alle informatie zouden moeten lezen voordat ze een test kopen. Vervolgonderzoek in de vorm van een procesevaluatie zal moeten uitwijzen hoe de keuzehulp is gebruikt, hoe consumenten te stimuleren om meer informatie te lezen en vooral hoe de keuzehulp bij consumenten onder de aandacht kan worden gebracht. 
List of publications 


\section{Publications}

Ickenroth MHP, Ronda G, Grispen JEJ, Dinant GJ, De Vries NK, Van der Weijden T. How do people respond to self-test results? A cross-sectional survey. BMC Family Practice 2010:11:77.

Ickenroth MHP, Grispen JEJ, Ronda G, Tacken M, Dinant GJ, De Vries NK, Van der Weijden T. Motivation and experiences of self-testers regarding tests for cardiovascular risk factors. Health Expectations 2011, Oct 28.

Ickenroth MHP, Grispen JEJ, Ronda G, Dinant GJ, De Vries NK, Van der Weijden T. A single-blind randomised controlled trial of the effects of a web-based decision aid on self-testing for cholesterol and diabetes. Study protocol. BMC Public Health 2012;12:6.

Grispen JEJ, Ickenroth MHP, De Vries NK, Dinant GJ, Ronda G, Van der Weijden T. Improving behaviour in self-testing (IBIS): Study on frequency of use, consequences, information needs and use, and quality of currently available consumer information (protocol). BMC Public Health 2010;10:453.

Grispen JEJ, Ickenroth MHP, De Vries NK, Van der Weijden T, Ronda G. Quality and use of consumer information provided with home test kits: room for improvement. Health Expectations 2012, Jul 19.

\section{Submitted manuscripts}

Ickenroth MHP, Grispen JEJ, Ronda G, Dinant GJ, De Vries NK, Van der Weijden T. Educating consumers in self-testing: lessons learned from the development of an online decision aid on glucose and cholesterol self-testing.

Ickenroth MHP, Grispen JEJ, De Vries NK, Dinant GJ, Ronda G,Van der Weijden T. Effects of a web-based decision aid on knowledge and informed choice regarding diagnostic self-testing for cholesterol and diabetes. A single-blind randomised controlled trial.

Grispen JEJ, Ickenroth MHP, Ronda G, Hurenkamp L, De Vries NK, Van der Weijden T. An intention to self-testing: A qualitative study regarding consumer's considerations and information needs about self-testing. 
Grispen JEJ, Ickenroth MHP, De Vries NK, Dinant GJ, Ronda G, Van der Weijden T. The effects of a web-based decision aid on the intention to diagnostic self-testing for cholesterol and diabetes: A randomised controlled trial.

\section{Presentations}

Ickenroth MHP, Grispen JEJ, De Vries NK, Dinant GJ, Ronda G,Van der Weijden T. Effects of a web-based decision aid on knowledge and informed choice regarding diagnostic self-testing for cholesterol and diabetes. A single-blind randomized controlled trial. (Presented at the International Shared Decision Making Conference, June 2013, Lima, Peru).

Ickenroth MHP, Grispen JEJ, De Vries NK, Dinant GJ, Ronda G,Van der Weijden T. A randomised controlled trial on the effect of an online decision aid for cholesterol and diabetes self-testing. (Presented at the NHG Wetenschapsdag, June 2012, Maastricht).

Ickenroth MHP, Grispen JEJ, De Vries NK, Dinant GJ, Ronda G,Van der Weijden T. Selftesting in the Netherlands. (Presented at the National Conference for General Practitioner trainees, January 2012, Noordwijkerhout).

Ickenroth MHP, Grispen JEJ, Ronda G, Dinant GJ, De Vries NK, Van der Weijden T. Development and field-testing of an online decision aid for self-testing. (Presented at the Medicine 2.0 Conference, November 2010, Maastricht).

Ickenroth MHP, Ronda G, Grispen JEJ, Dinant GJ, De Vries NK, Van der Weijden T. Follow-up behaviour after self-testing: reassurance, self-management and consulting a doctor. (Presented at the NHG Wetenschapsdag, June 2010, Amsterdam).

\section{Media}

Dagblad De Limburger en Het Limburgs Dagblad, Wednesday September $5^{\text {th }}, 2012$ : Eiallergie, maar géén griep, by Will Gerritsen.

TV Limburg, Limburg Vandaag, October 3th, 2012: Hoe betrouwbaar zijn zelftesten? http://www.tvl.nl/nl/programmas/limburg-vandaag/uitzendingen/limburg-vandaag-3oktober-2012-1/ 
Dankwoord 


\section{Dankwoord}

Er zijn veel mensen die hun steentje hebben bijgedragen aan dit proefschrift, in de afgelopen zes jaar, maar ook daarvoor al. Graag wil ik de volgende mensen persoonlijk bedanken voor hun inzet, steun en vertrouwen.

Gaby, jij hebt tijdens het project de dagelijkse begeleiding op je genomen. Als afgestudeerd geneeskunde student waren mijn wetenschappelijke vaardigheden helaas niet zo groot en ik heb dan ook veel van je geleerd. Je hebt alles nauwkeurig bijgehouden, en ik kon bij je terecht met alle vragen die ik had. Het laatste jaar hebben we elkaar wat minder vaak gezien, maar als we beiden aanwezig waren in Maastricht liepen we altijd even bij elkaar binnen om bij te praten. Bedankt voor al je tijd en interesse.

Beste Trudy, je bent met enorme toewijding en enthousiasme betrokken bij jouw projecten. Ik ben ook erg blij dat jij daarmee dit project hebt weten op te zetten. Bedankt dat ik altijd bij je kon binnenvallen en voor de tijd en aandacht die je eraan besteedde om uitgebreide feedback te geven op alle 'drafts' die ik je gestuurd heb tijdens de afgelopen 5,5 jaar.

Geert-Jan, het was erg fijn om iemand met ervaring in het huisartsenvak erbij te hebben. Je wist altijd de dagelijkse praktijk erbij te betrekken en breder te kijken. Bedankt voor je advies en jouw altijd positieve feedback.

Nanne, bedankt voor al het prettige overleg en projectgroepvergaderingen die we samen gehad hebben. Je had altijd snel door waar de knelpunten zaten en kwam met belangrijke aanvullingen en nieuwe gezichtspunten. Met jouw hulp had ik het gevoel dat we opeens weer veel stappen verder waren.

Het ondersteunend personeel. Met name Paddy, Karin en Ine wil ik even noemen. Paddy, jij bent in het begin van het project betrokken geweest bij het kwalitatieve werk. Dank voor de tijd die je hierin gestoken hebt. Karin, aan jou was regelmatig de taak om het hele team met ingewikkelde agenda's en planningen bij elkaar te krijgen, maar het is allemaal goed gekomen. Bedankt voor alle regelzaken waarmee ik bij jou kon aankloppen. Ine, dank voor het luisterend oor dat je aan iedereen biedt en je grote betrokkenheid bij het reilen en zeilen van de afdeling.

Marloes, Laurie, Karlijn en Loes. Jullie hebben als Wesp/ AKO studenten een enthousiaste bijdrage geleverd aan dit onderzoek. Bedankt voor de prettige samenwerking.

Mark, bij jou zette ik mijn eerste wetenschappelijke stappen. Waar ik tijdens mijn studie nog dacht dat onderzoek niets voor mij zou zijn, was ik erg enthousiast nadat ik mijn eigen onderzoek had kunnen doen naar de kwaliteit van telefonische triage. Het artikel heeft het helaas nooit gehaald tot een publicatie, maar het heeft er wel toe geleid dat ik na mijn studie wist dat onderzoek mijn 'extra' was. 
Dr. Haak, beste Harm, mijn primeur als arts maakte ik in het Maxima Medisch Centrum, als arts assistent interne geneeskunde. Ik denk dat we er allebei al vrij snel uit waren dat mijn hart meer bij de huisartsgeneeskunde ligt, maar ik heb een mooie, leerzame tijd bij jullie gehad. Je stimuleerde me om mijn grenzen te verleggen en meer uitdaging te zoeken naast de huisartsopleiding.

Ben en Loes, jullie wil ik apart noemen omdat jullie meedachten over het project en voor jullie betrokkenheid, ook op persoonlijk vlak. Piet, bedankt, je hebt gelijk: chocolade helpt. Altijd.

Tiny Wouters en Bilbo Schickenberg, bedankt voor jullie belangrijke bijdrage aan de totstandkoming van dit boekje. Jullie waren met veel zorg betrokken en ik ben erg blij met het uiteindelijke resultaat.

De 'dames op de 2de': Petra, Sil, Esther, Mandy, Viola en Tineke. Jullie zorgden ervoor dat ik met plezier naar het Deb kwam. We hebben heel wat gelachen, ideeën over onderzoek uitgewisseld, adviezen gegeven en ook samen een belangrijke periode in het leven doorgemaakt. Ook dank aan mijn mede (ex)aiotho's: Merijn, Joris, Philippe, Jochen, Anique, Jolien, Wemke. Eva en Eefje schoven later aan als de nieuwe lichting. Bedankt voor de gezellige tijd!

Mijn opleiders van het eerste en derde jaar: Toy, bij jou in Melick begon ik aan mijn eerste jaar als huisarts in opleiding. Bedankt voor de fijne sfeer en je goede begeleiding. Marcel, van jou heb ik wel enige flexibiliteit gevraagd. Een aiotho, ook nog eens zwanger, het was even wat gepuzzel. Maar ik ben erg blij dat ik mijn hele derde jaar bij jou in Venlo heb kunnen doen. Jullie beiden hebben me het vertrouwen gegeven dat ik nodig had, in een mooie balans van opleiden en loslaten, en me geholpen om de huisarts te worden die ik graag wil zijn.

Ook een woord van dank aan de huisartsopleiding: in het bijzonder Joost en Bas voor de ondersteuning en regelzaken. Ik heb samen met jullie een mooi, op maat gemaakt traject kunnen opstellen. Alle mede AIOS en groepsbegeleiders waar ik in vijf jaar tijd mee heb samengewerkt, bedankt voor de gezelligheid, de broodjes Fit en de fijne sfeer.

Maar naast het werk moet er ook tijd zijn voor ontspanning! Ik wil graag onze vrienden bedanken voor de gezelligheid, etentjes, high tea's (ik geloof dat ik daar inmiddels ook expert in ben), sportmomentjes en muzikale verrassingen. Wat is het fijn om met jullie samen bij te komen van de werkweek, en weer nieuwe energie op te doen!

Er zijn wel twee mensen die ik speciaal wil noemen. Yvonne, we maakten voor het eerst kennis tijdens onze studententijd, toen we appartementgenoten werden. En gelukkig is onze mooie vriendschap die daar is ontstaan gebleven, ook toen we niet meer samenwoonden. Dank voor je onvoorwaardelijke steun en betrokkenheid, lieve kaartjes en belletjes. Je hebt een goed voorbeeld gezet vorig jaar, ik ga een poging doen in de buurt te komen! 
Janaica, natuurlijk ben jij mijn paranimf! Lief en leed hebben we gedeeld de afgelopen jaren. Je hebt me wegwijs gemaakt in de wondere wereld van de wetenschap en statistiek en samen hebben we heel wat gebrainstormd. Ik kwam iedere dag met plezier naar het werk, ook op vrijdag, om vervolgens vrijdagmiddag het weekend samen in te luiden. Tijdens ons traject hebben we een hoop gedeeld: bruiloftszorgen, zwangerschapshormonen etc. Bedankt voor de super samenwerking en hopelijk blijven we elkaar in de toekomst nog regelmatig zien.

Mijn schoonouders, Chrétien en Joke, bedankt dat we met onze drukke planningen altijd een beroep op jullie kunnen doen.

Pap en mam. Bedankt voor de liefdevolle en stabiele basis die jullie me gegeven hebben en waar ik nog altijd op terug kan vallen. Het is voor mij erg fijn om te zien hoe trots jullie zijn op iets wat voor mij alweer vanzelfsprekend lijkt. Pap, bedankt voor het meedenken in de afronding van dit proefschrift. Simone, een zus zoals iedereen er een wil hebben. Je bent gedreven, enthousiast en staat altijd voor iedereen klaar. Bedankt voor alle keren dat ik je voor advies gebeld of geappt heb, of het nu ging om belangrijke carrière beslissingen of wat ik de volgende dag aan moest, we kwamen er samen wel uit!

En tot slot natuurlijk de belangrijkste mannen in mijn leven. Ruben, wat een heerlijk vrolijk mannetje ben je toch. Eén blik van jou en mijn dag is weer helemaal goed. Rob, je hebt me op alle mogelijke manieren gesteund, steeds met een luisterend oor maar ook met de nodige humor. Je lijfspreuk, 'kump good', klinkt simpel, maar heeft me toch heel wat keren geholpen. We vullen elkaar perfect aan, samen met jou en onze kleine man zie ik vol vertrouwen de toekomst tegemoet. 
Curriculum Vitae

173 


\section{Curriculum Vitae}

Martine Ickenroth was born on July 6, 1982 in Roermond, the Netherlands. She completed higher secondary education in 2000, and in the same year started her medical studies at Maastricht University. During her study, she did electives in Sweden, Belgium and Thailand. During her final year of the medical studies, she participated in research on the quality of triagists in out of hours primary care. After her graduation as a medical doctor in 2006, she started working as a resident at the Department of Internal Medicine in the Maxima Medisch Centrum in Eindhoven.

In 2008, she started as 'aiotho' (general practitioner trainee and PhD student) at Maastricht University. She combined research with vocational training in general practice in the practices of Toy Broen (Melick) and Marcel Crobach (Venlo). Her research project concerned diagnostic self-testing in the Netherlands.

She recently graduated as a general practitioner (September 2013), and is currently working in several general practices in Limburg. She is happily married to Rob Geurts and has one son, Ruben (November 2012). 
